University of New Hampshire

University of New Hampshire Scholars' Repository

Natural Resources and the Environment

Scholarship

Natural Resources and the Environment

Spring 3-2-2020

\title{
Eelgrass Health Survey and Results
}

\author{
Nicholas B. Anderson \\ University of New Hampshire, nbn3@wildcats.unh.edu \\ Catherine M. Ashcraft \\ University of New Hampshire, catherine.ashcraft@unh.edu \\ Dante D. Torio \\ University of New Hampshire, dante.torio@unh.edu \\ Frederick T. Short \\ University of New Hampshire, fred.short@unh.edu
}

Follow this and additional works at: https://scholars.unh.edu/nren_facpub

Part of the Environmental Monitoring Commons, Environmental Studies Commons, Natural Resources and Conservation Commons, Other Ecology and Evolutionary Biology Commons, Plant Biology Commons, Quantitative, Qualitative, Comparative, and Historical Methodologies Commons, and the Terrestrial and Aquatic Ecology Commons

\section{Recommended Citation}

Anderson, Nicholas B.; Ashcraft, Catherine M.; Torio, Dante D.; and Short, Frederick T., "Eelgrass Health Survey and Results" (2020). Natural Resources and the Environment Scholarship. 138.

https://scholars.unh.edu/nren_facpub/138

This Report is brought to you for free and open access by the Natural Resources and the Environment at University of New Hampshire Scholars' Repository. It has been accepted for inclusion in Natural Resources and the Environment Scholarship by an authorized administrator of University of New Hampshire Scholars' Repository. For more information, please contact Scholarly.Communication@unh.edu. 


\section{Eelgrass Health Survey and Results}

Nicholas B. Anderson

University of New Hampshire, Durham, NH, U.S.A., nbn3@wildcats.unh.edu

Catherine M. Ashcraft

University of New Hampshire, Durham, NH, U.S.A., catherine.ashcraft@unh.edu

Dante D. Torio

University of New Hampshire, Durham, NH, U.S.A., dante.torio@unh.edu

Frederick T. Short

University of New Hampshire, Durham, NH, U.S.A., fred.short@unh.edu 


\section{Eelgrass Health Survey and Results}

Nicholas B. Anderson, University of New Hampshire (corresponding author)

Catherine M. Ashcraft, University of New Hampshire

Dante T. Torio, University of New Hampshire

Frederick T. Short, University of New Hampshire (emeritus)

Eelgrass Health Survey Introduction

Researchers at the University of New Hampshire designed, tested, and conducted an eelgrass health survey, which aimed:

- To increase the accuracy of research results. Survey respondents provided health ratings based on images of eelgrass beds, which were used to calibrate and validate a novel visual health index to assess eelgrass health using video monitoring,

- To build confidence in the new visual health index among potential future users by incorporating experiential knowledge from individuals familiar with eelgrass beds.

- To identify the plant-specific and environmental characteristics survey respondents consider important for assessing eelgrass health.

The University of New Hampshire Institutional Review Board for the Protection of Human Subjects in Research approved this study (IRB \#: 8004; Study approval date: 3/21/2019; Modification approval date: 10/17/19). The survey was conducted online using Qualtrics during October and November 2019.

Researchers recruited individuals with prior experience observing eelgrass beds to participate in the survey. Recruitment aimed to survey participants with diverse backgrounds and, therefore, diverse experiences with eelgrass beds. Nineteen individuals completed the survey. Participant backgrounds included coastal researchers, resource managers, educators, and fishermen. Their level of experience ranged from less than five to more than 30 years. Most respondents had earned a graduate degree. Respondents reported most often observing eelgrass beds in Maine, New Hampshire, and Massachusetts

Survey participants were presented with images. The order in which images were presented was randomly rotated. Respondents were asked to select one of five eelgrass health ratings: "Very Bad", "Poor", "Fair", "Good", and "Excellent". Respondents could also provide a rationale for their selections. Images used in the survey came from sites in James Bay, Québec, Canada, and the Great Bay and Piscataqua River estuaries in New Hampshire and Maine, U.S.A. Images were chosen to represent a broad range of eelgrass health conditions. Prior to use in the survey, the survey researchers rated all images using the eelgrass health index (range: $1-100$ ) and standardized to the scale used in the survey (Very Bad: 1-20, Poor: 21-40, Fair: 41-60, Good: 61-80, Excellent: 81-100). 
This document aims to make the survey and complete data openly available to anyone interested in the results or who wants to build on this research. Consistent with the approved IRB protocol, survey data were de-identified and are presented in an aggregated format to protect the identity of individual respondents. The data set includes:

Part 1:

- Demographic data and general background data about survey respondents

Part 2:

- The eelgrass images presented to survey respondents

- Respondents' eelgrass health ratings for each image (y-axis in the sample bar plot below) and the number of survey respondents who selected each rating ( $\mathrm{x}$-axis in the sample bar plot below). Where respondents provided a rationale for their selection of specific ratings, their written responses are included on the page following the corresponding data plot. In order to protect respondents' confidentiality, respondents' comments are presented in aggregate and their order randomly rotated across survey images.

- Researchers' rating of each image calculated using the eelgrass health index, presented in two formats:

- The value of the Eelgrass Health Index rating (EHI) is indicated at the top of each image ("EHI=42.2" in the sample data plot below).

- The standardized rating of the EHI is indicated as a gray shaded box around the title of the appropriate rating on the y-axis (see gray shading around "Fair" in the sample plot below)

\section{Sample Bar Plot}

\section{EHI: 22.3}

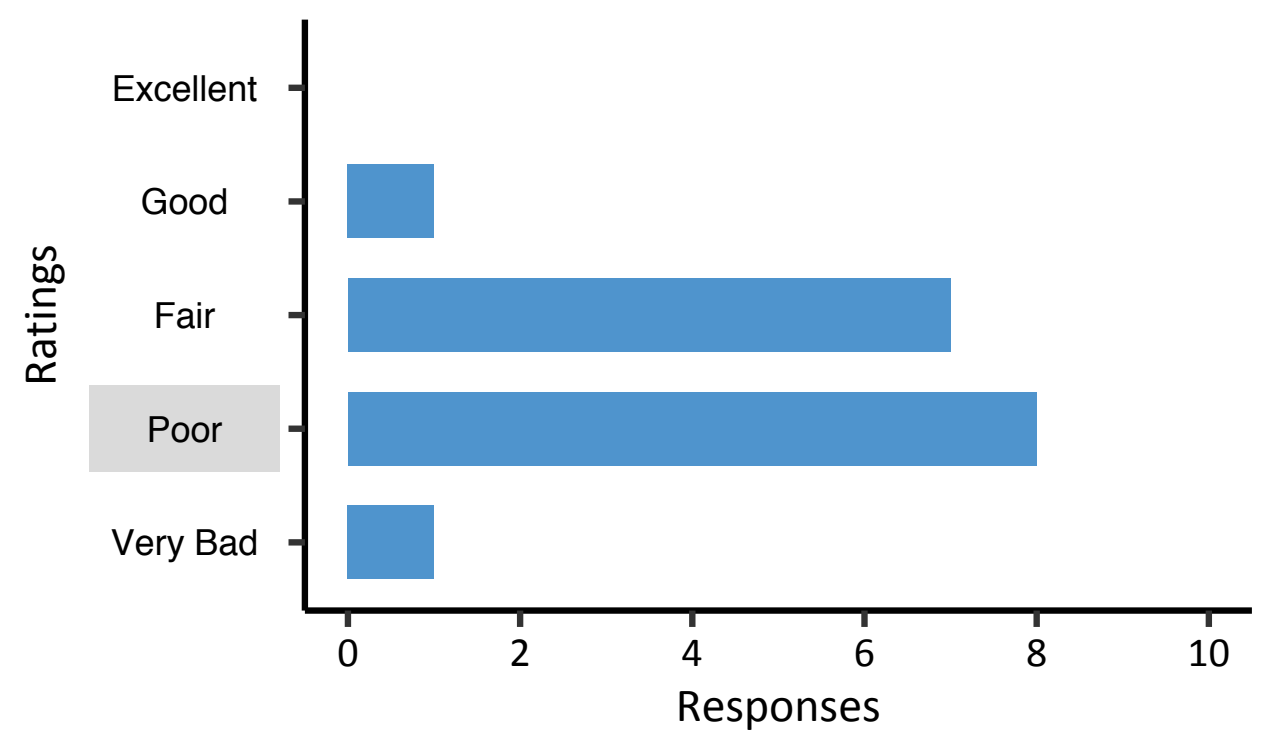


Part I: Background Questions

Q2 - What is Your Profession?

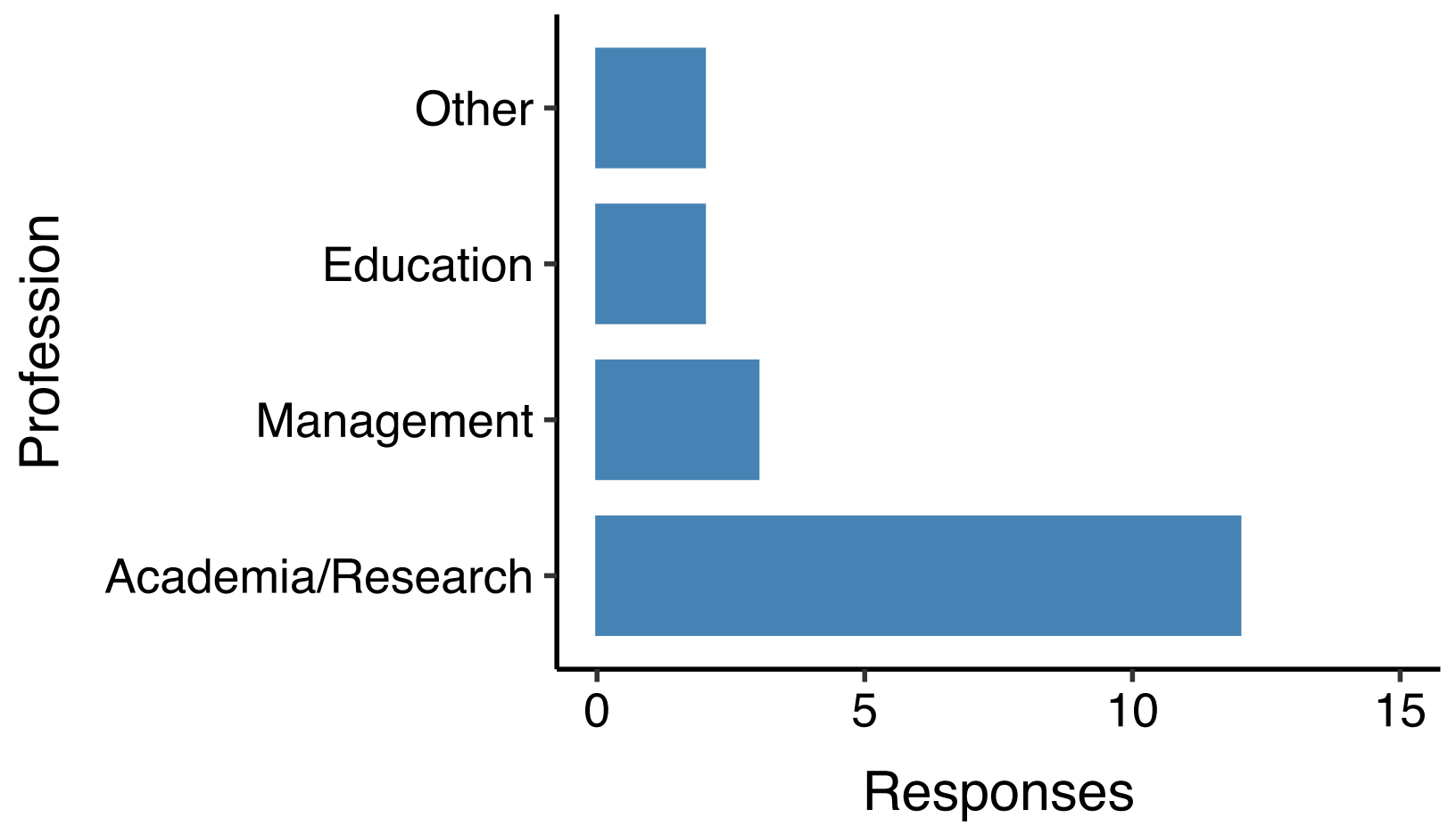


Q3 - What is the highest level of school you have completed or degree you have received?

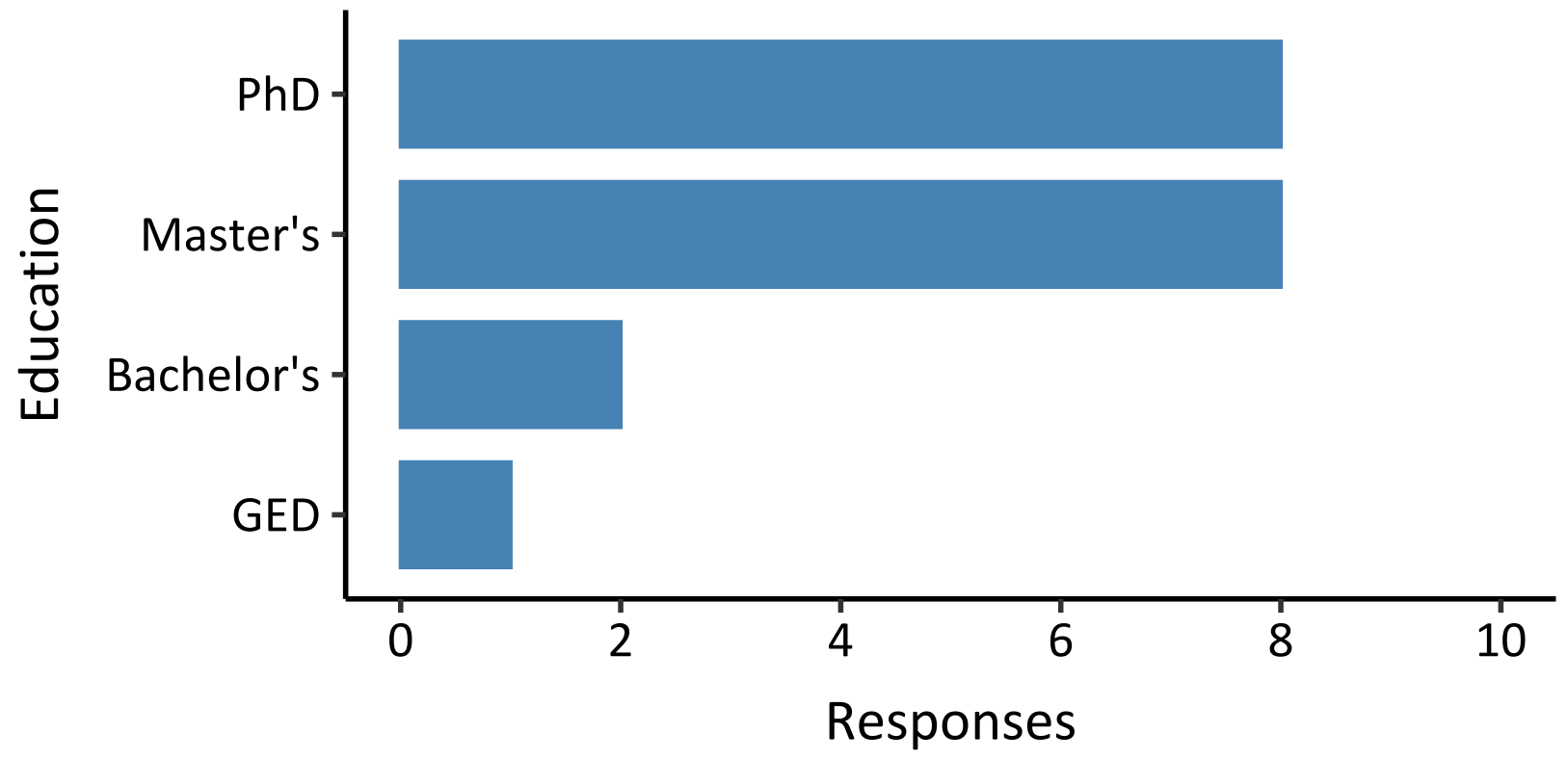

Q4 - In what capacity do you have experience with eelgrass? (Check all that apply)

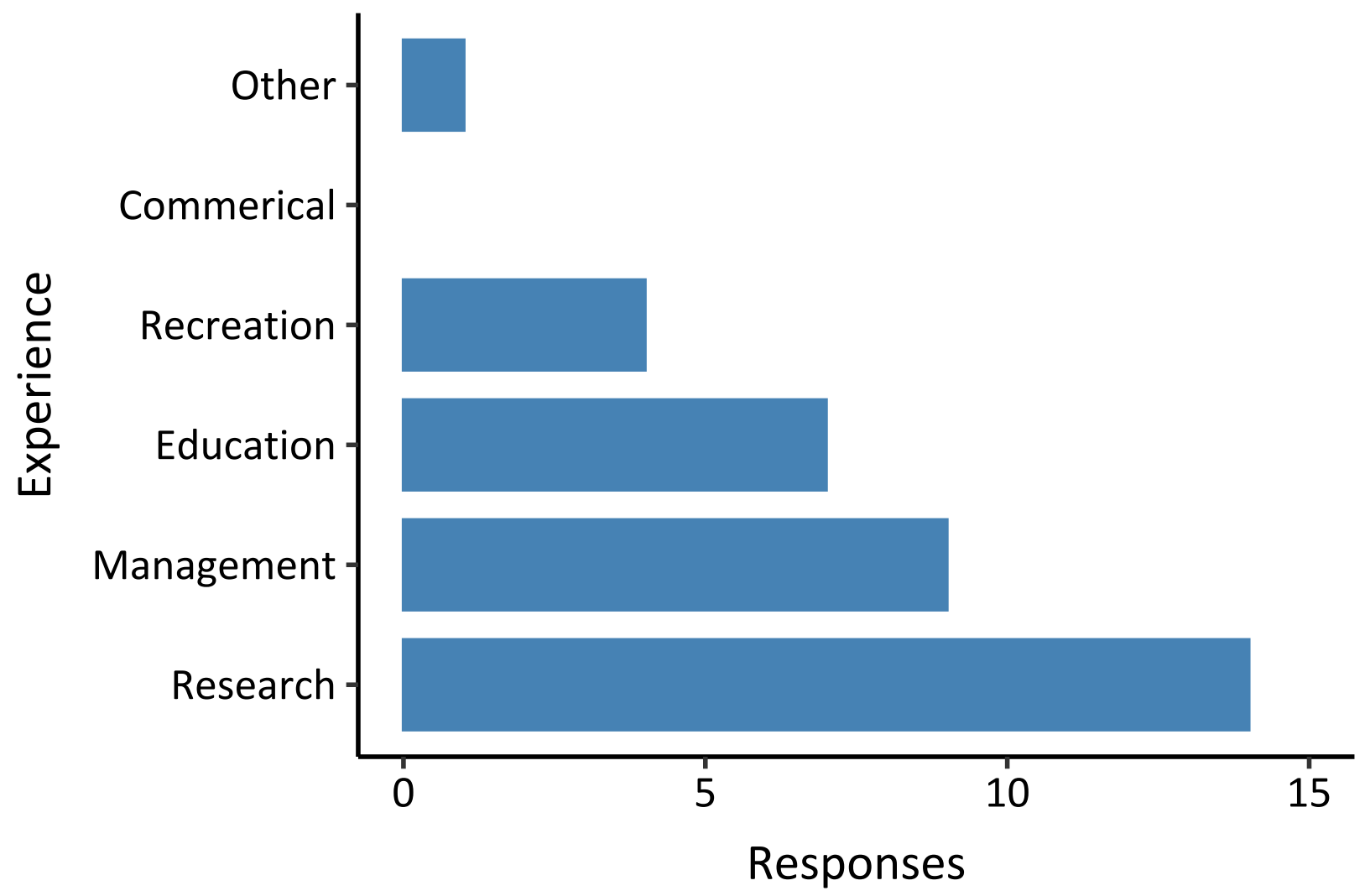

Q5 - Please explain why you selected other for experience.

- No responses. 
Q6 - How long have you been working with and/or observing eelgrass?

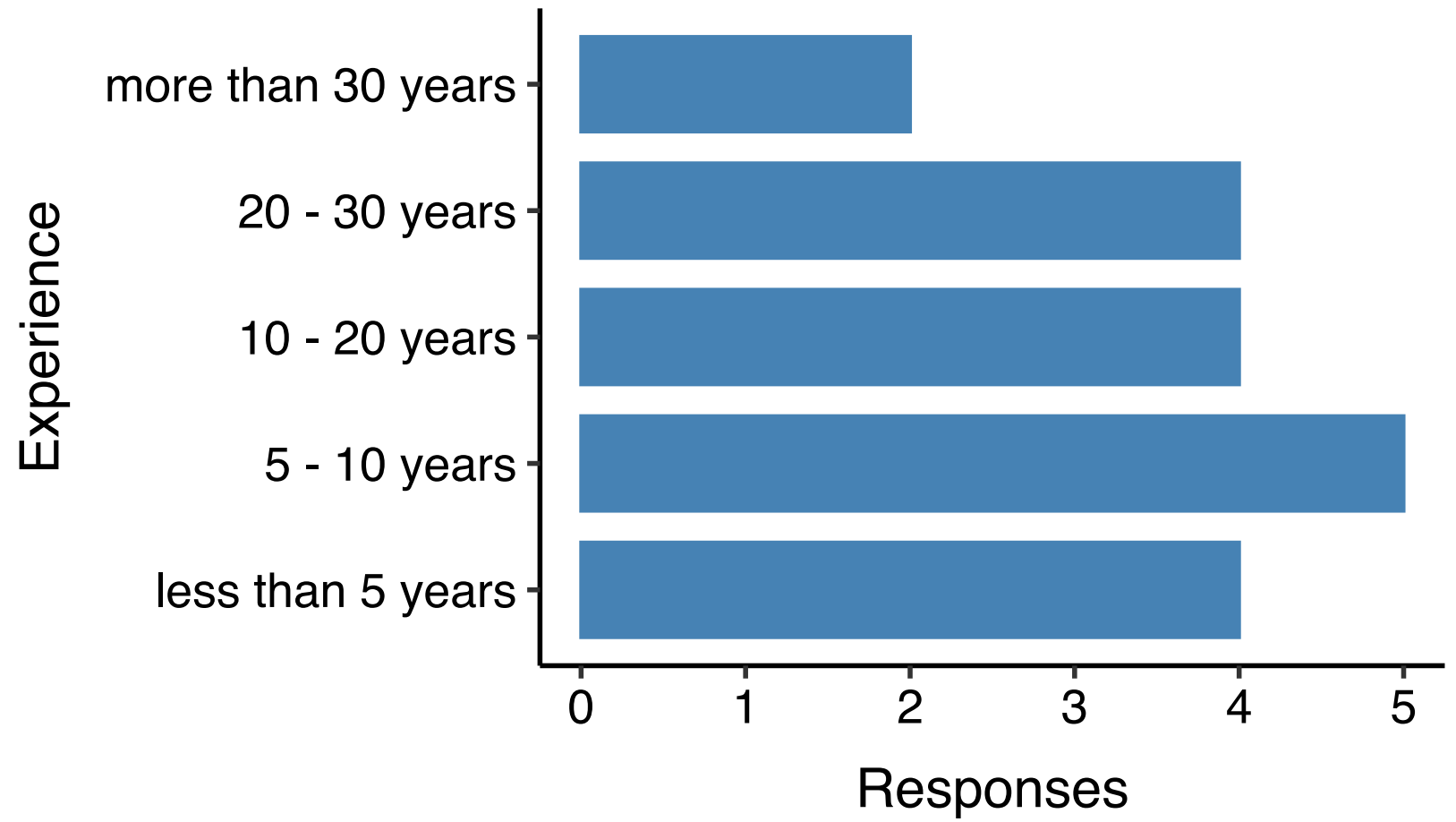

Q7 - Where do you most often observe eelgrass?

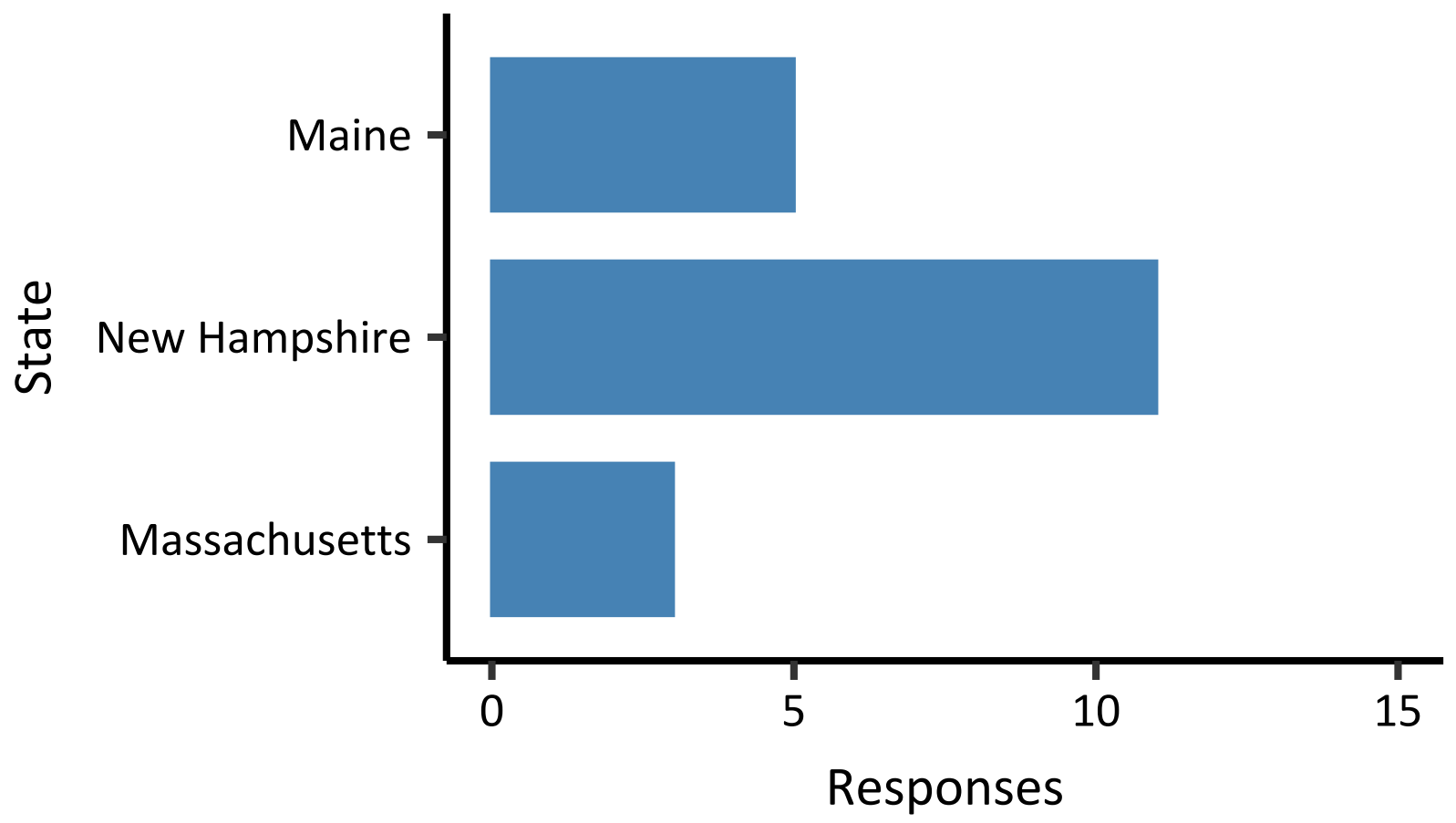


Q8 - In this population, how would you describe the current eelgrass health status?

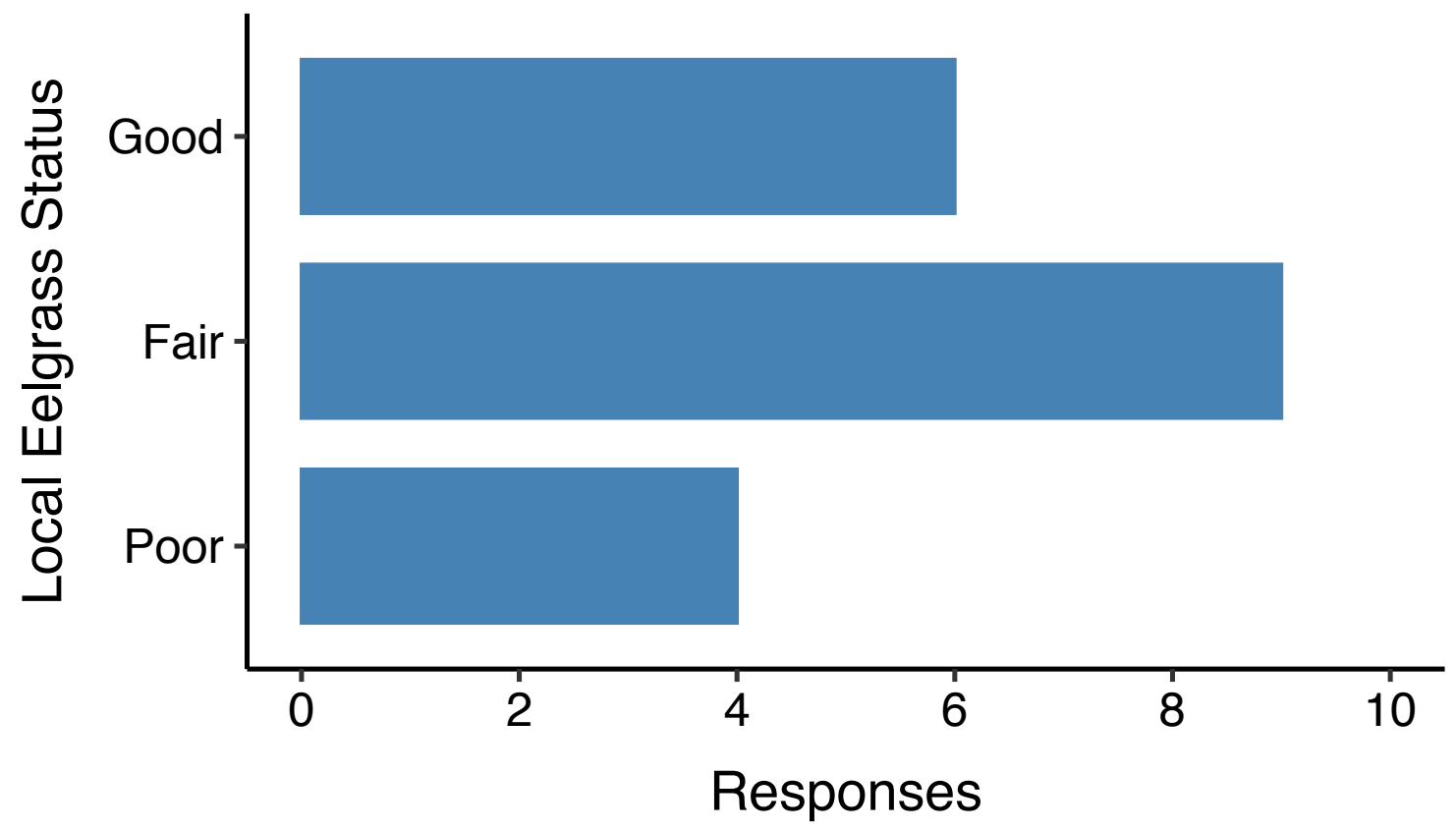

Q9 - In this population, how would you describe eelgrass conditions as they have changed over the last 5 years.

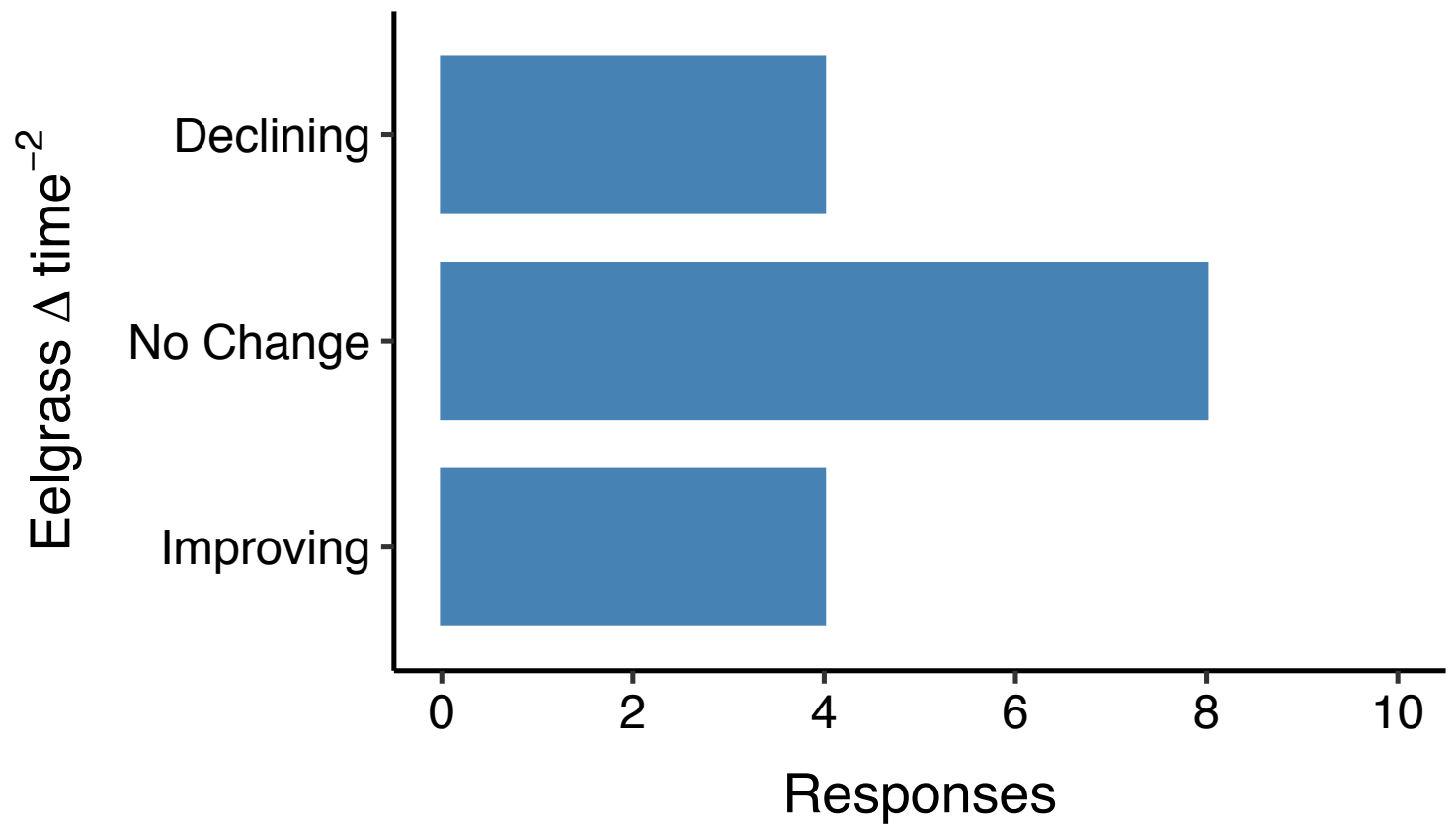


Q10 - How have you observed eelgrass? (Check all that apply)

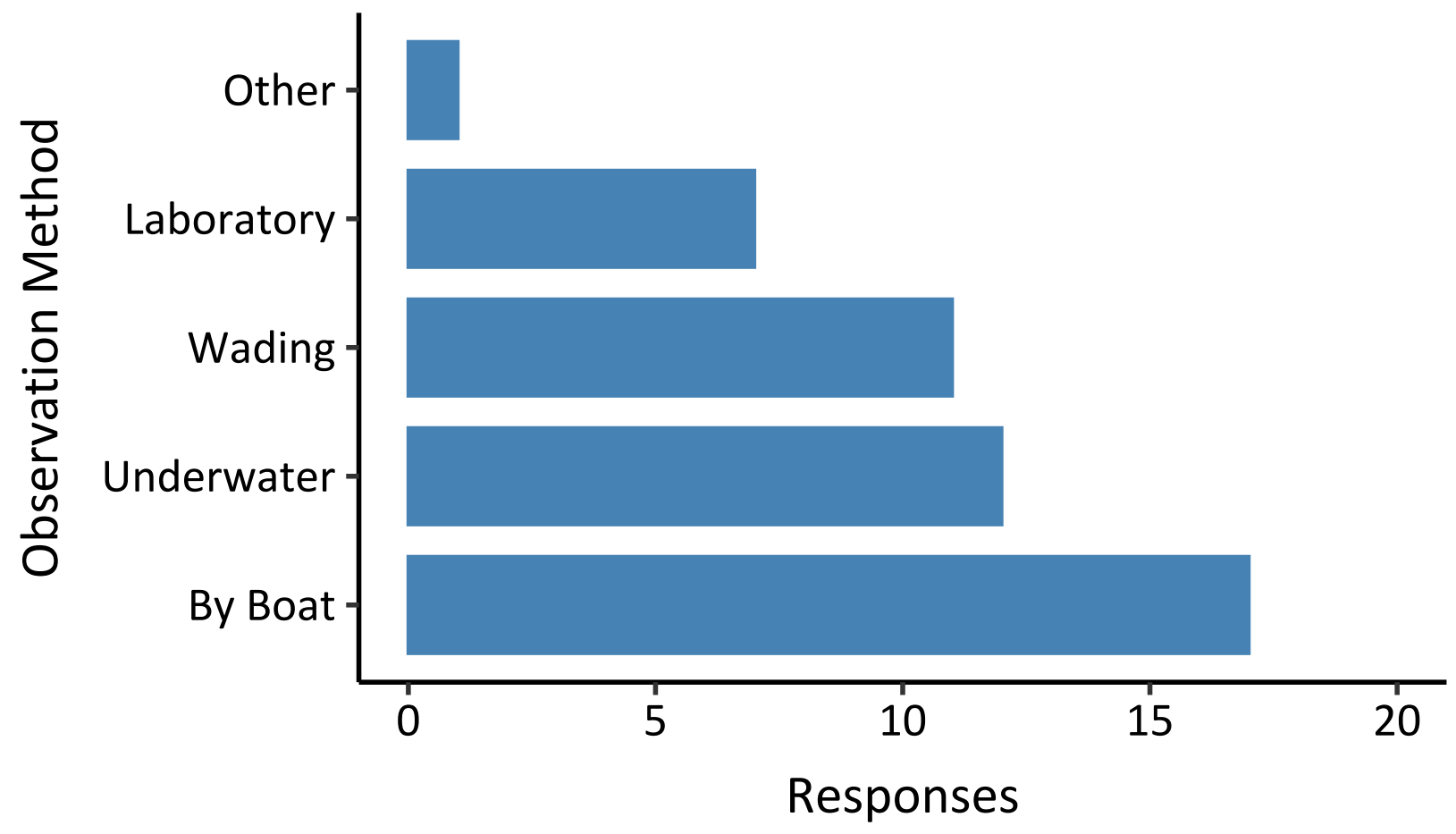

Q11 - If 'Other' please explain

- From Shore

- Underwater camera from boat

- Review Reports of Others 


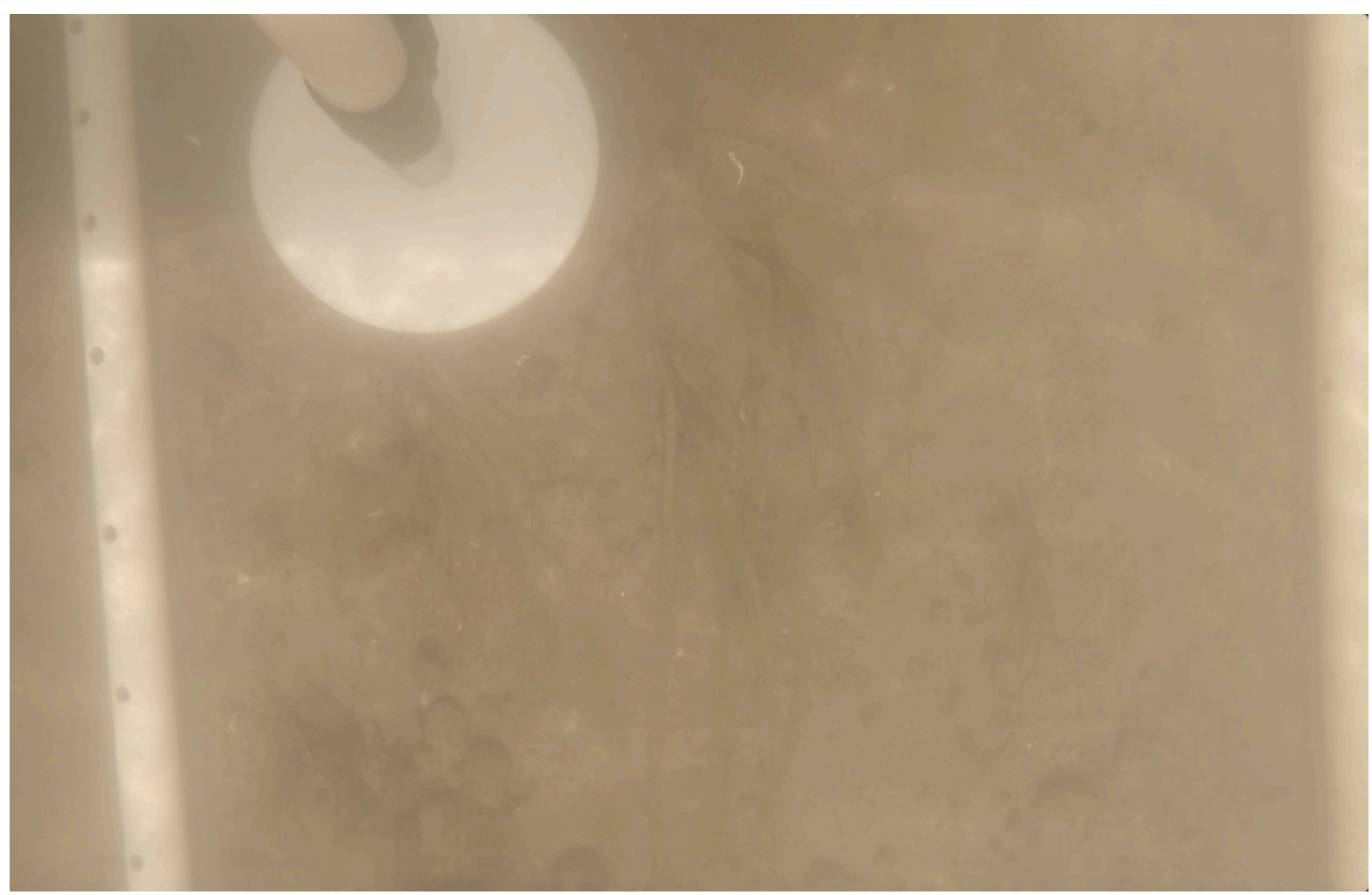

Q1.1 - How would you rate the health of the eelgrass in this frame?

\section{EHI: 7.70}

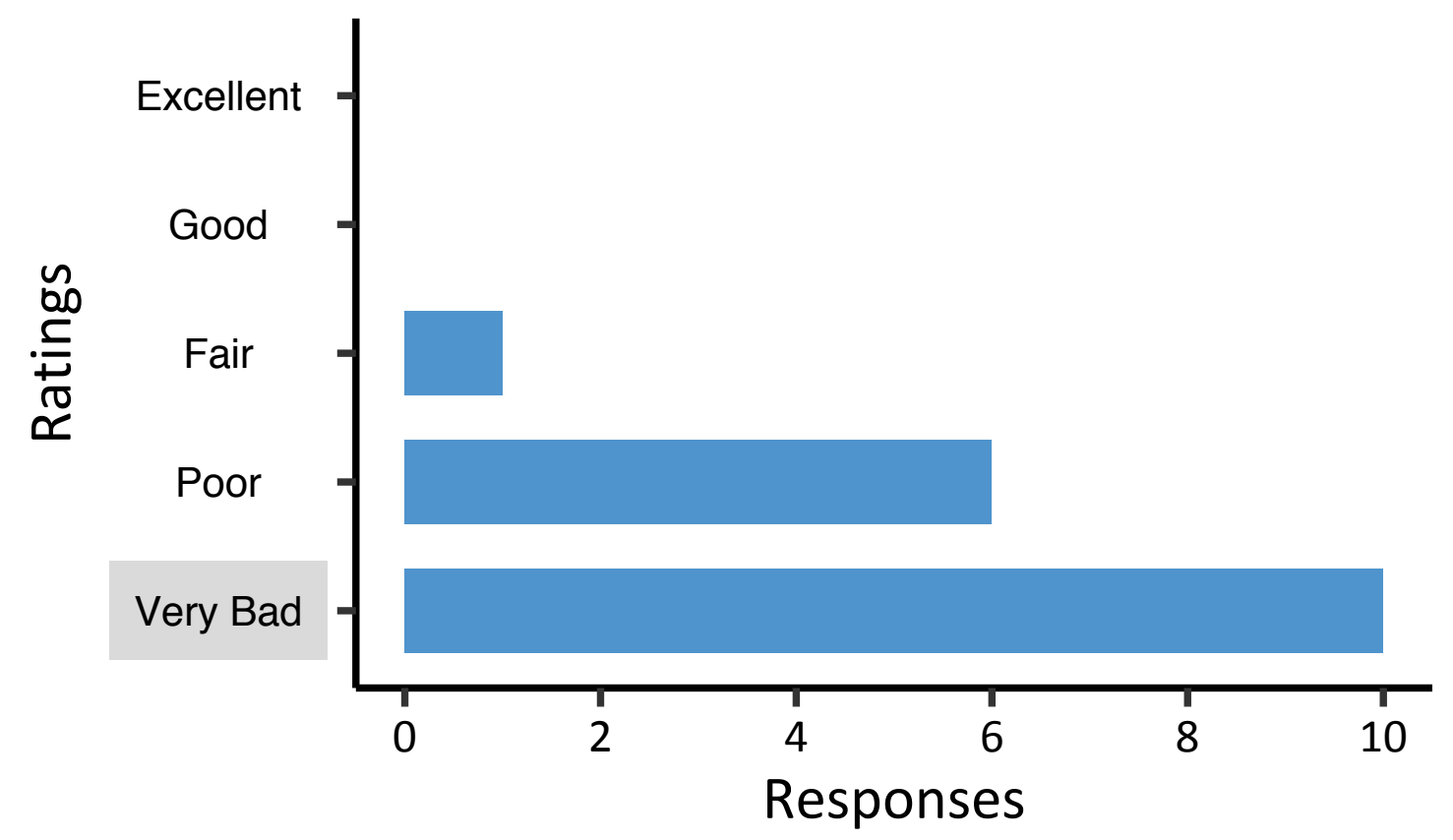


Q1.2 - Why did you select this rating? If you would like use a specific value (1 - 100) to rate the eelgrass please include that here. (optional)

- small shoots, sparse density

- That's an eelgrass bed? Those poor little shoots...

- low cover, poor water clarity

- Low clarity and no eelgrass

- Low density and percent cover, sediment accumulated on above ground biomass

- poor image?

- about $10 \%$ cover with poor WQ

- borderline very bad/poor low shoot density, poor water clarity

- Qualitative Visual Assessment

- sparse blades and cloudy water

- small, sparse cover, etc. 

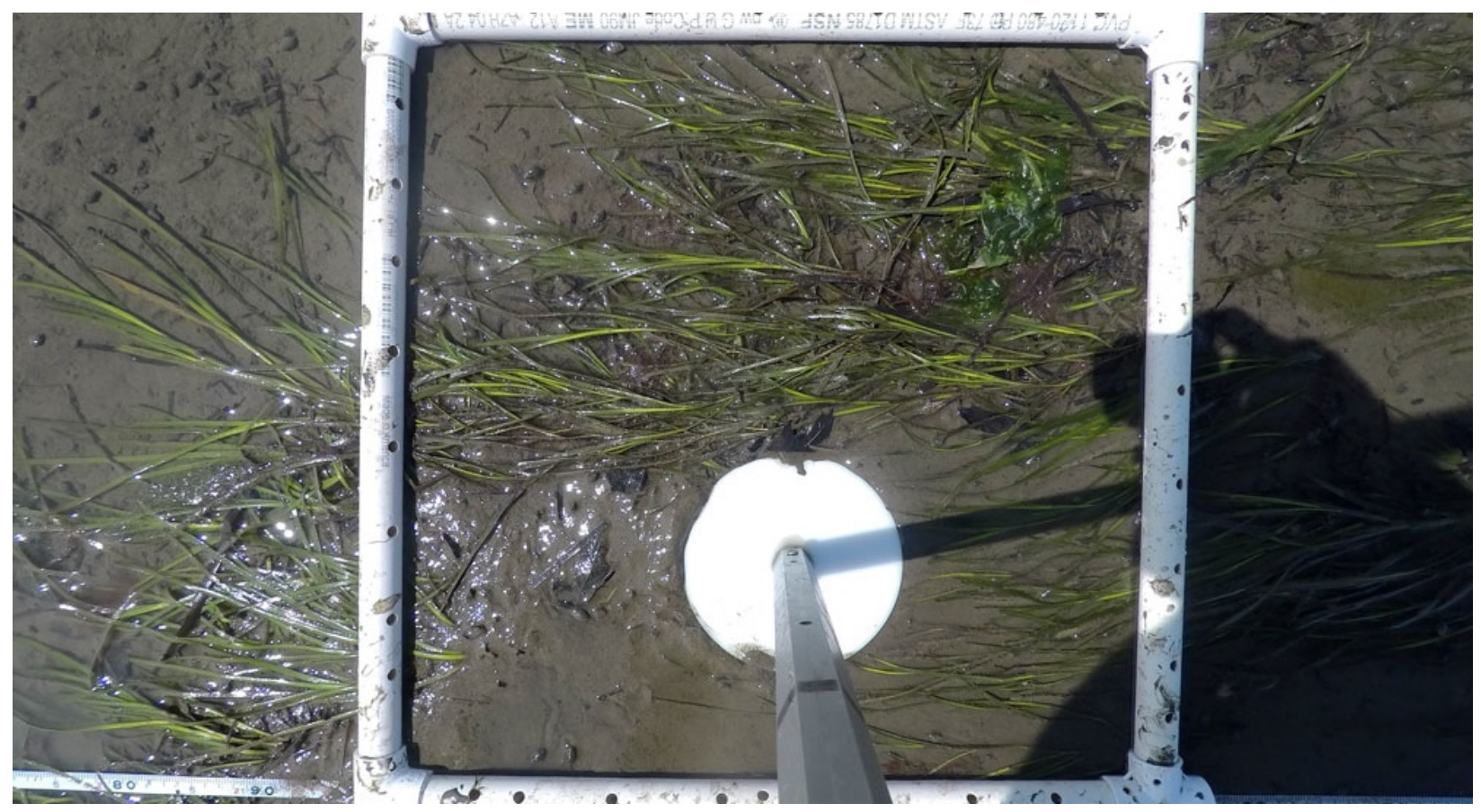

Q2.1 - How would you rate the health of the eelgrass in this frame?

\section{EHI: 42.2}

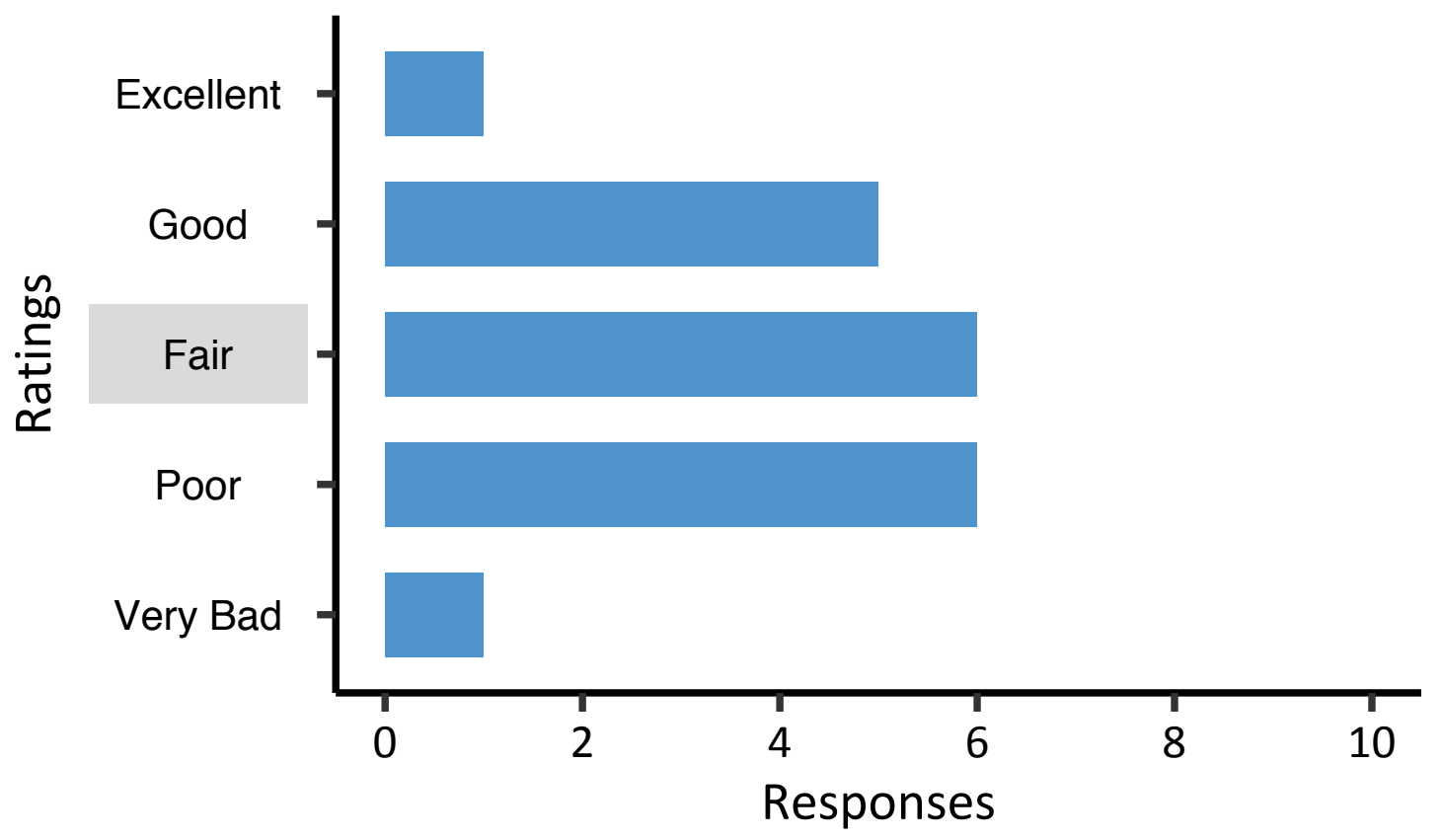


Q2.2 - Why did you select this rating? If you would like use a specific value (1 - 100) to rate the eelgrass please include that here. (optional)

- $\quad$ presence of some macroalgae, moderate cover eelgrass

- moderate density, low epiphyte

- Qualitative Visual Assessment

- Sparse but some healthy looking shoots

- sparse coverage and some competition from ulva

- smaller plants, patchy coverage

- This bed is on the upper end of the Poor category (maybe low end of Fair?). Plants look healthy but small. In addition, they must be fully exposed at low tide which probably doesn't help their survival.

- About $50 \%$ cover with drift algae observed

- Plants are green and look healthy, intertidal meadows are always more sparse due to the physical stress of where they exist and the potential exposure to geese and other grazers

- poor cover, some coating, small 
Q3.1 - How would you rate the health of the eelgrass in this frame?

\section{EHI: 27.8}

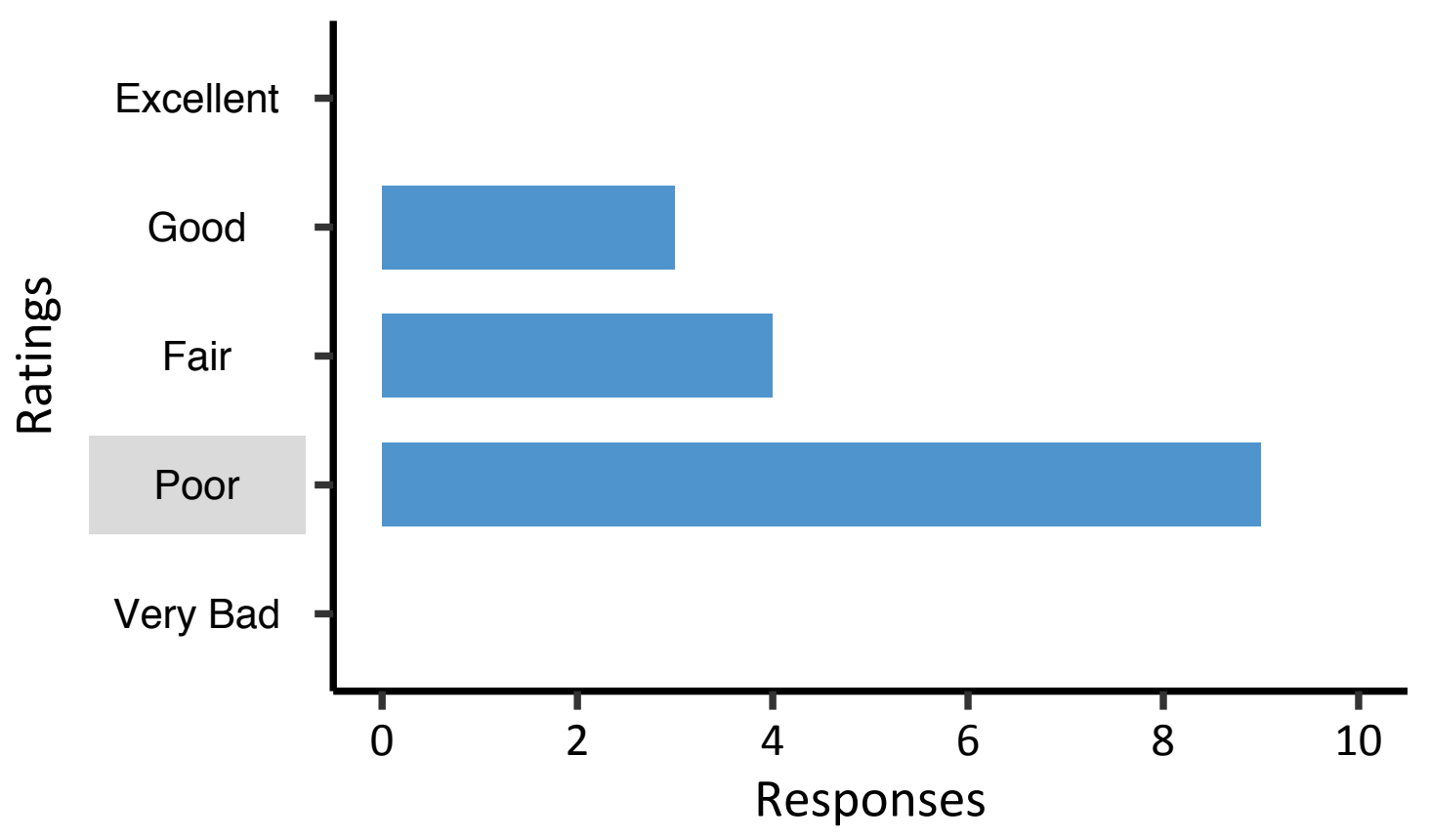


Q3.2 - Why did you select this rating? If you would like use a specific value (1 - 100) to rate the eelgrass please include that here. (optional)

- borderline poor/fair, water clarity looks

poor, but shoot density could be in the fair range

- Qualitative Visual Assessment

- maybe hard to tell with bad water clarity

- hard to tell - looks very sparse

- can't tell, poor image

- Water quality is poor but about $60 \%$ cover of plants

- moderate density, poor water clarity

- Thicker than previous picture

- plants look ok despite poor water clarity 
Q4.1 - How would you rate the health of the eelgrass in this frame?

EHI: 37.5

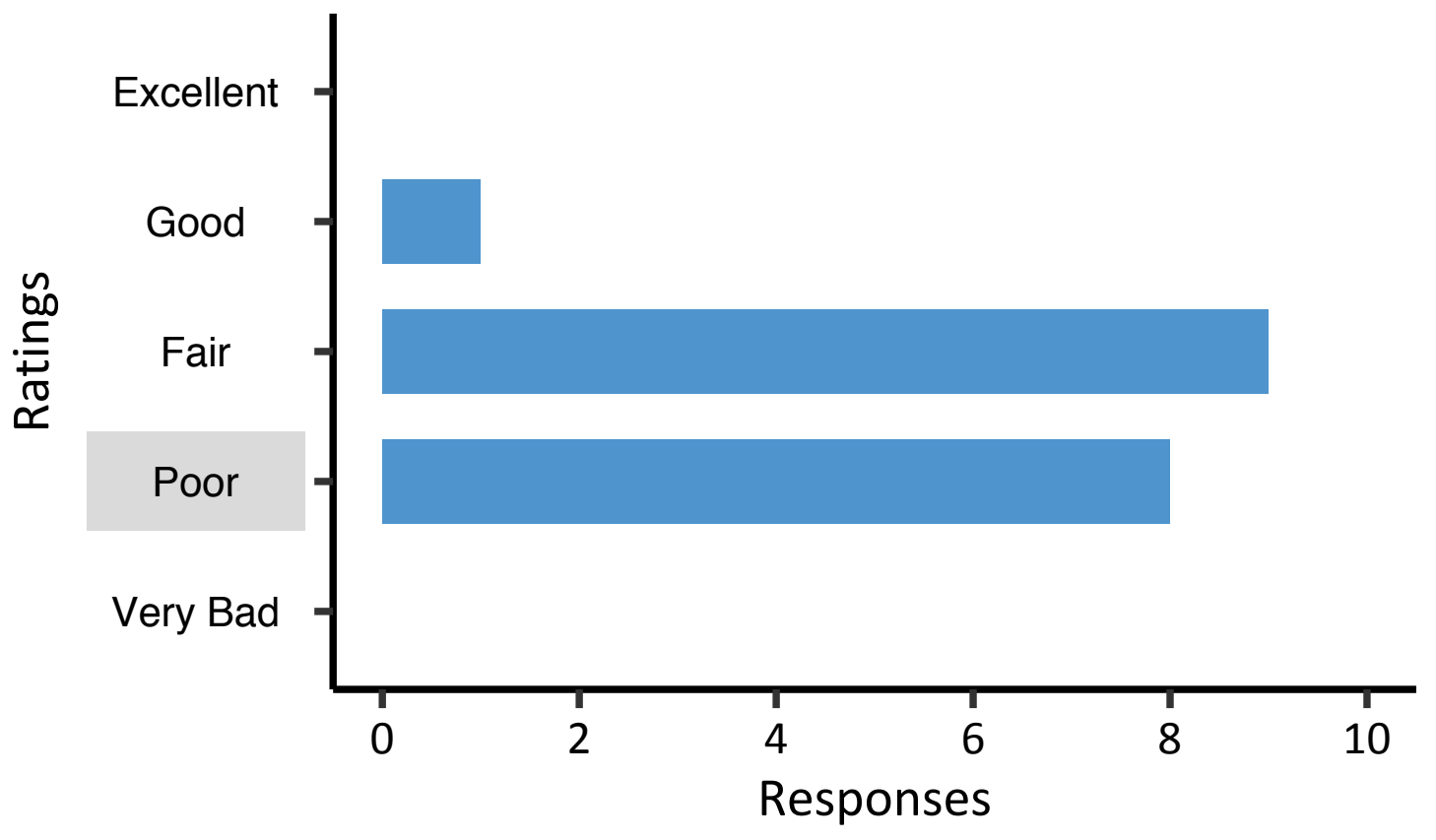


Q4.2 - Why did you select this rating? If you would like to use a specific value (1 - 100) to rate the eelgrass please include that here. (optional)

- low shoot density, limited water clarity and the evidence of wasting disease prevalent on some leaves

- water is cloudy; some epiphytes are noticeable; and some wasting disease is evident

- Ugh! $25 \%$ cover but poor WQ and algae level unknown

- densey vegetated with many reproductive shoots

- Qualitative Visual Assessment

- Moderate water column turbidity, moderately lengthy shoots with fouling

- Decent bed density 


\section{Q5.1 - How would you rate the health of the eelgrass in this frame?}

\section{EHI: 22.3}

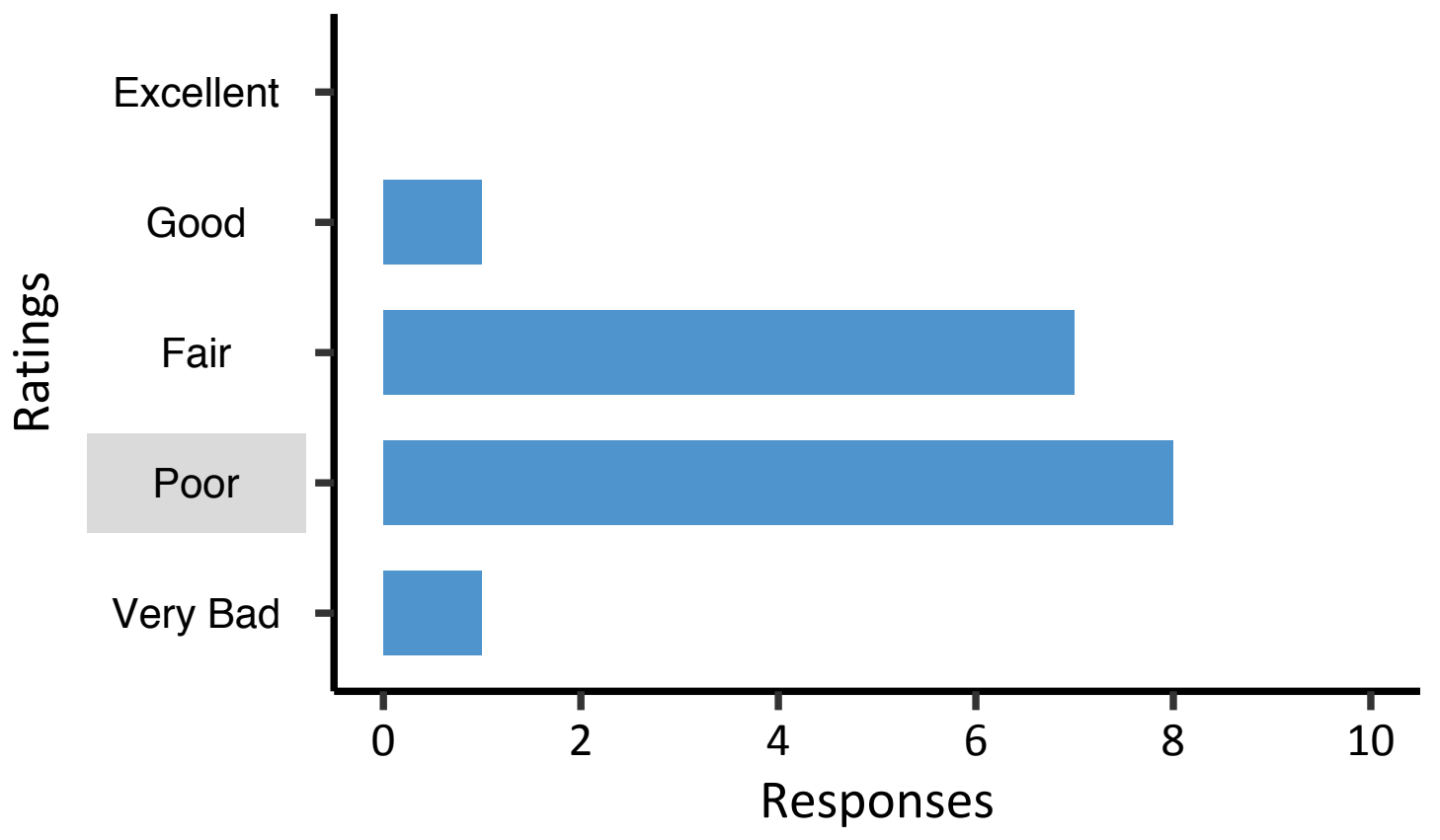


Q5.2 - Why did you select this rating? If you would like to use a specific value (1 - 100) to rate the eelgrass please include that here. (optional)

- Low clarity but moderate density

- Few shoots rooted in quadrat

- Really hard to tell from the picture. Plants seem tall but can't get a real indication of density.

- Hard to tell - looks sparse

- Qualitative Visual Assessment

- Hard to tell, but water column turbidity and presence of fouling community combined with lower density would indicate a less healthy bed

- borderline fair/poor; water clarity is poor, but shoot density looks fair, under the premise that water clarity may reflect short term conditions while shoot density integrates conditions over time, putting this in the fair category

- I do not see much algae or epiphytes, but it is not very dense

- moderate density, little algae, poor water clarity

- can't tell, poor image

- About 50\% plant cover but lousy WQ 
Q6.1 - How would you rate the health of the eelgrass in this frame?

\section{EHI: 65.0}

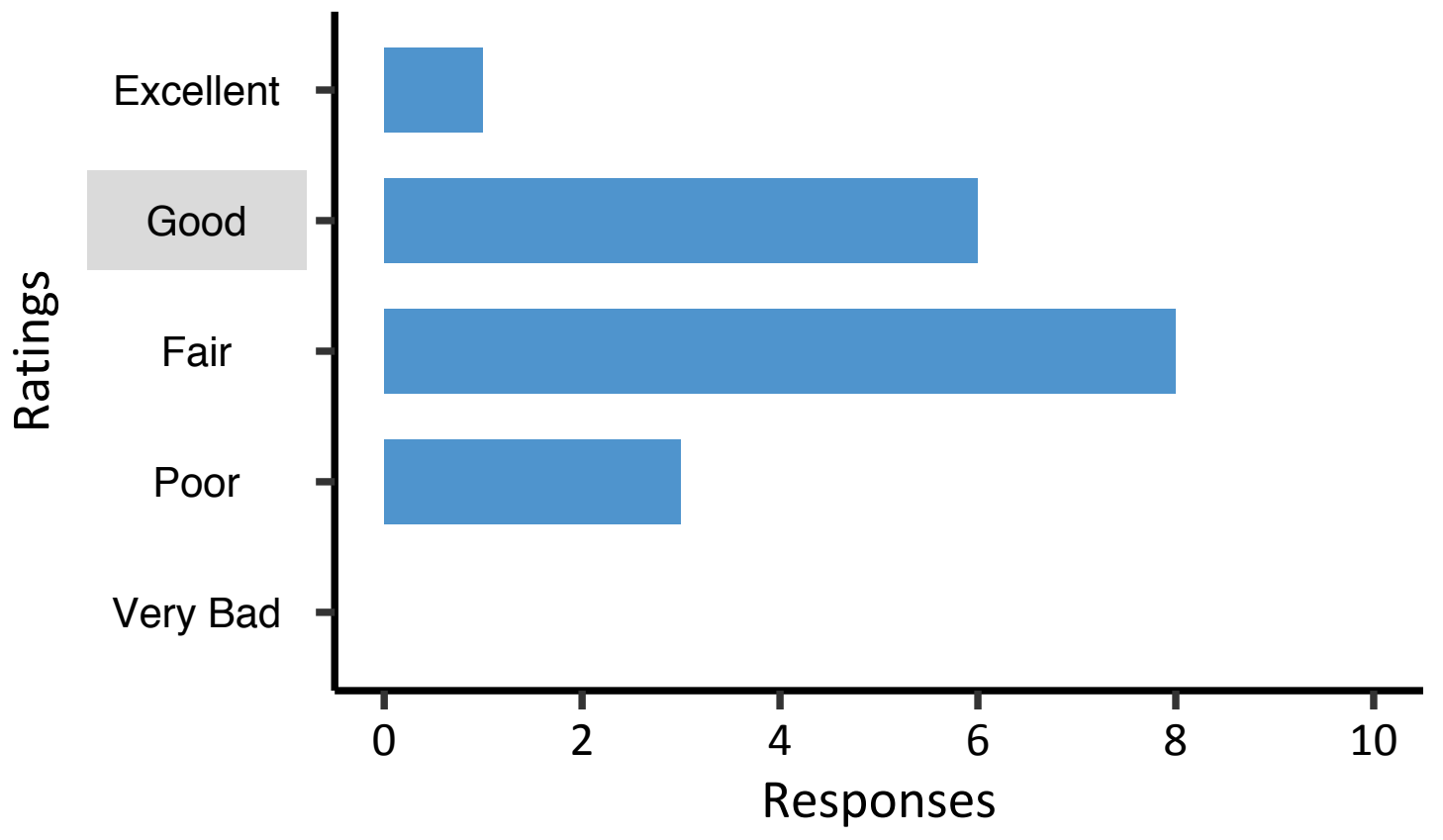


Q6.2 - Why did you select this rating? If you would like to use a specific value (1 - 100) to rate the eelgrass please include that here. (optional)

- high density, low epiphytes

- Good density, plants look ok

- Qualitative Visual Assessment

- lots of epiphytes

- wasting disease?, epiphytes

- Similar to previous but poorer water quality but at the same time good coverage by plants

- unhealthy

- very similar to meadows I see on Martha's Vineyard, where by the late summer/early fall they begin to get covered with epiphytes, but somehow the meadows persist 


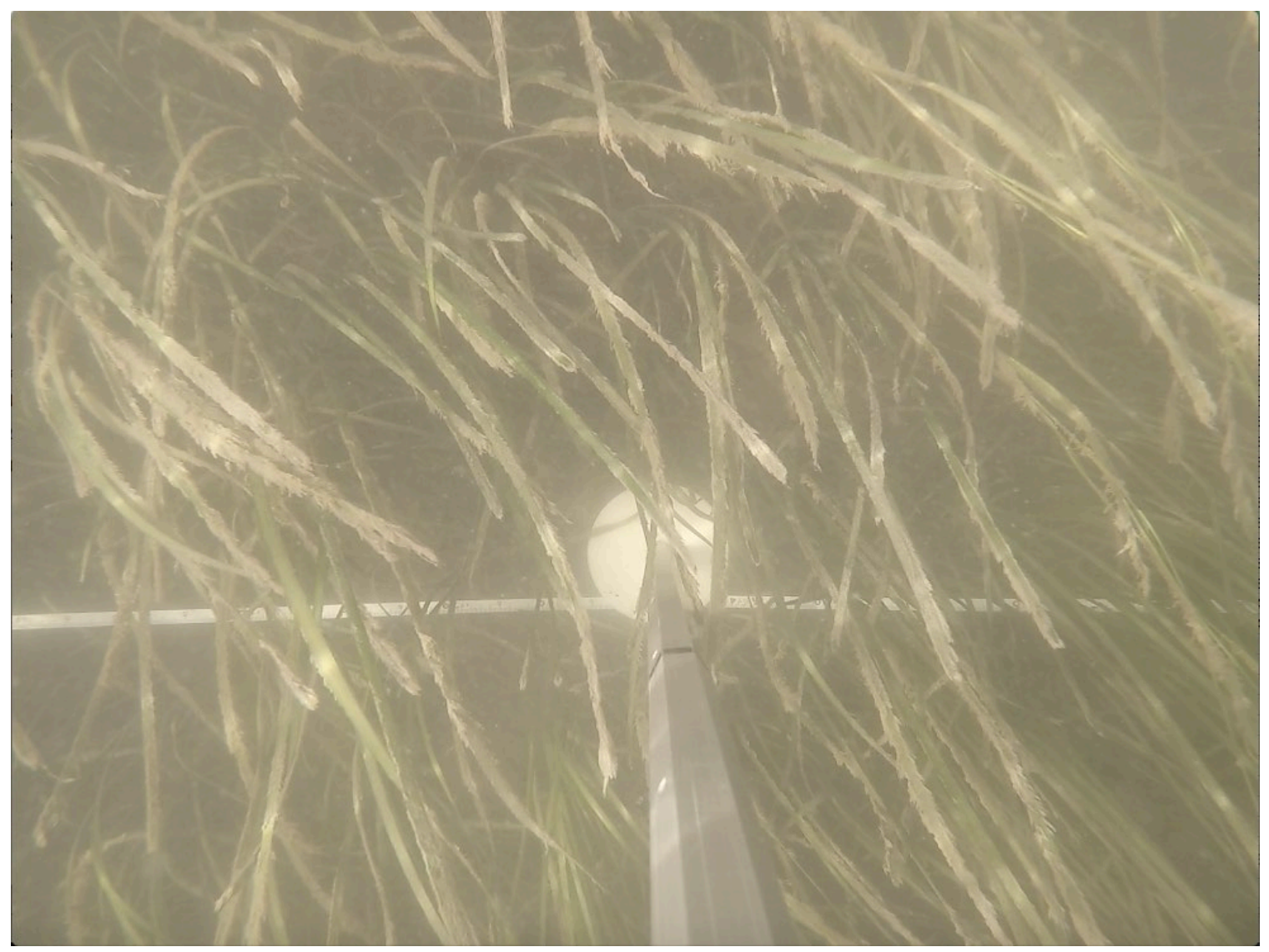

Q7.1 - How would you rate the health of the eelgrass in this frame?

\section{EHI: 56.1}

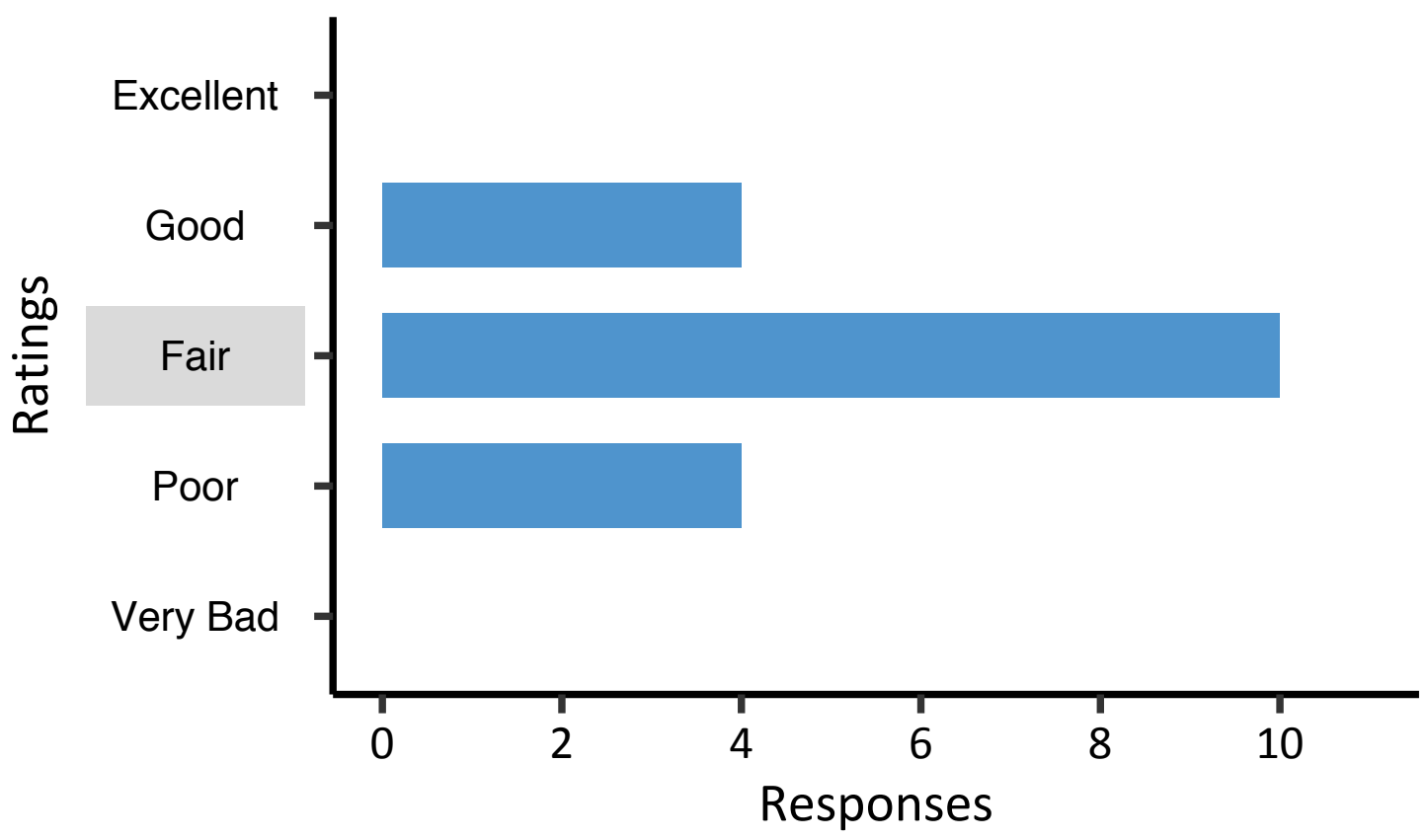


Q7.2 - Why did you select this rating? If you would like to use a specific value (1 - 100) to rate the eelgrass please include that here. (optional)

- denser, but looks like it does have growth on the blades

- looks unhealthy

- borderline good to excellent, high shoot density, but plenty of epiphytes, would be useful to know the time of year when photos are taken as each meadow will look different at various parts of the growing season

- high cover, moderate to high epiphytes

- high density, high epiphytes

- Epiphytes on leaves and graying water color are questionable

- Qualitative Visual Assessment

- dense plants (80 \% cover) with many old, epiphytized leaves

- dense but epiphytes

- high density, high epiphyte

- epiphytes 


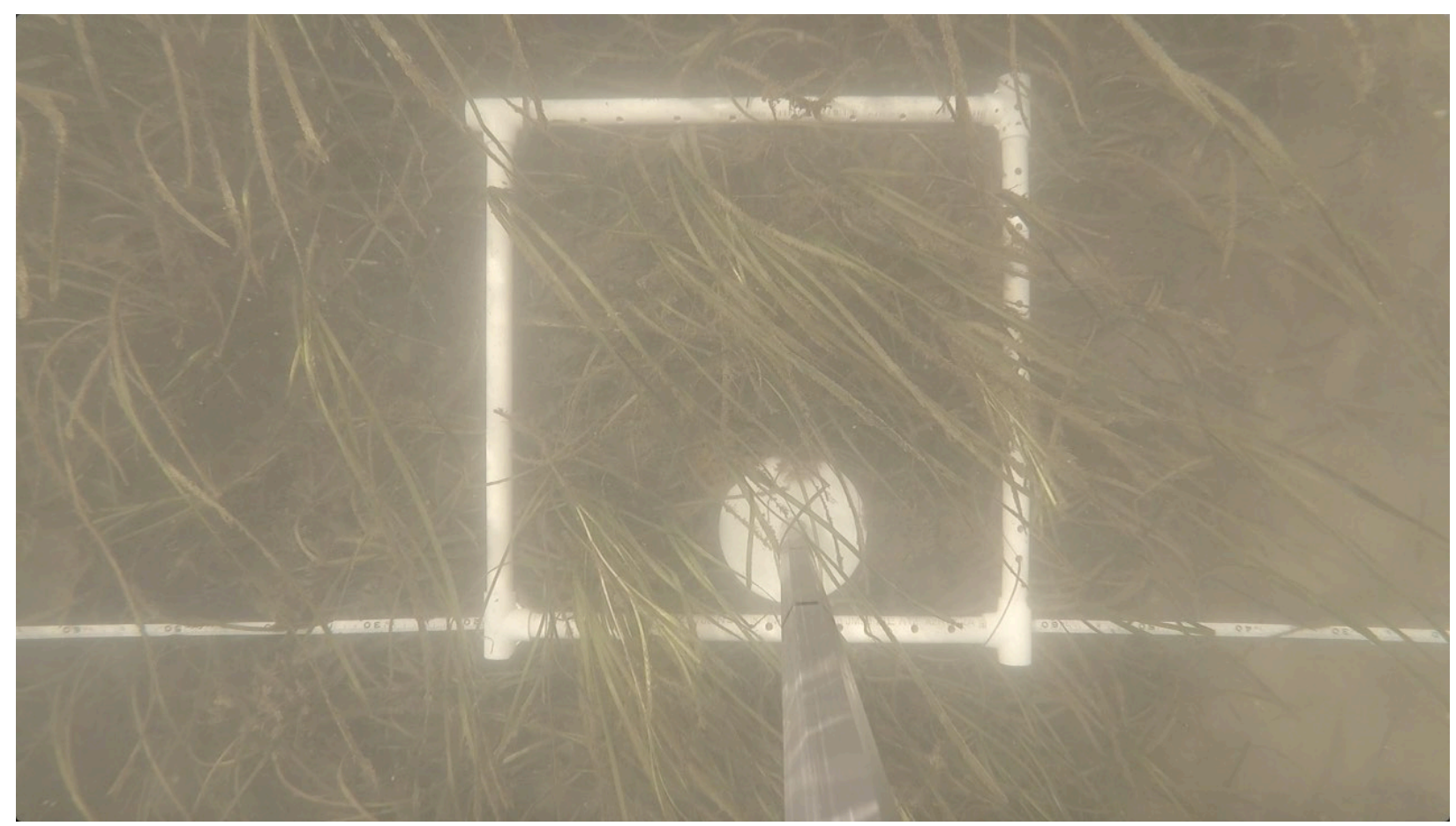

Q8.1 - How would you rate the health of the eelgrass in this frame?

\section{EHI: 33.6}

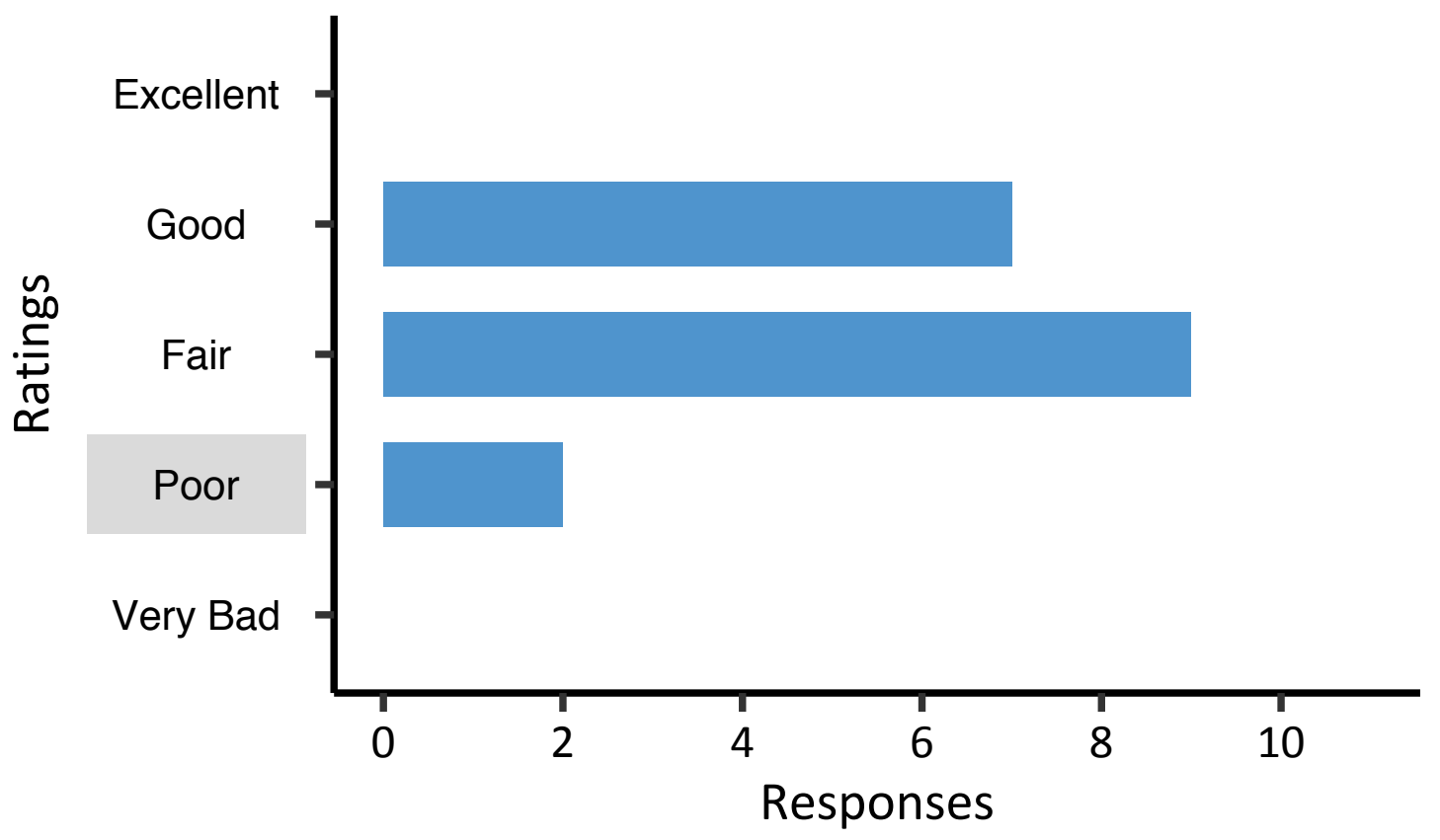


Q8.2 - Why did you select this rating? If you would like to use a specific value (1 - 100) to rate the eelgrass please include that here. (optional)

- thin blades, water quality could be light limiting, looks like there's some algal cover at sediment level

- High density but clarity ok

- Dense plants but algae and smothering evident

- based on the \%cover, color of the vegetation and the hint of epiphytes

- Qualitative Visual Assessment

- high cover, moderate epiphytes

- Plants look ok, I think that's macroalgae 


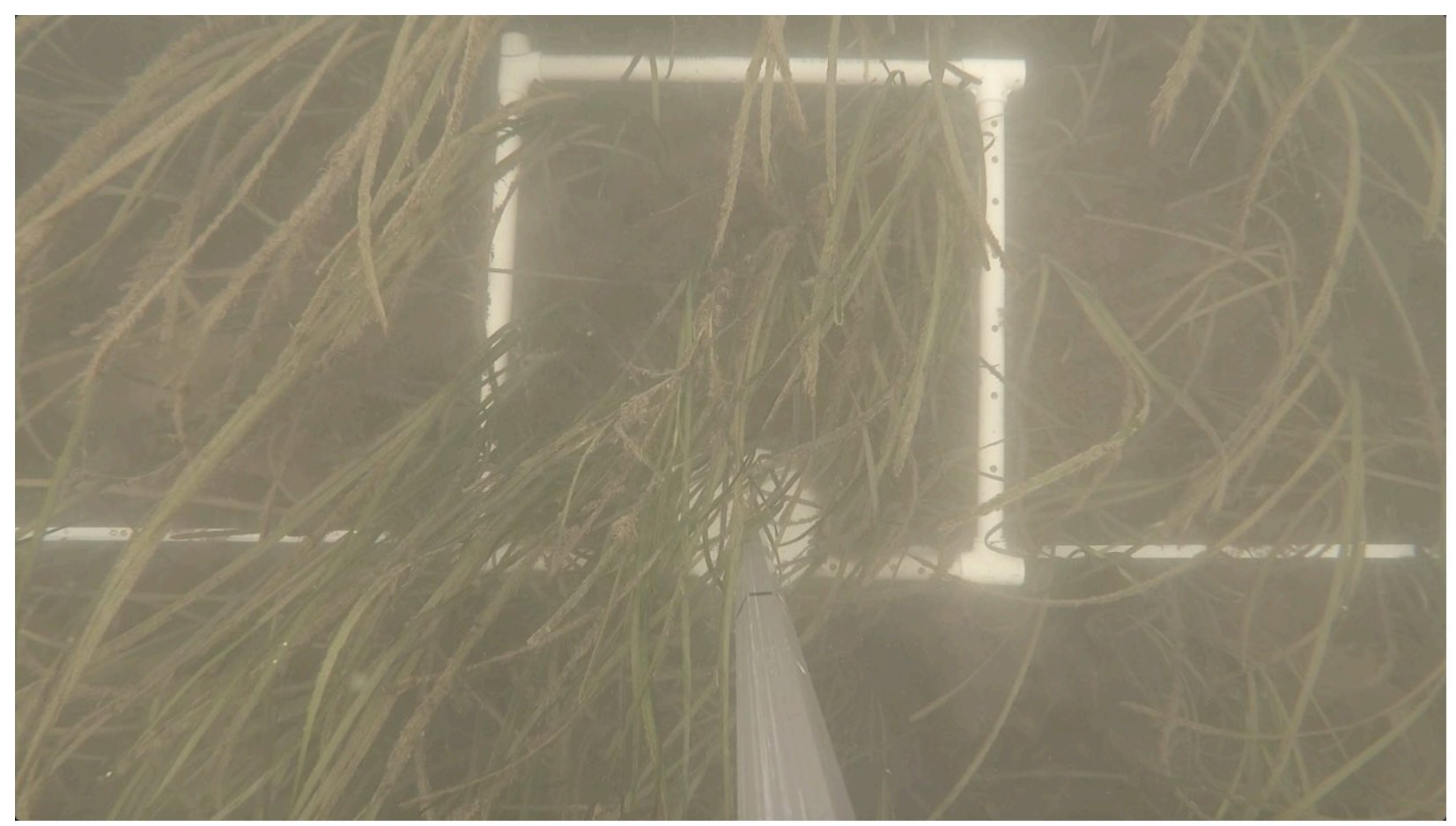

Q9.1 - How would you rate the health of the eelgrass in this frame?

\section{EHI: 50.9}

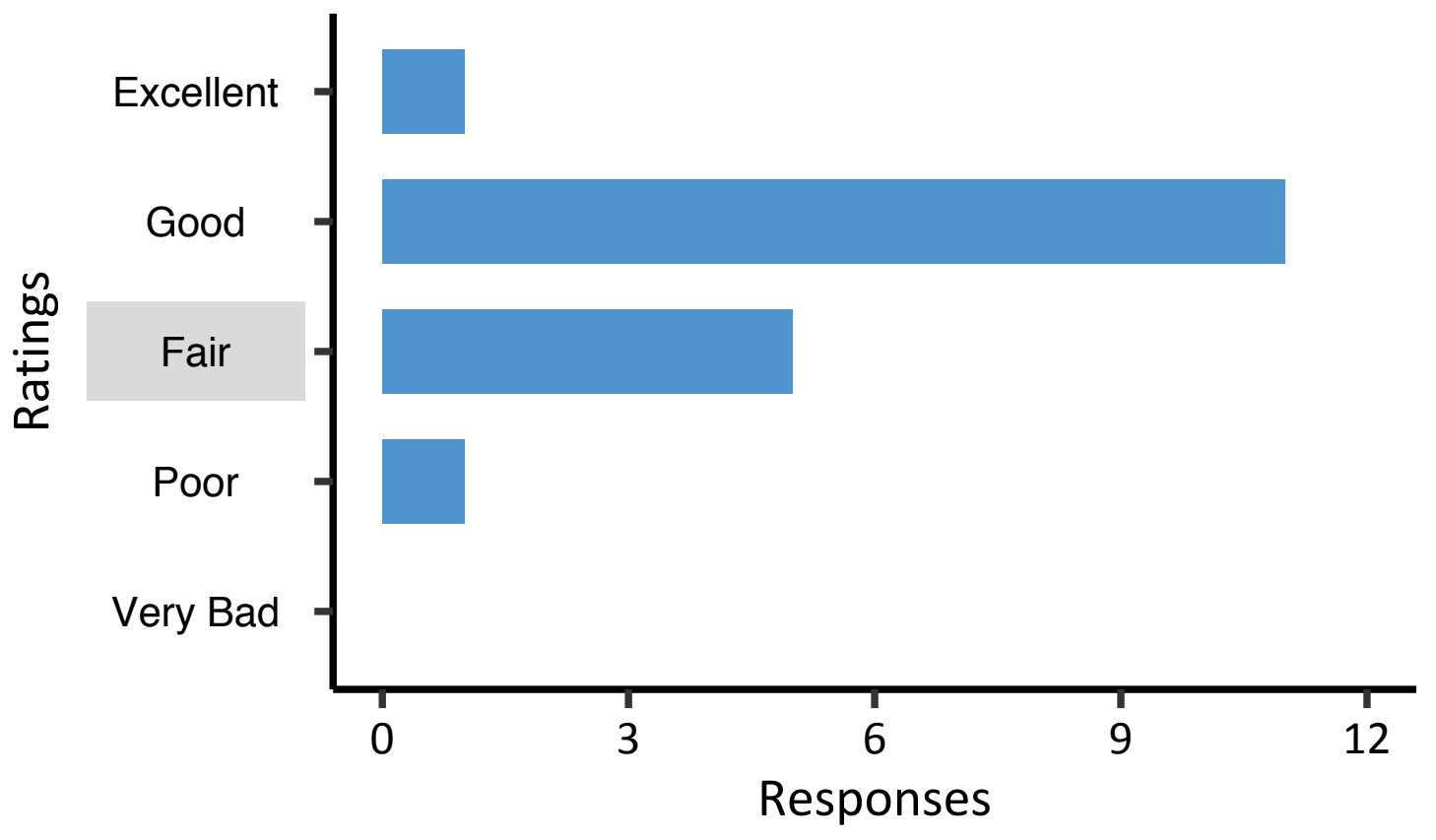


Q9.2 - Why did you select this rating? If you would like to use a specific value (1 - 100) to rate the eelgrass please include that here. (optional)

- Qualitative Visual Assessment

- shoot density are water clarity are good, despite the presence of epiphytes

- Good density, lot of algae

- Vacilating between good and fair. great eelgrass cover and tall stems but WQ not great and leaves covered by epiphytes; some but not all shoots are reproductive

- dense, high epiphytes

- no disease, long blades, moderate density, but some epiphytes

- Relatively high aboveground biomass and potentially shoot density--hard to say if minor-moderate fouling is present

- Fairly dense moderate clarity

- lots of epiphytes

- dense 


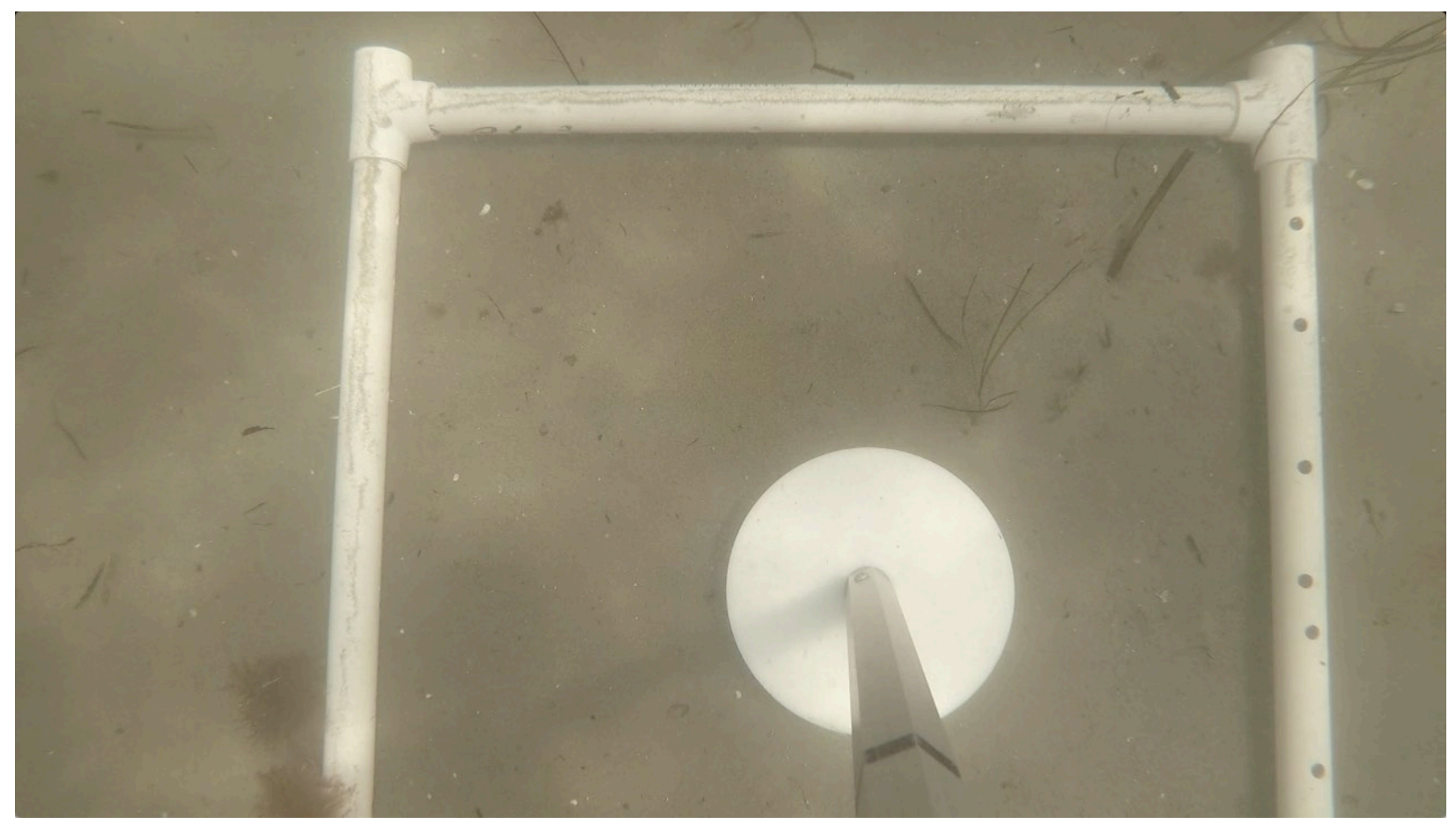

Q10.1 - How would you rate the health of the eelgrass in this frame?

\section{EHI: 2.94}

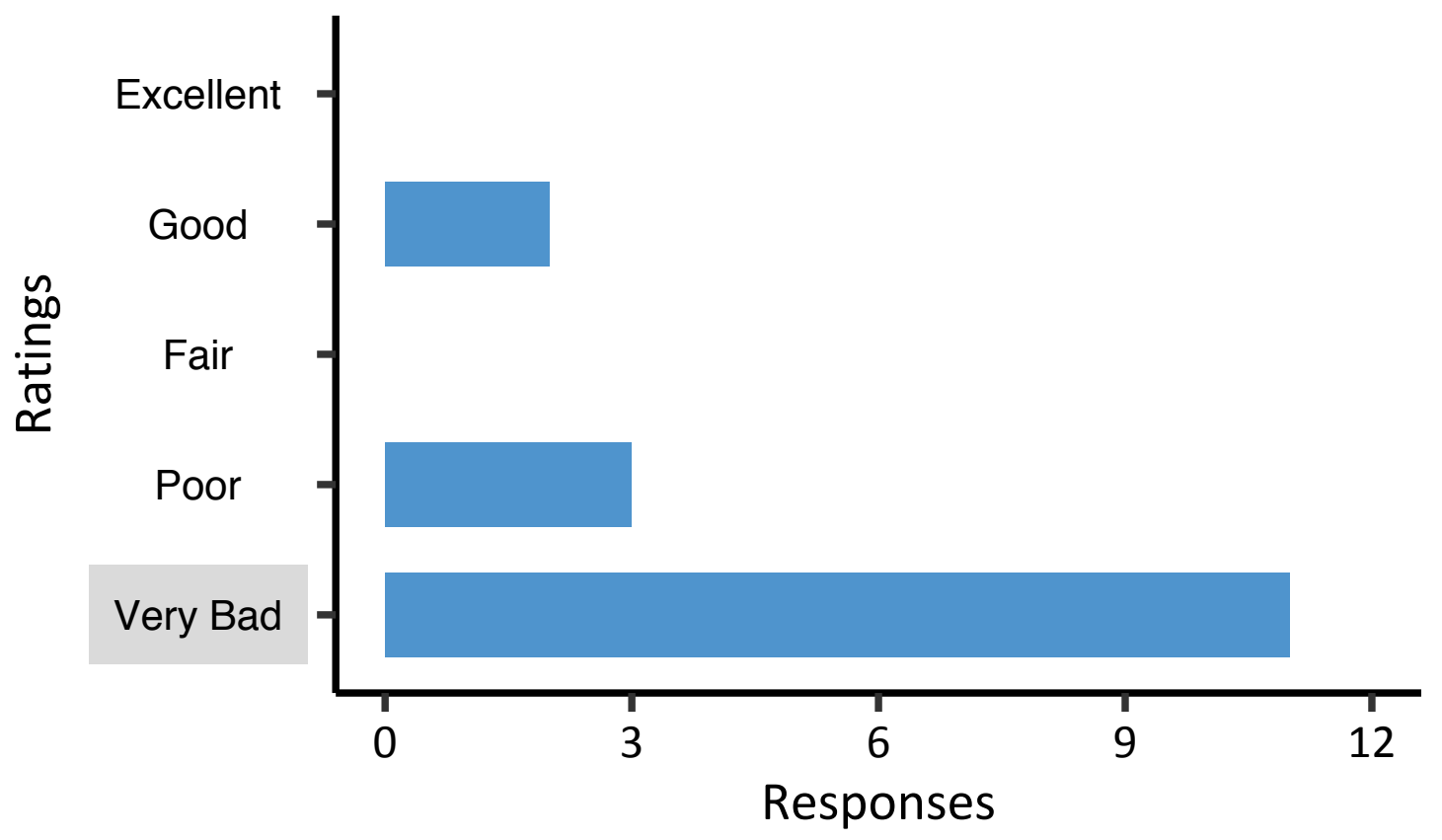


Q10.2 - Why did you select this rating? If you would like to use a specific value (1 - 100) to rate the eelgrass please include that here. (optional)

- find this one impossible to rate accurately -- newly colonizing seedling?

- One shoot and high water clarity

- Really hard to tell without context as to where in the bed this occurs. Could well be located at the shallow edge.

- Just bad

- 1-2\% ZM but good WQ and little algae

- Very little eelgrass visible.

- Rating strictly based on shoot density, but that being said without knowing the context of this photo it is difficult to judge. Water clarity looks good and there may be many reasons why eelgrass is currently not present. Perhaps this shoot is the first to colonize this area

- Qualitative Visual Assessment

- what eelgrass?

- Low everything

- only one seedling in frame, chance of survival is minimal

- No grass? 


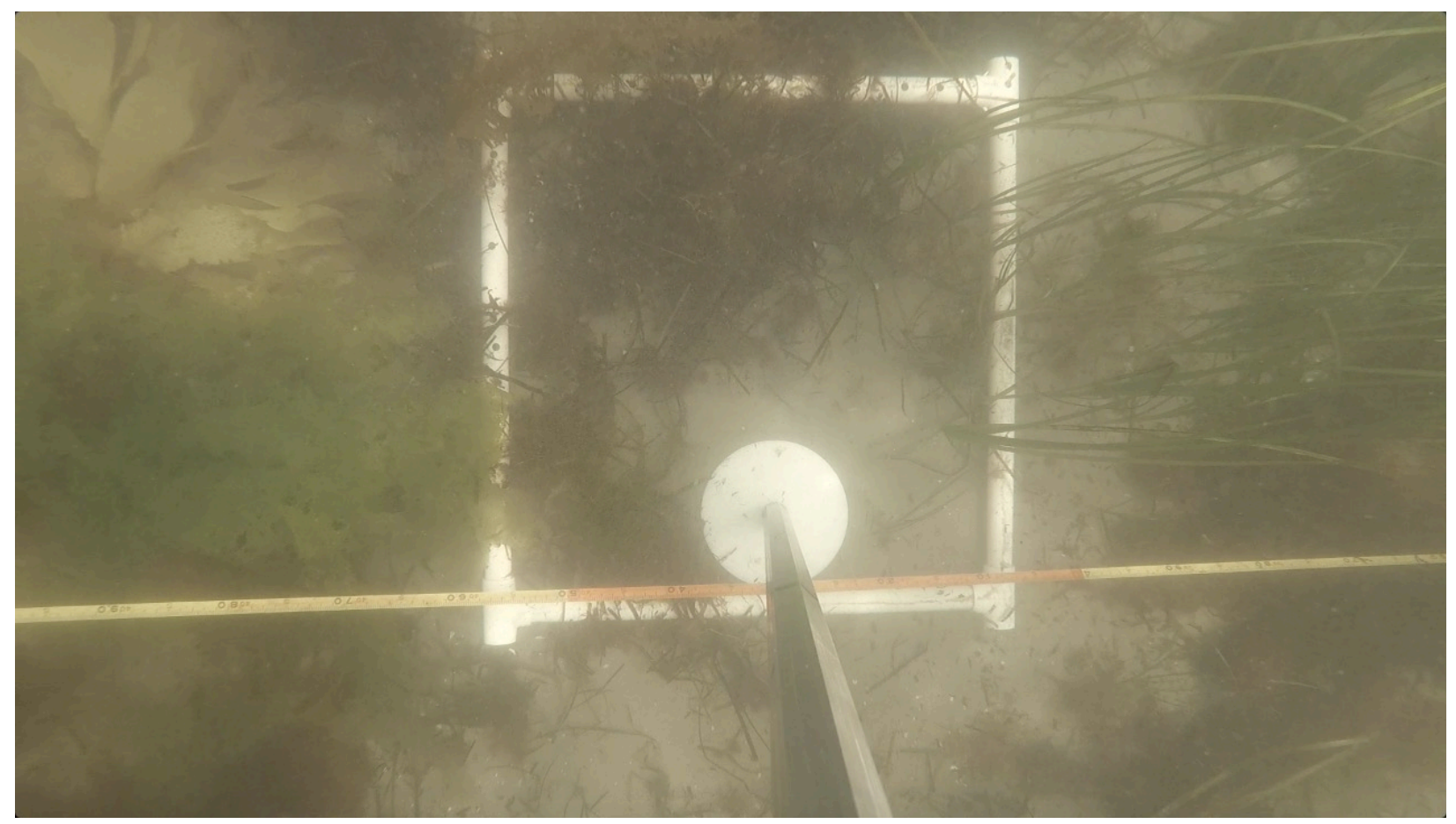

Q11.1 - How would you rate the health of the eelgrass in this frame?

\section{EHI: 16.7}

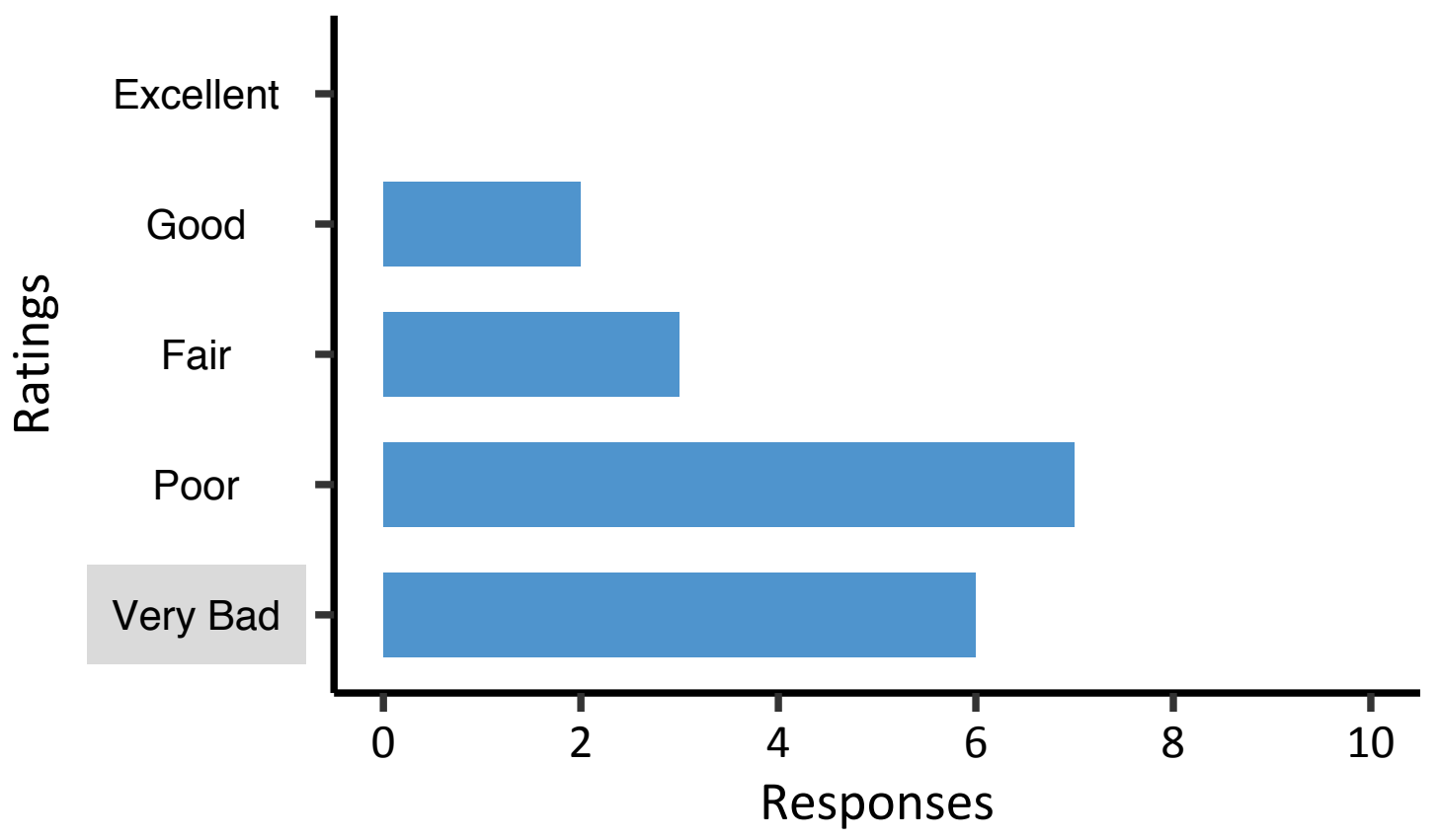


Q11.2 - Why did you select this rating? If you would like to use a specific value (1 - 100) to rate the eelgrass please include that here. (optional)

- Few healthy looking plants, macro algae

- green leave, low epiphytes, sparse density

- Qualitative Visual Assessment

- low levels of plants cover (15\%) but looking healthy; major problems of drift macro algae

- Eelgrass is alive however there is a lot of algae

- Eelgrass appears healthy but sparse. Hard to tell if dark tissue within quad is necrotic eelgrass or macroalgae.

- borderline poor to fair, fair water clarity, but low shoot density, plus the presence of drift algae that may hinder eelgrass growth 


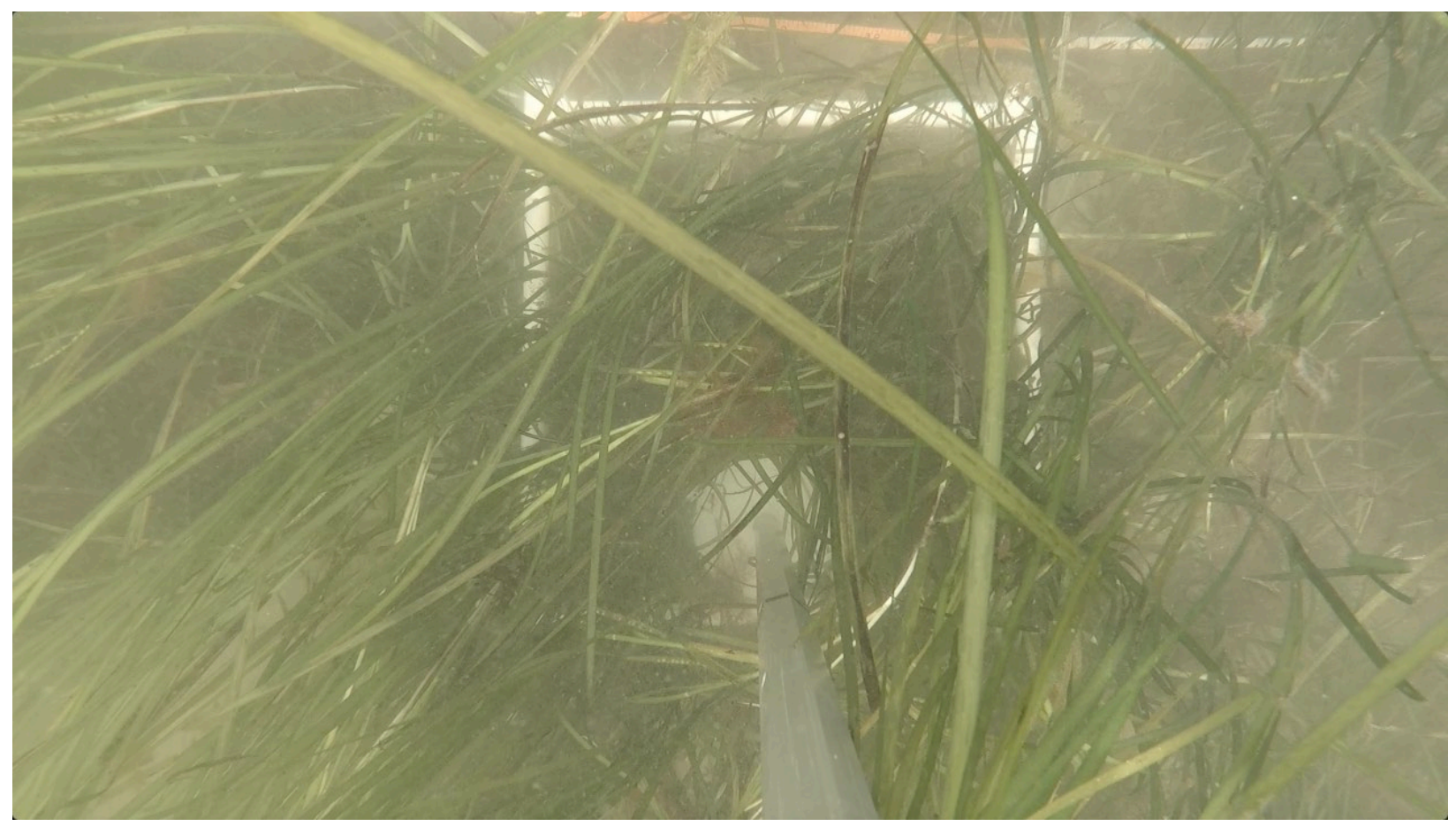

Q12.1 - How would you rate the health of the eelgrass in this frame?

\section{EHI: 77.4}

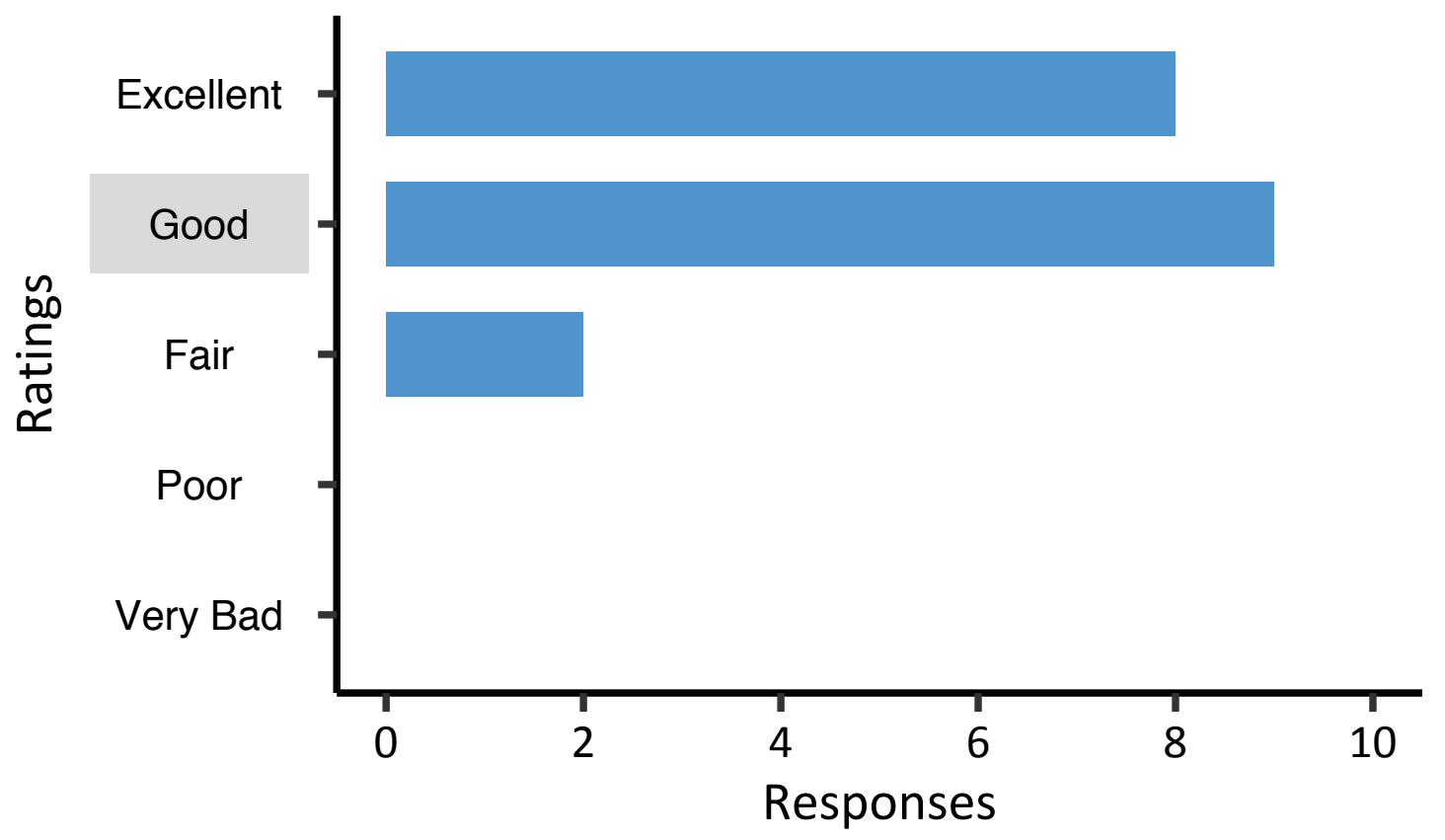


Q12.2 - Why did you select this rating? If you would like to use a specific value (1 - 100) to rate the eelgrass please include that here. (optional)

- borderline good to excellent, high shoot density, water clarity a bit compromised, perhaps some evidence of disease

- $\quad$ high density, few epiphytes, tall growth

- high cover, low to moderate epiphytes

- Great density and healthy looking leaves

- within the frame, quite dense and clean blades

- Good clarity and high density

- dense plants within quadrat, minor macro algae

- Qualitative Visual Assessment

- Plants are very dense and seemingly tall. Blades are wides. There are reproductive shoots!

- some loss or disturbance 


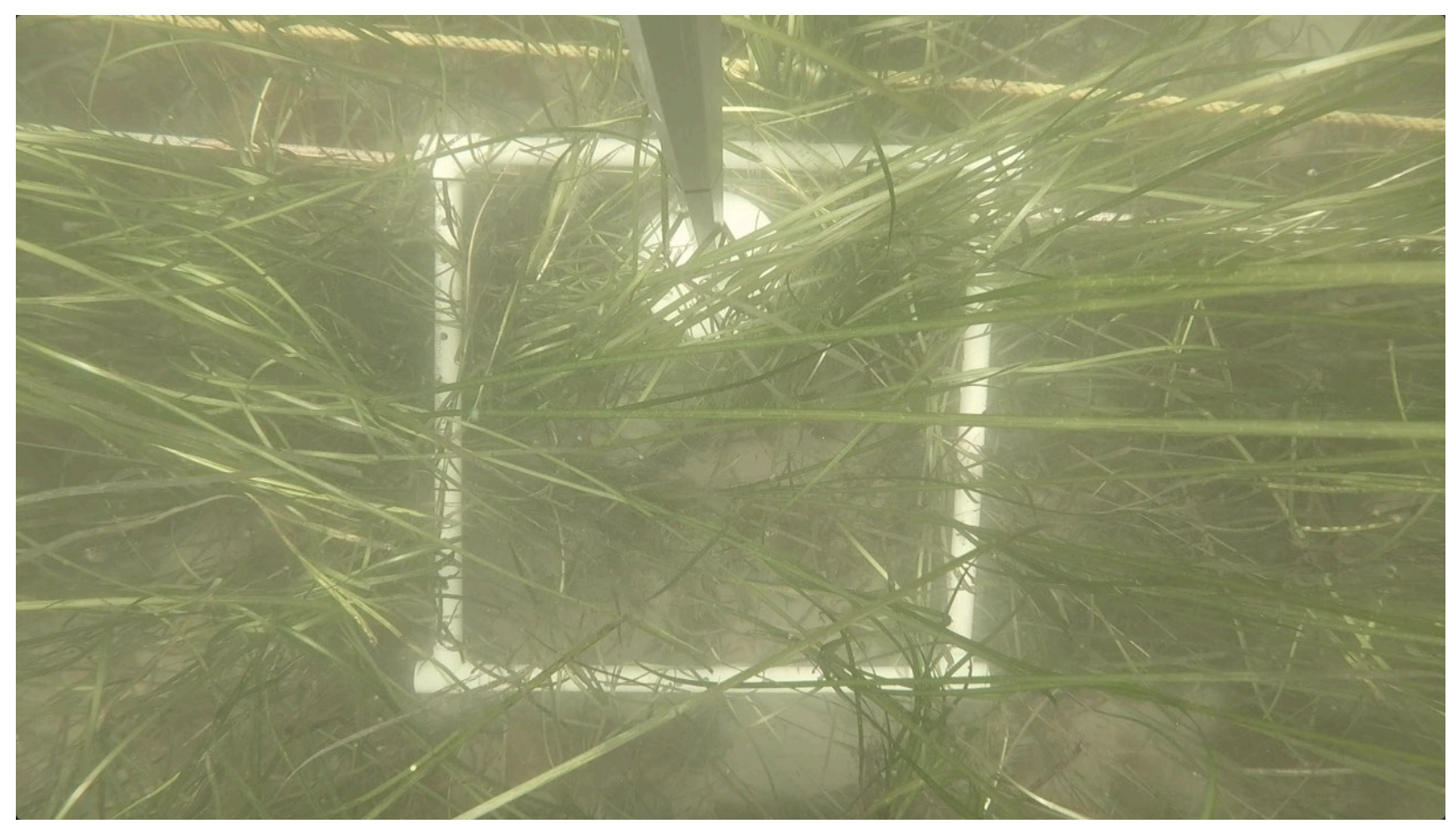

Q13.1 - How would you rate the health of the eelgrass in this frame?

\section{EHI: 59.9}

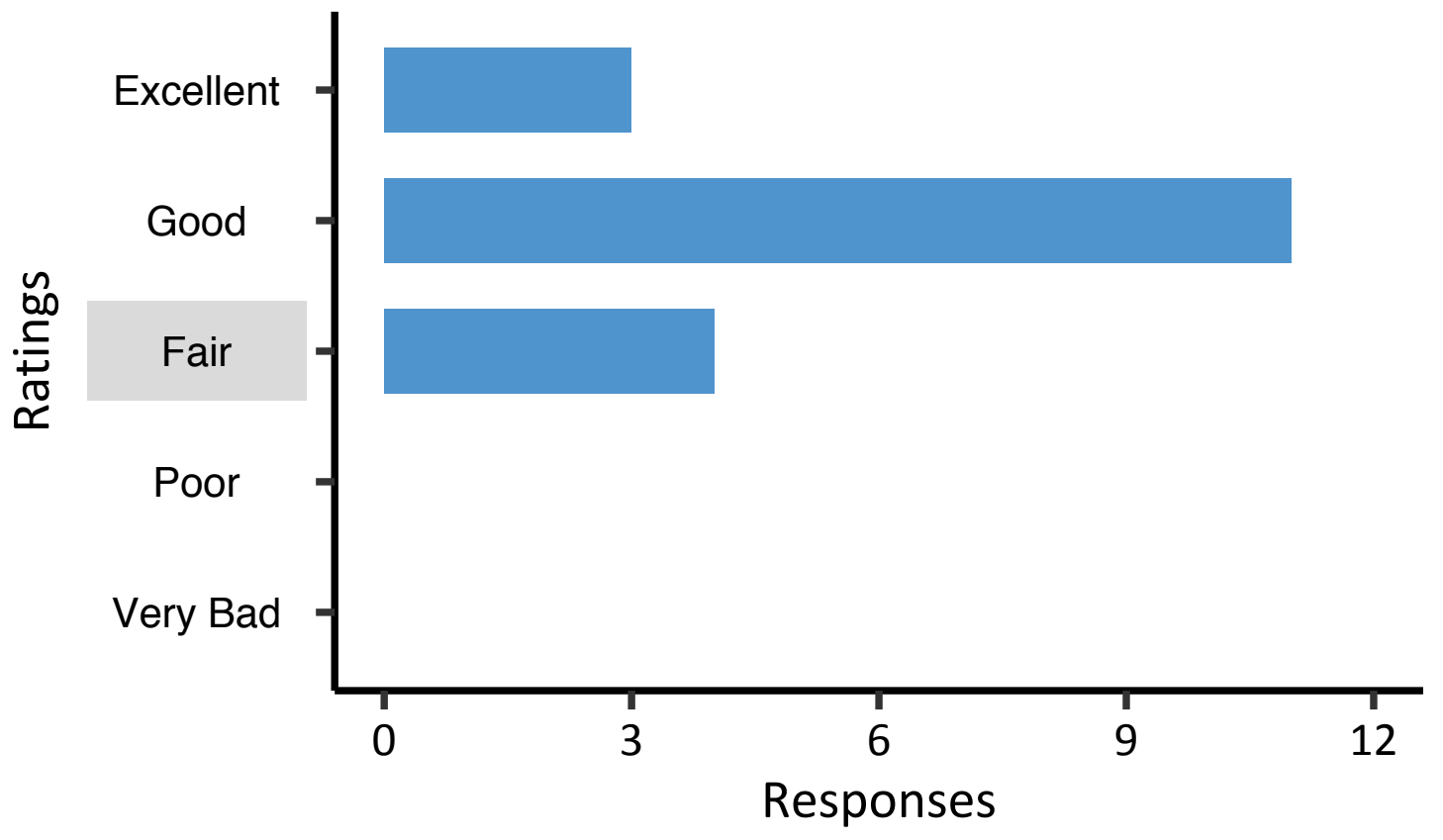


Q13.2 - Why did you select this rating? If you would like to use a specific value (1 - 100) to rate the eelgrass please include that here. (optional)

- Qualitative Visual Assessment

- borderline excellent to good, plants look healthy, shoot density is good, though might be lower than previous picture due to the high number of reproductive shoots

- Goof density and clarity

- some bare spots

- Good density, healthy looking plants

- About $60 \%$ cover but algae mixed in the bed 


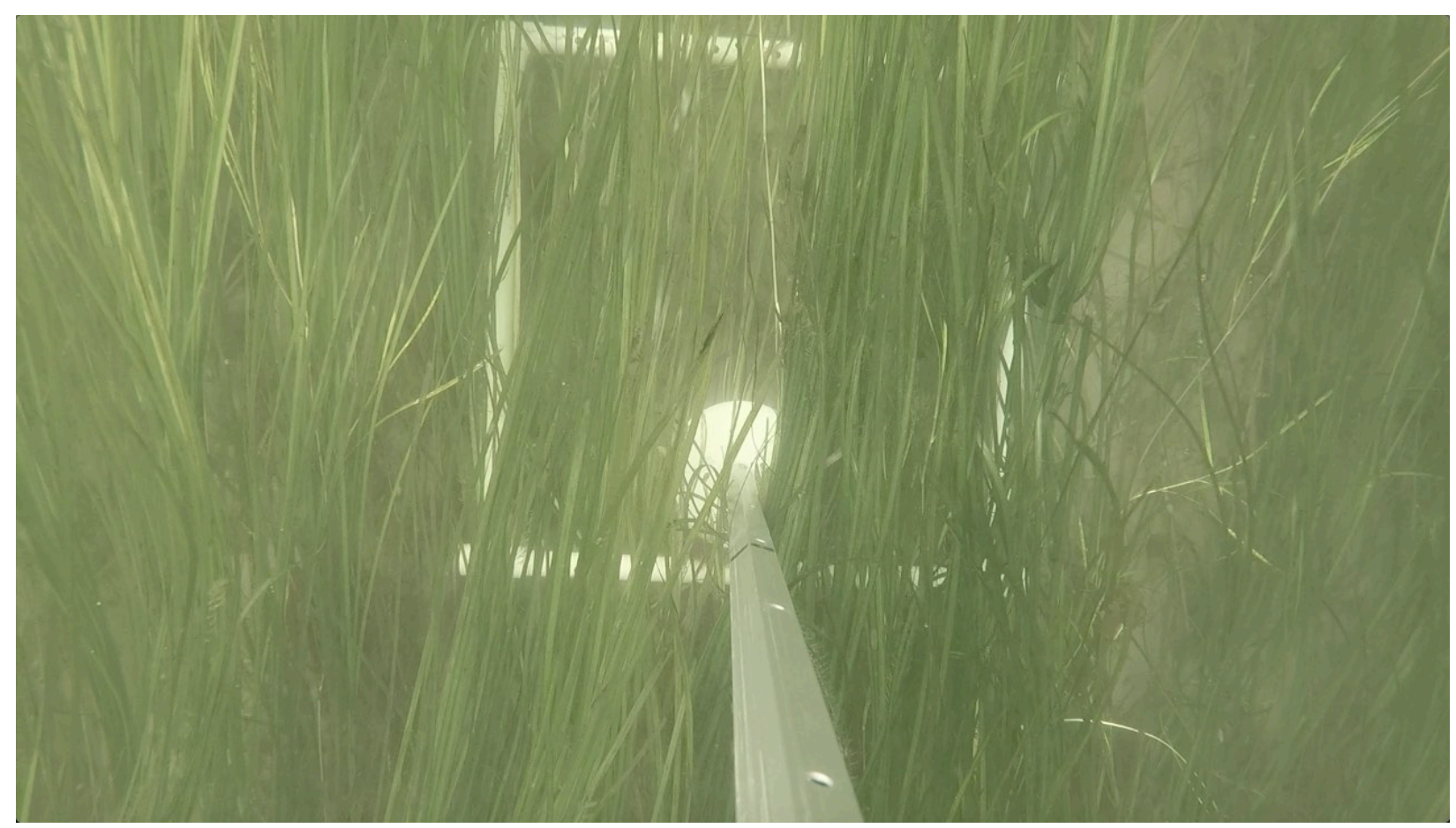

Q14.1 - How would you rate the health of the eelgrass in this frame?

\section{EHI: 86.8}

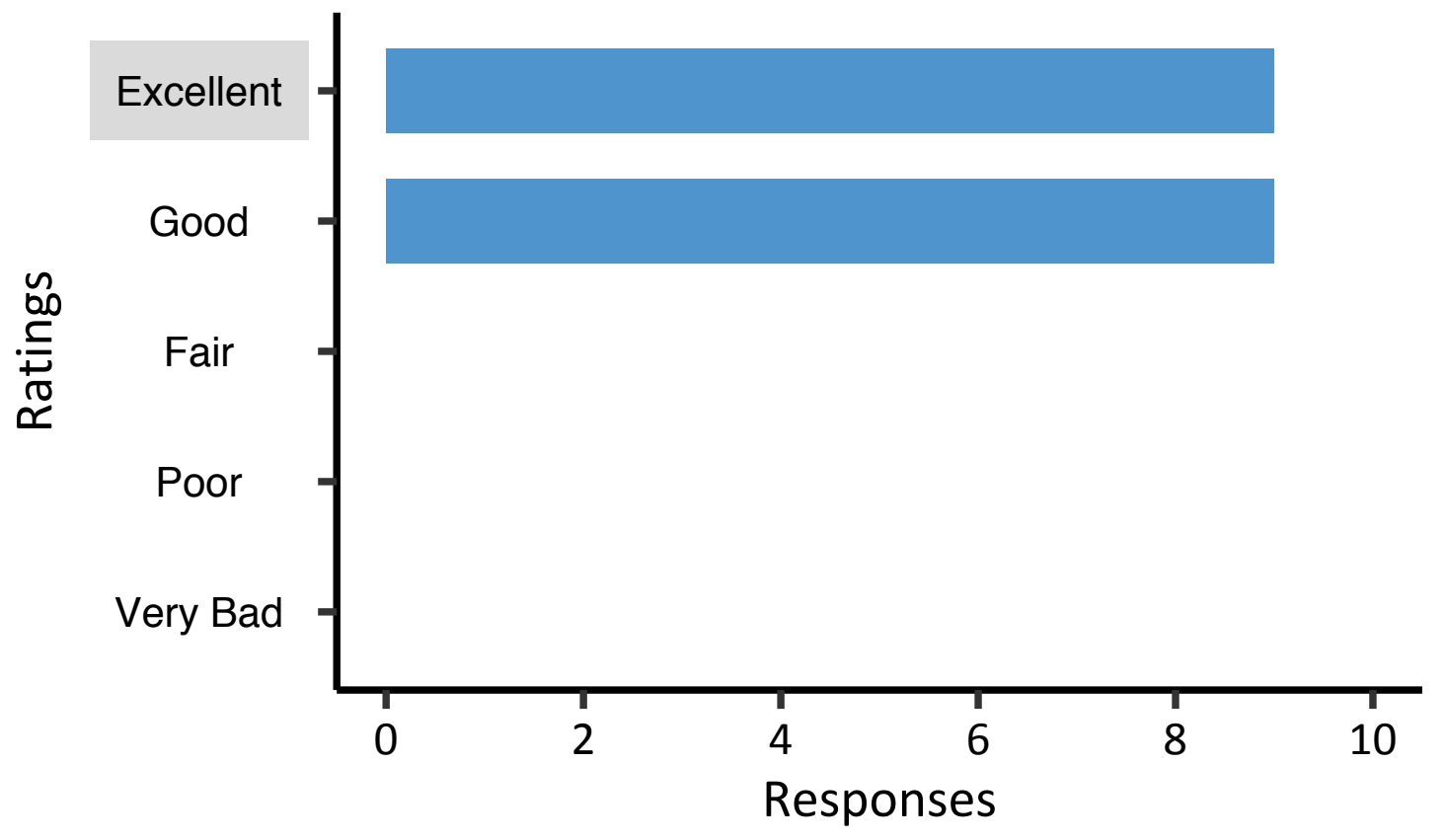


Q14.2 - Why did you select this rating? If you would like to use a specific value (1 - 100) to rate the eelgrass please include that here. (optional)

- Blades seem longer and more dense, but that could just be a function of longer blades making it look like there are more plants, when the density is actually similar.

- dense, unfouled shoots, relatively high percent cover

- dense plants

- great water clarity, healthy long thick green leaves

- green leaves, dense, no algae

- Qualitative Visual Assessment

- dense, long leaves in good health

- Great density, healthy looking plants

- Water clarity could better but overall good density and clarity 


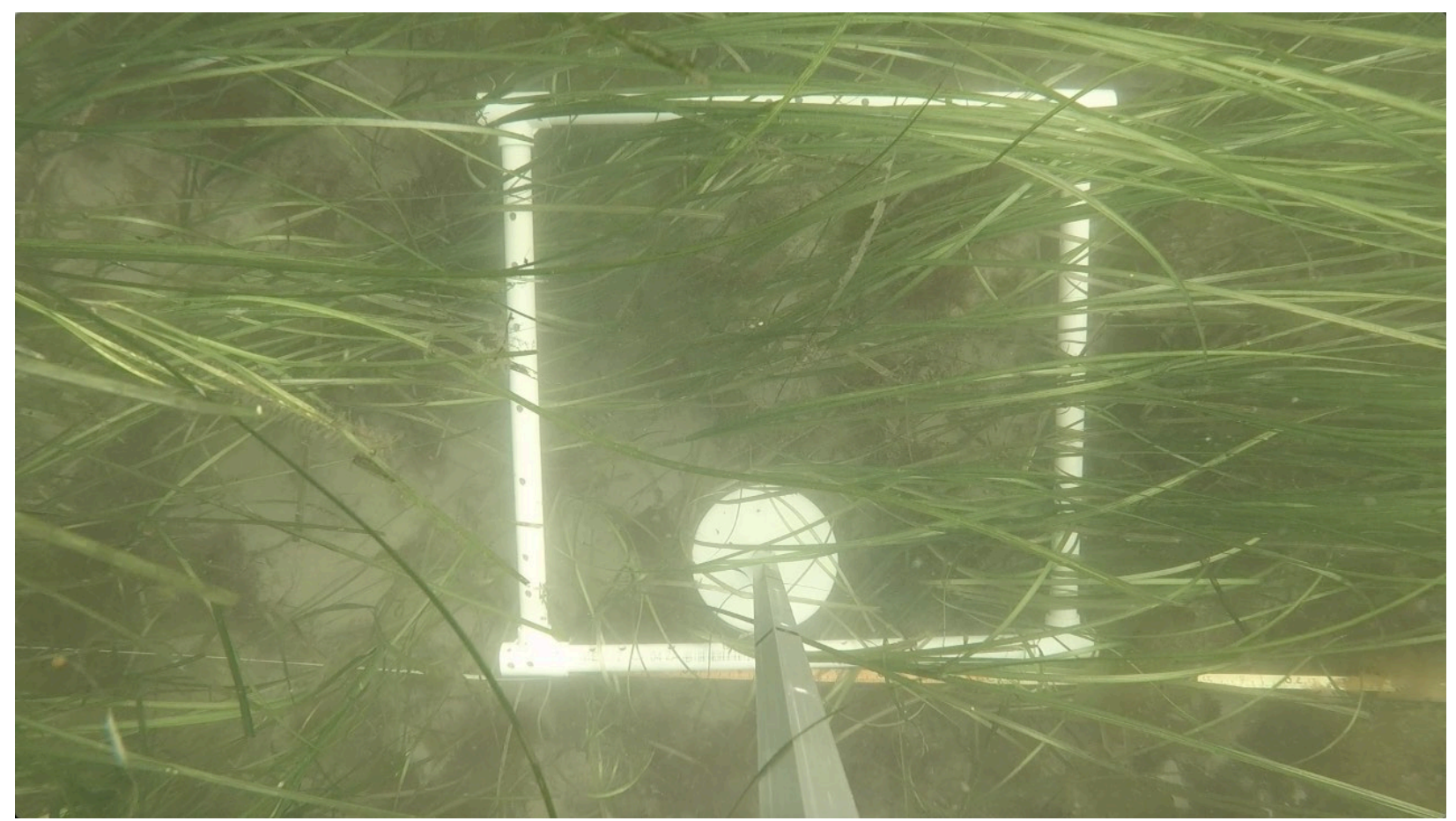

Q15.1 - How would you rate the health of the eelgrass in this frame?

\section{EHI: 84.5}

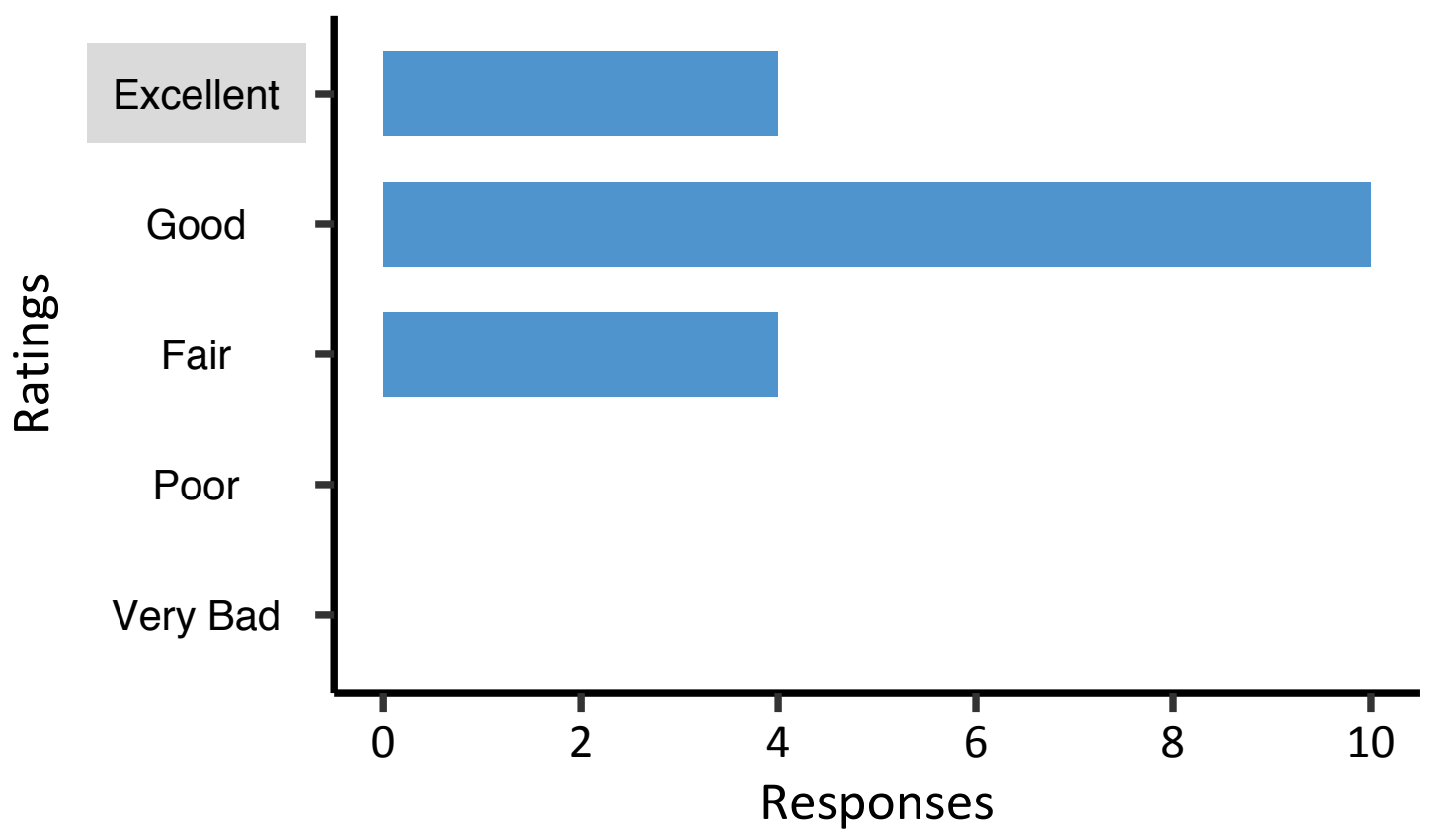


Q15.2 - Why did you select this rating? If you would like to use a specific value (1 - 100) to rate the eelgrass please include that here. (optional)

- About $60 \%$ cover but drift algae visible

- green leaves, dense, little algae

- would have been excellent but for the bare spots

- A "high Good" - dense and healthy looking plants

- have never seen excellent.

- good water clarity, healthy looking plants

- Qualitative Visual Assessment

- borderline excellent/good, water clarity is better than prior picture, plants look healthy and shoot density is good 


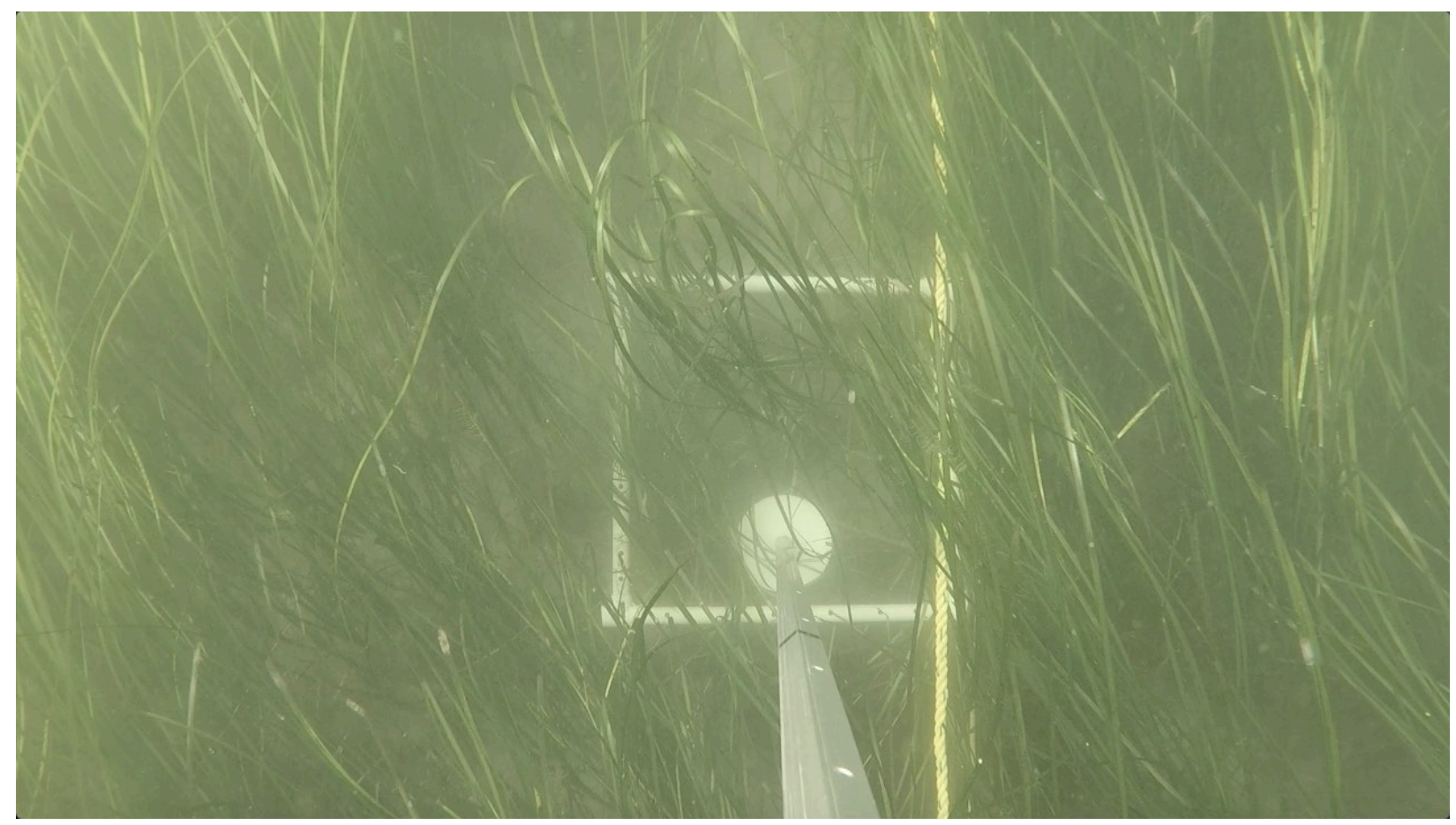

Q16.1 - How would you rate the health of the eelgrass in this frame?

\section{EHI: 69.0}

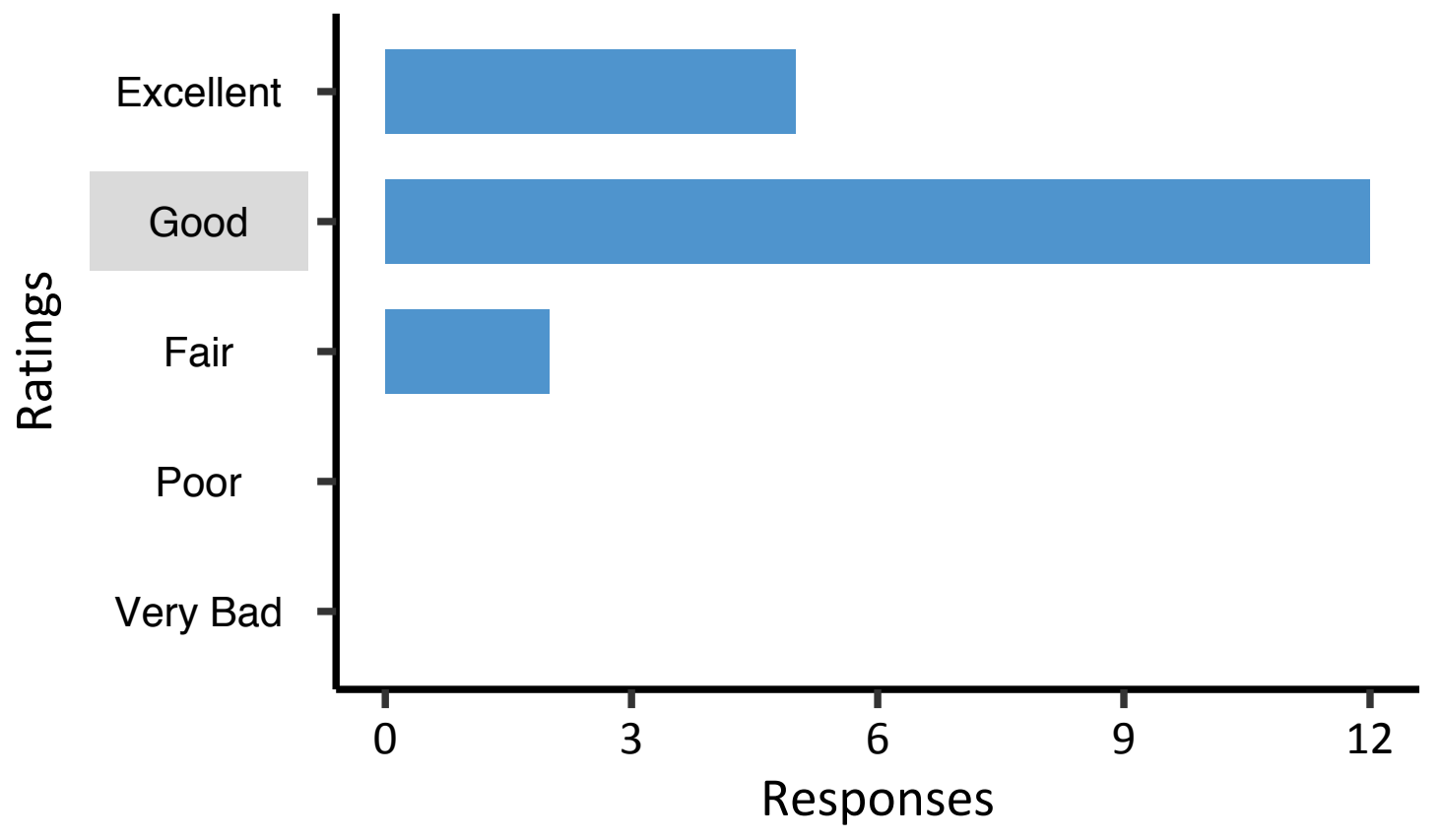


Q16.2 - Why did you select this rating? If you would like to use a specific value (1 - 100) to rate the eelgrass please include that here. (optional)

- This bed seems to be on the lower end of the Excellent spectrum. Eelgrass is a decent height although there is definitely some bare space in the quadrat. Grass isn't covered with epiphytes or algae.

- Some bare ground visible, otherwise would have rated it excellent

- Qualitative Visual Assessment

- borderline good to excellent, shoot density is pretty good and the shoots are a healthy green color

- about $30 \%$ of bottom is visible through the blades

- Shoots look healthy and green high density

- Excellent density and healthy-looking plants 


\section{Q17.1 - How would you rate the health of the eelgrass in this frame?}

\section{EHI: 85.1}

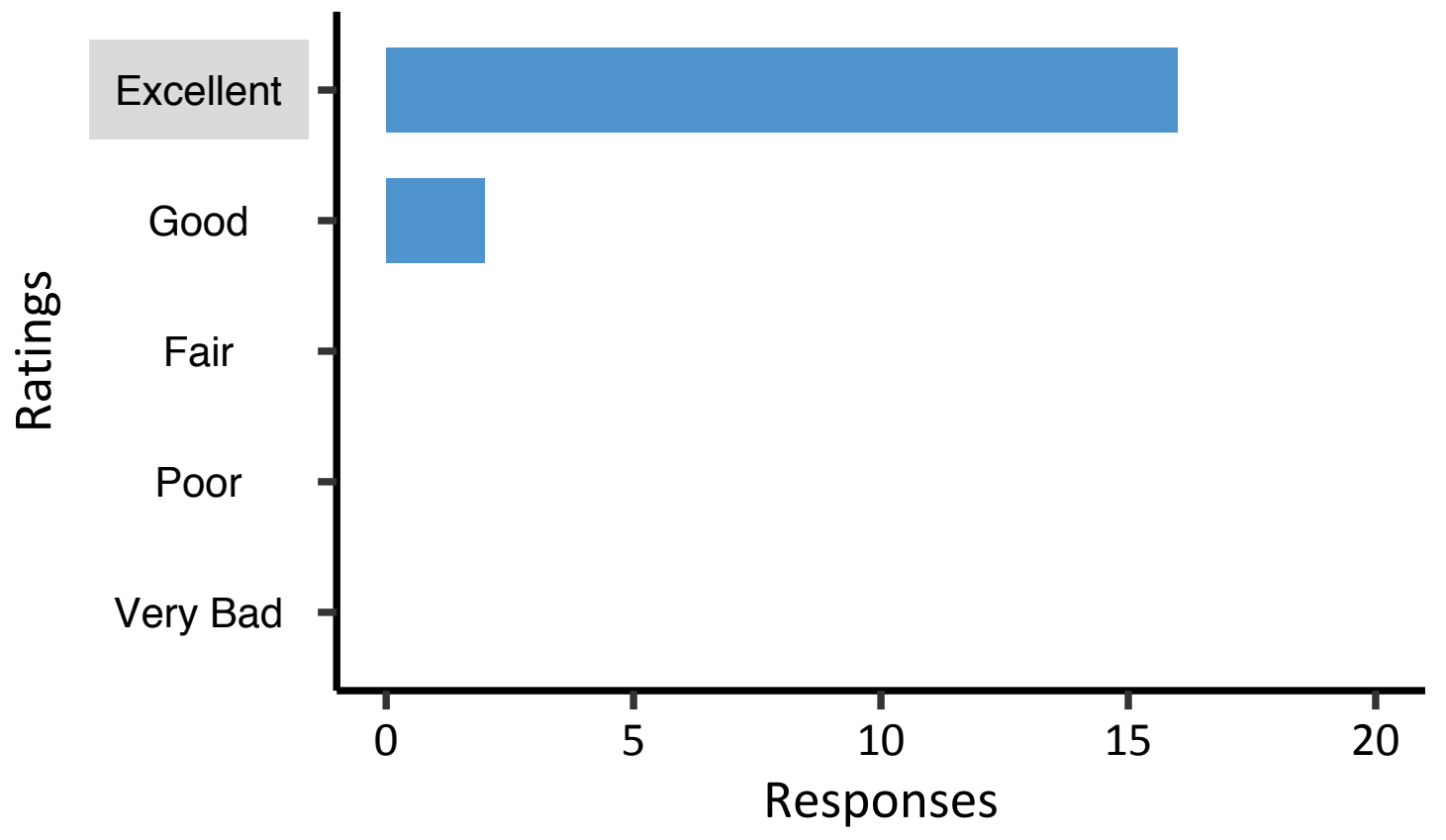


Q17.2 - Why did you select this rating? If you would like to use a specific value (1 - 100) to rate the eelgrass please include that here. (optional)

- long, dense, clean

- really healthy lush thick meadow, no evidence of disease or epiphytes on leaves

- Qualitative Visual Assessment

- Great density, healthy looking plants

- Dense bed water clarity not bad

- same comments as for prior photo, with even higher percent cover

- appears to be healthy and very dense eelgrass, though it could be the angle of the photo and the length of the blades.

- I cannot even discern the quadrat

- Thickest picture yet

- bright green leaves, no macro algae 


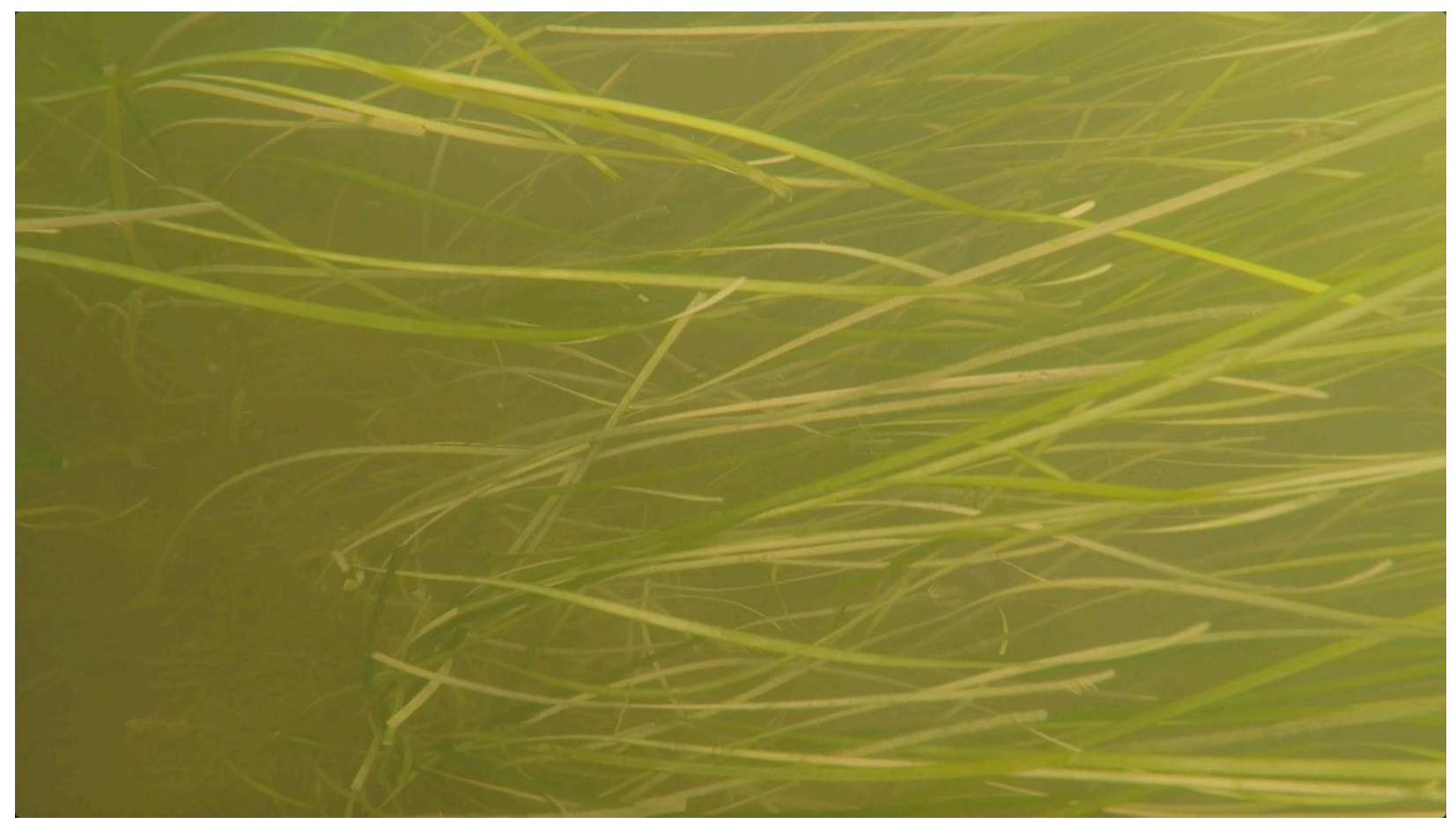

Q18.1 - How would you rate the health of the eelgrass in this frame?

\section{EHI: 82.2}

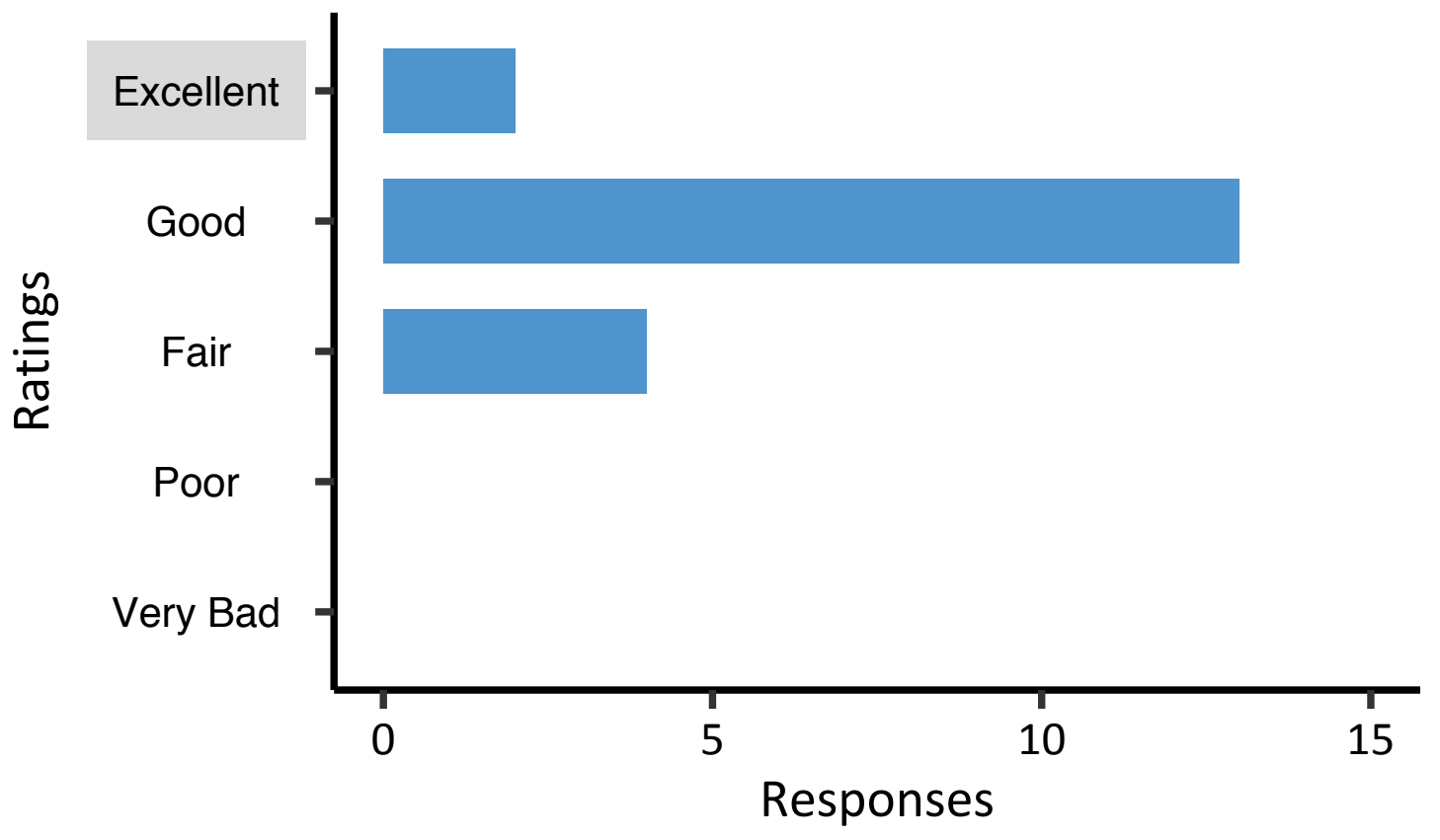


Q18.2 - Why did you select this rating? If you would like to use a specific value (1 - 100) to rate the eelgrass please include that here. (optional)

- dense and bright green blades, no macro algae

- The plants here are tall which puts this in the Good category. Many of the blades look muddy and broken though.

- Qualitative Visual Assessment

- Water quality not optimal

- Pretty dense looking, healthy looking plants

- Large amount of aboveground biomass with lengthy shoots and possible epiphytic or sediment cover demonstrates stress.

- not much green

- shoot density not quite excellent and some yellowing of shoots, could be taken late in growing season

- bare spot ; leaves whitefish brown with epiphytes

- clean blades, large plants 


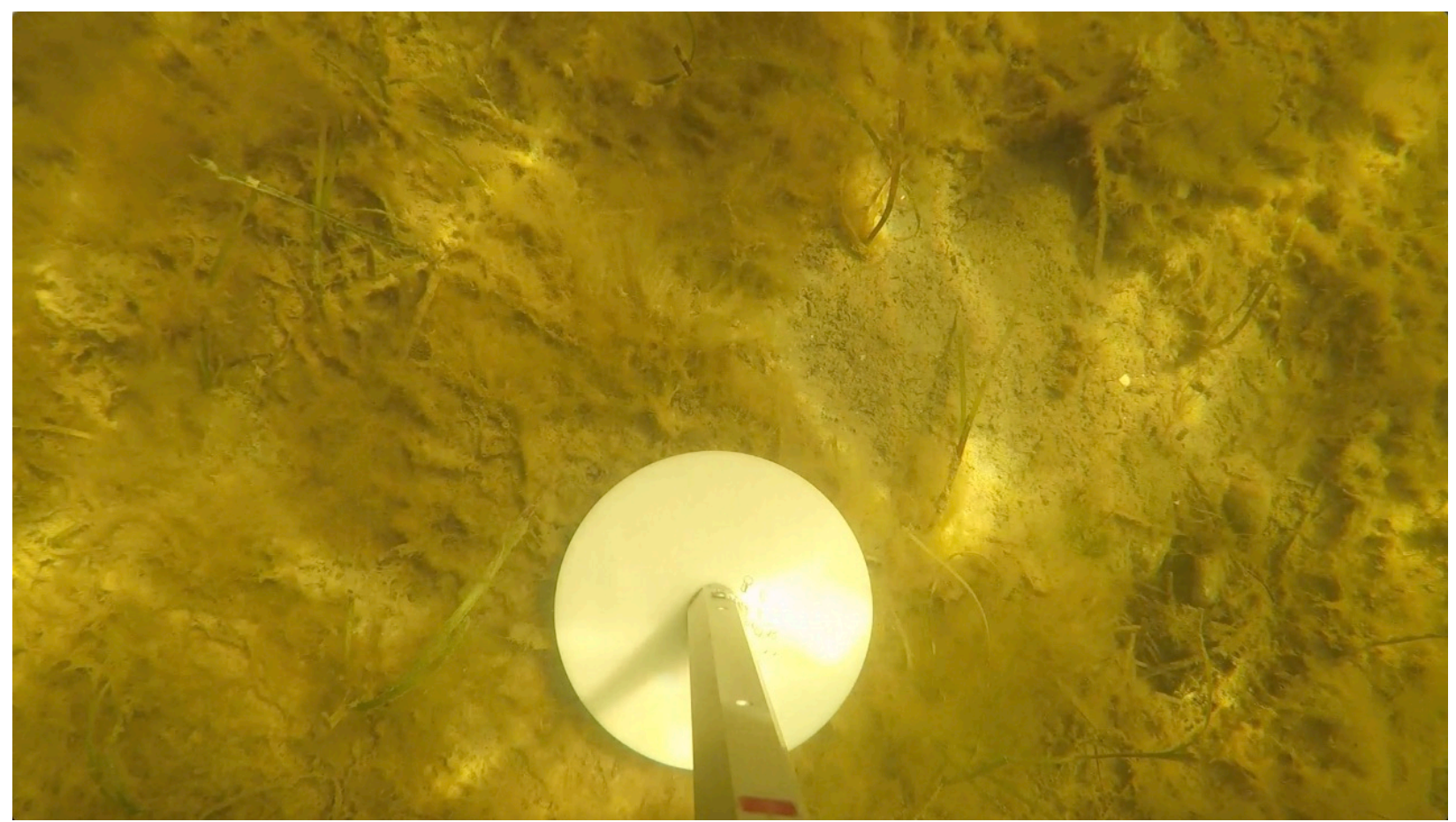

Q19.1 - How would you rate the health of the eelgrass in this frame?

\section{EHI: 5.18}

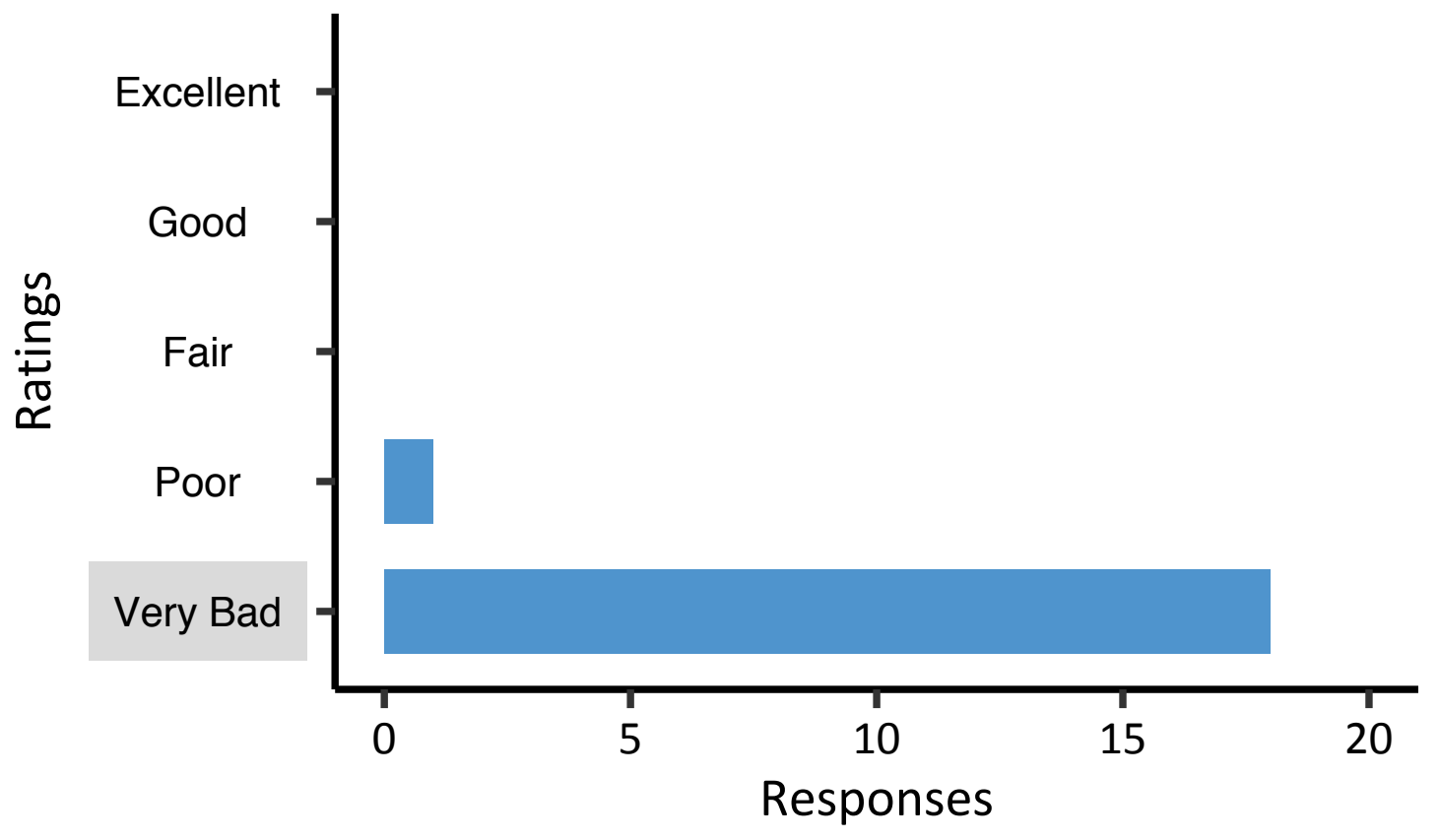


Q19.2 - Why did you select this rating? If you would like to use a specific value (1 - 100) to rate the eelgrass please include that here. (optional)

- About $\% 5$ cover and smothered by algae; yuck

- extensive epiphytes, algal growth some evidence of diseasae

- heavy epiphytes, very low density

- Lots of algae and low density

- very few shoots, high macro algae cover

- Comments same as for prior photo.

- heaps of epiphytes or algae

- just a couple of struggling shoots

- Qualitative Visual Assessment 


\section{Q20.1 - How would you rate the health of the eelgrass in this frame?}

\section{EHI: 39.8}

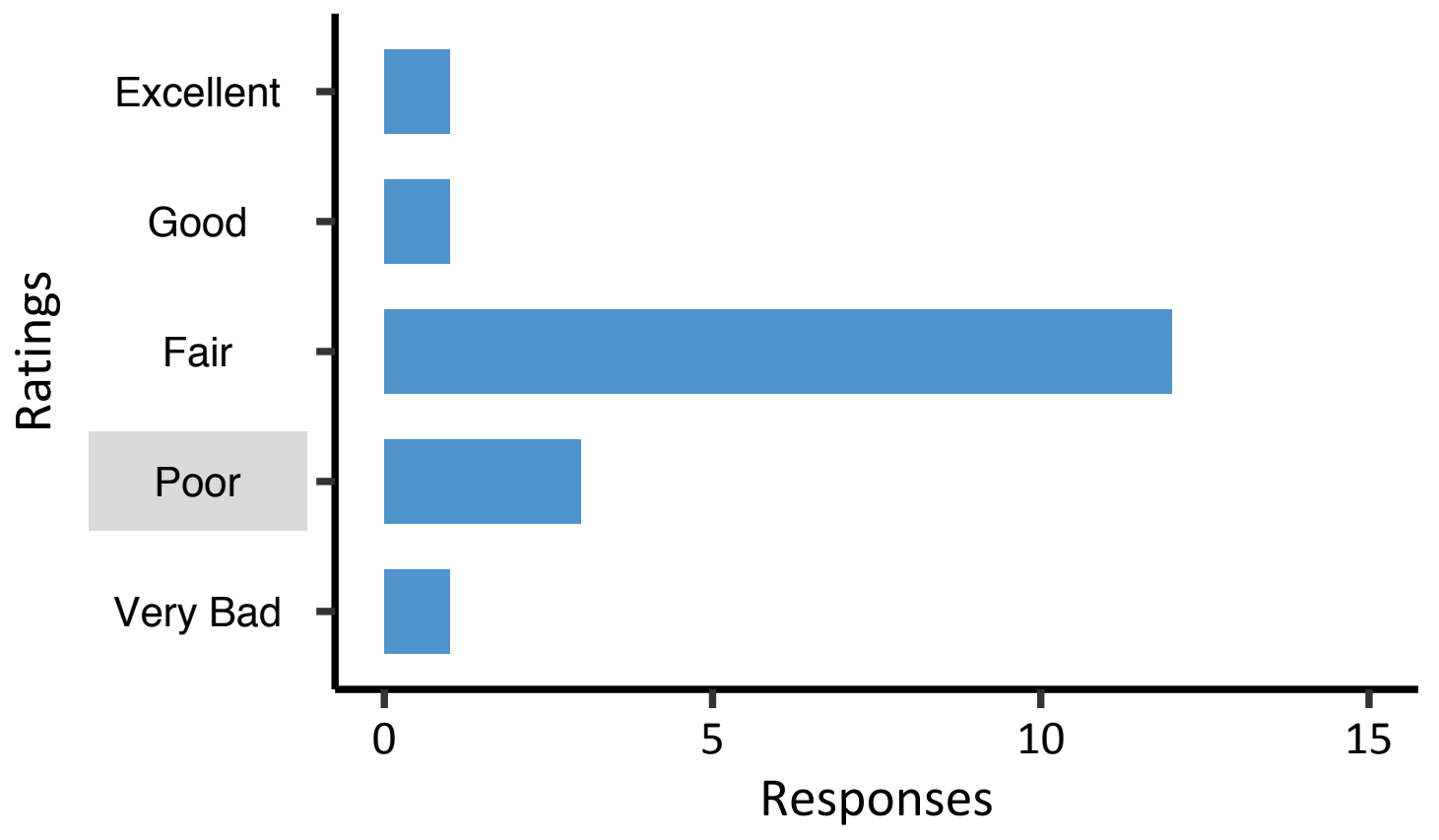


Q20.2 - Why did you select this rating? If you would like to use a specific value (1 - 100) to rate the eelgrass please include that here. (optional)

- high end of fair to low end of good, shoot density in this particular spot is fair, but water clarity and the shoots themselves look good

- Qualitative Visual Assessment

- sparse bed

- green leaves, moderate density, low epiphytes

- blades look healthy, but sparse cover

- slightly more bare spots and cloudier water

- Under $50 \%$ cover with some macro algae present

- Low clarity and density 


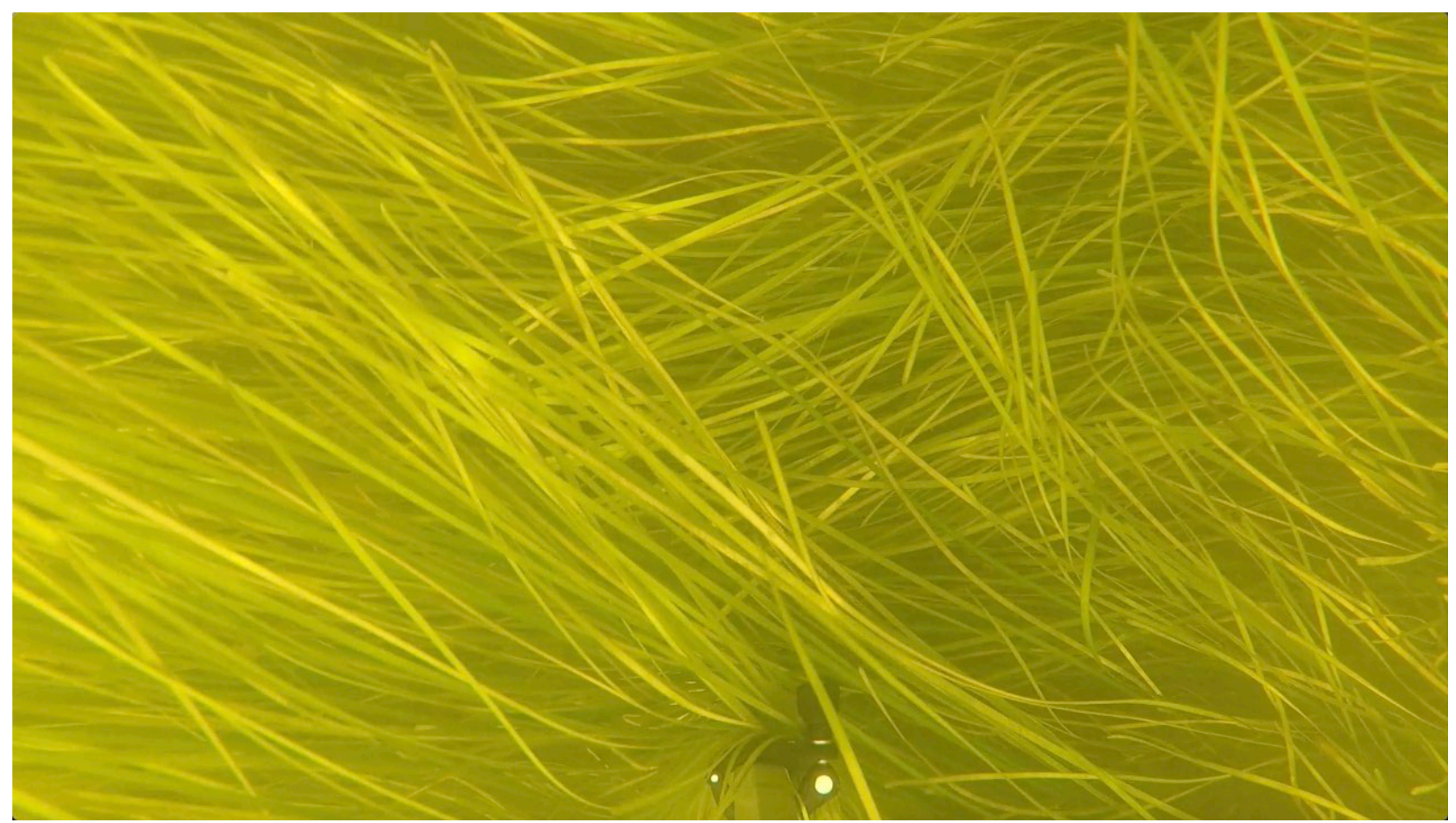

Q21.1 - How would you rate the health of the eelgrass in this frame?

\section{EHI: 79.6}

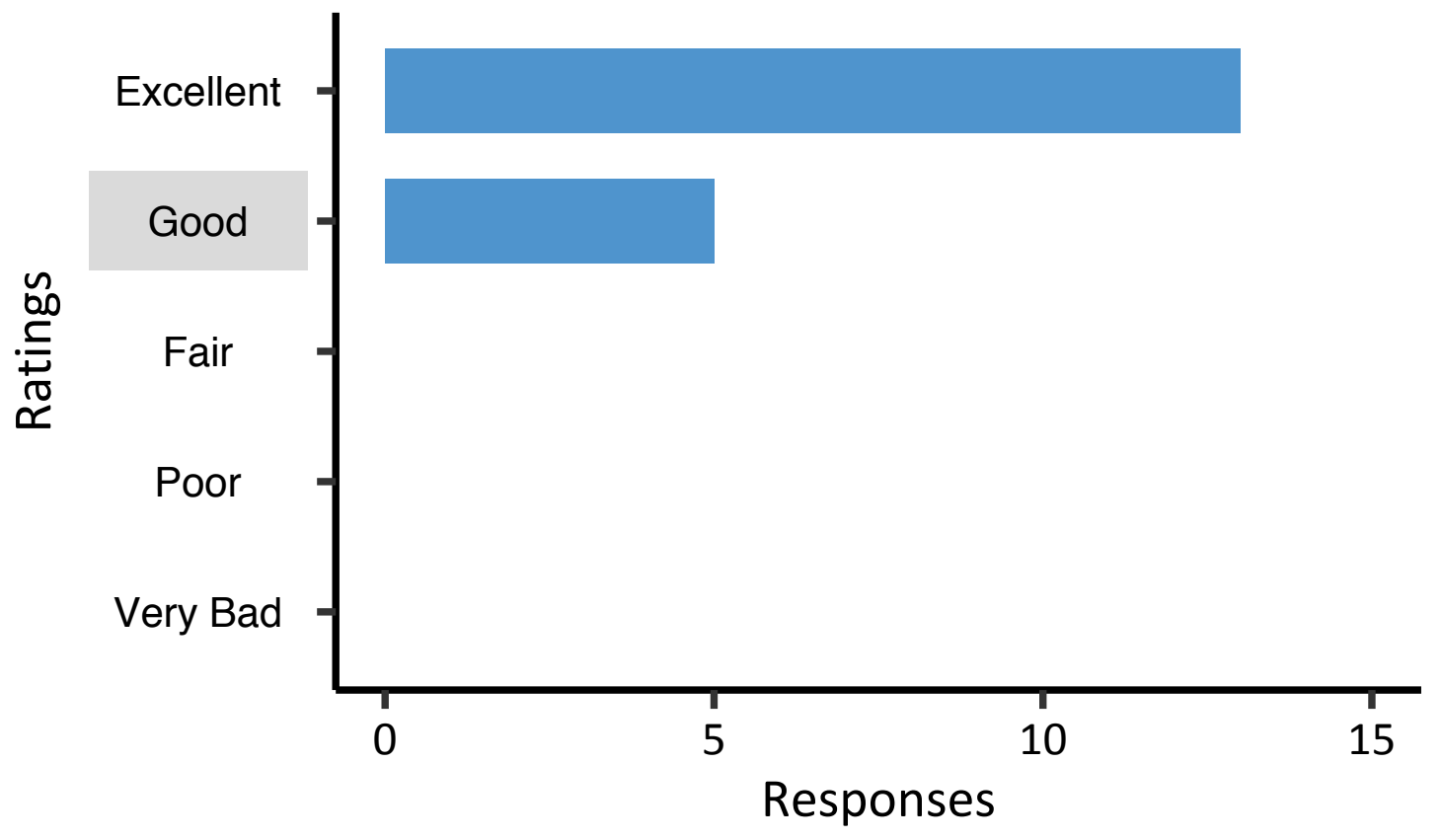


Q21.2 - Why did you select this rating? If you would like to use a specific value (1 - 100) to rate the eelgrass please include that here. (optional)

- Plants look really healthy and shoots are long but yellowish tint to water may be affecting health

- nice thick meadow with good water clarity

- Dense plants with little to no epiphytes or macro algae

- maybe good to excellent, high density low epiphytes blades look healthy

- Great density, healthy looking plants

- high good but not excellent due to bleached blades

- Qualitative Visual Assessment 


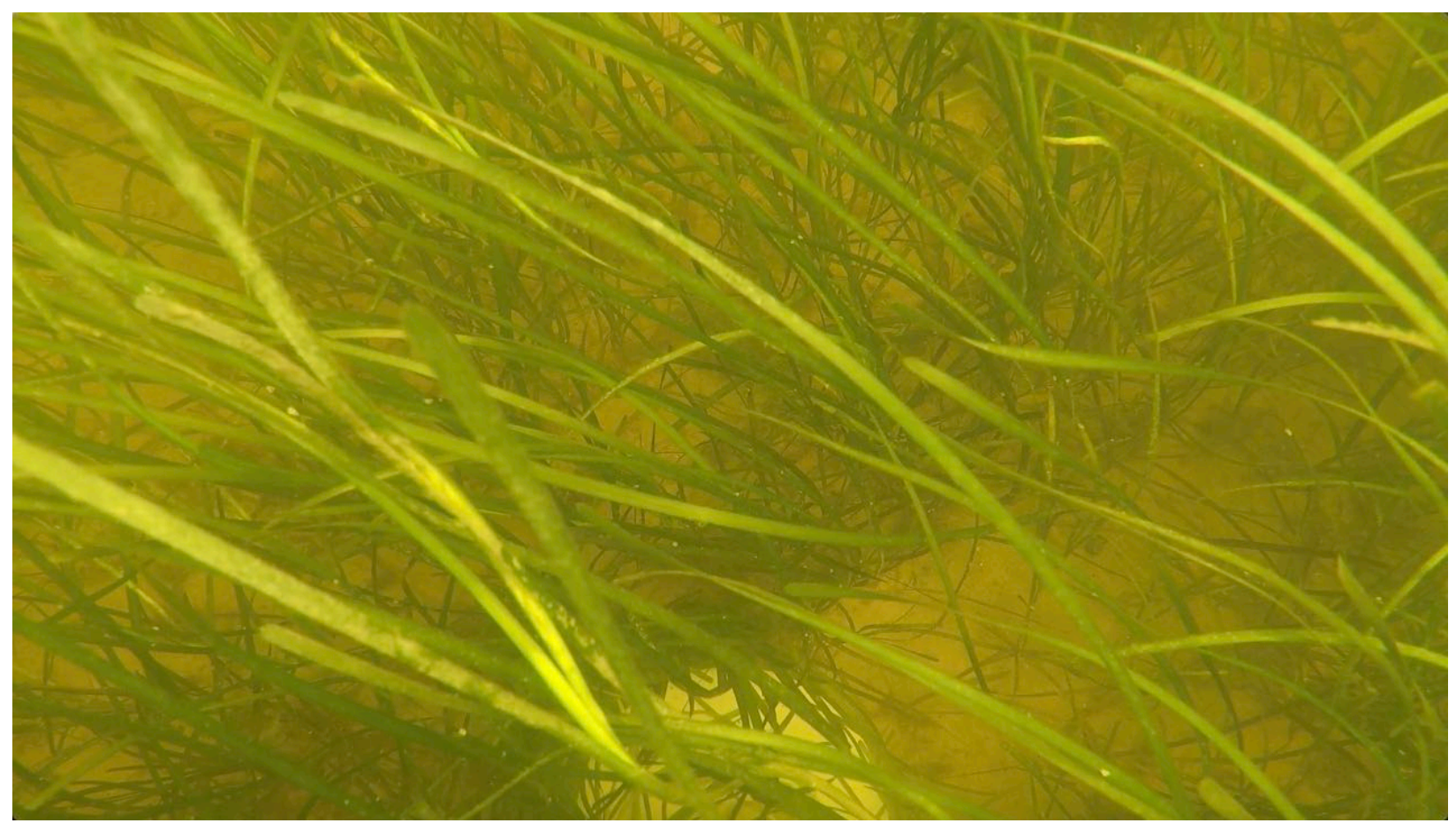

Q22.1 - How would you rate the health of the eelgrass in this frame?

\section{EHI: 63.6}

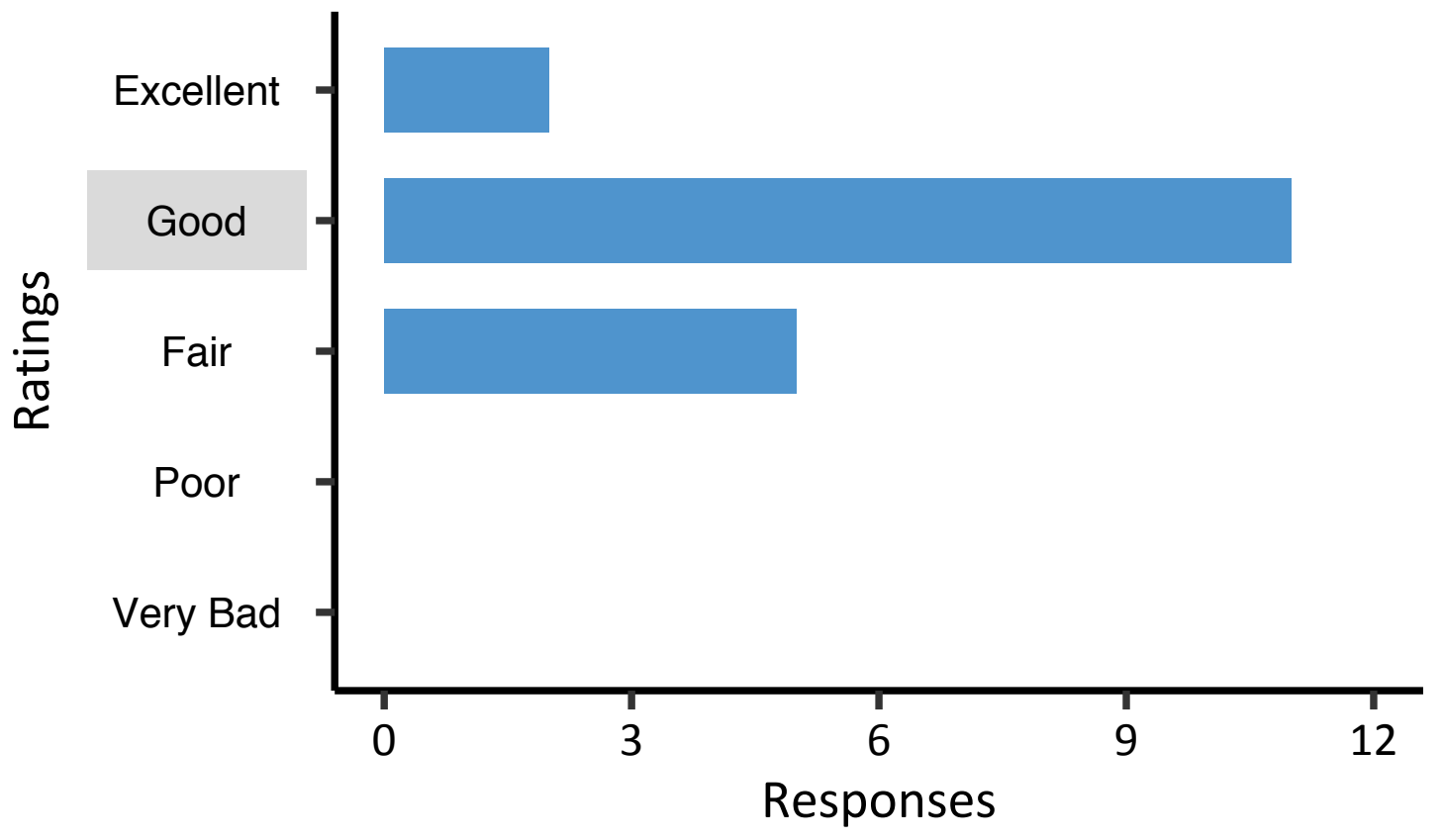


Q22.2 - Why did you select this rating? If you would like to use a specific value (1 - 100) to rate the eelgrass please include that here. (optional)

- Yellow water color not great for eelgrass

- Qualitative Visual Assessment

- wasting disease?

- I don't see the frame; looks to be about 40$50 \%$ cover

- green eaves, high density, low epiphytes

- Plants look healthy and thick, water clarity seems good

- good density and healthy looking plants

- I've never seen excellent 


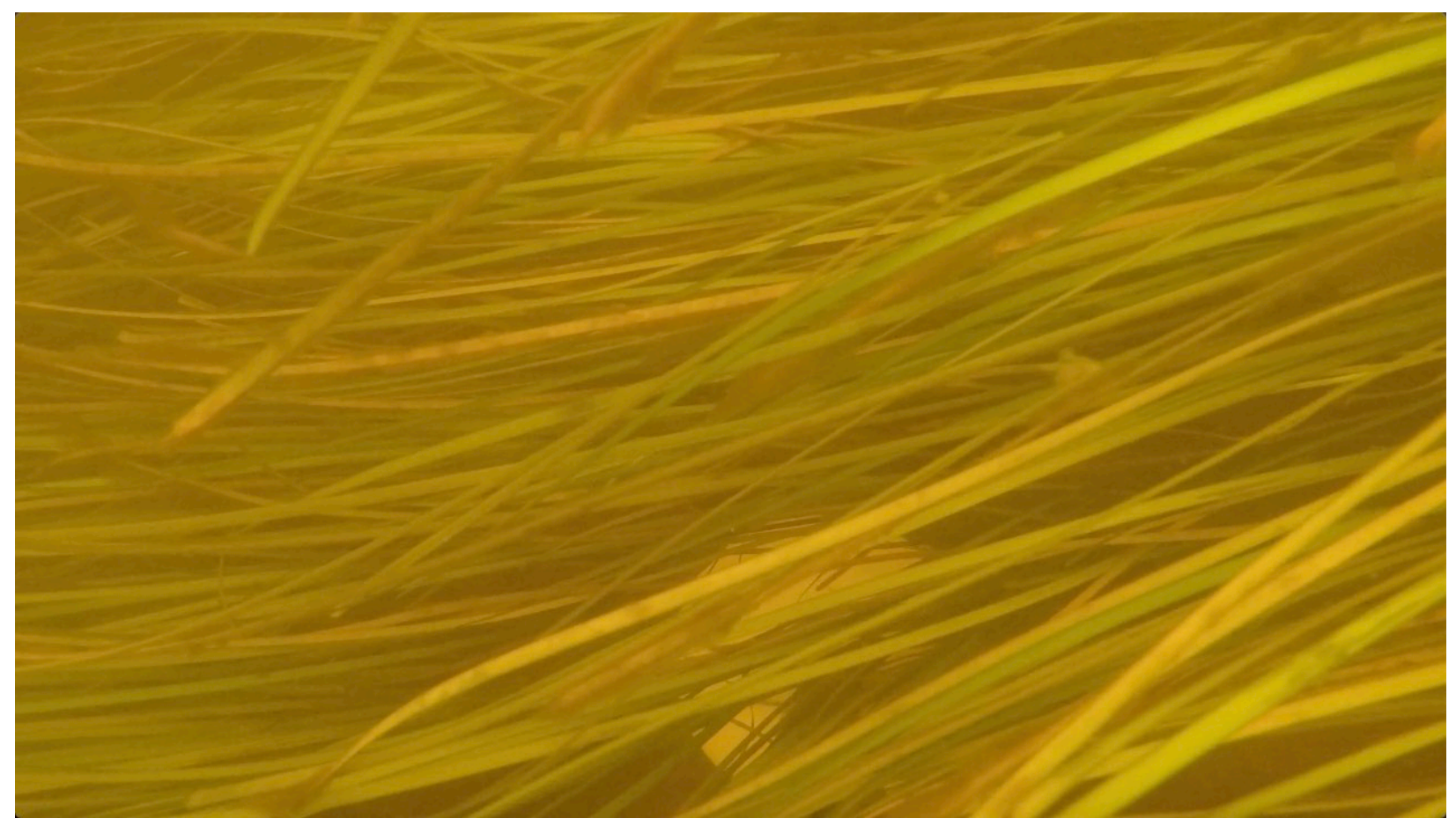

Q23.1 - How would you rate the health of the eelgrass in this frame?

\section{EHI: 71.7}

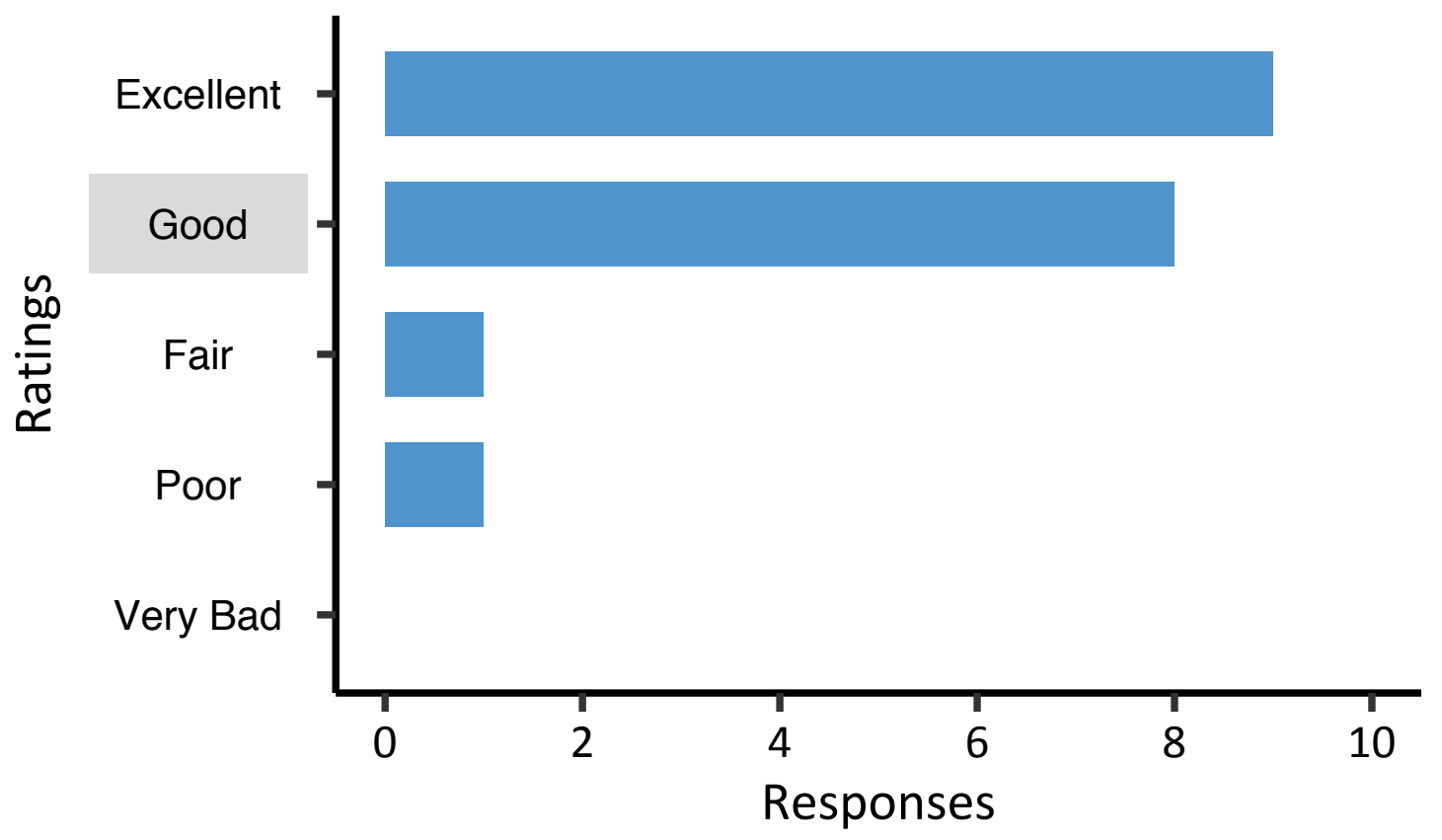


Q23.2 - Why did you select this rating? If you would like to use a specific value (1 - 100) to rate the eelgrass please include that here. (optional)

- high fair, low good

- dense grass, though water is a bit cloudy and some epiphytes are evident

- Lower end of good, high density but high red algae or other epiphytes

- some wasting disease or leaves in poor shape

- Water is yellow not sure of health of plants without seeing them

- Qualitative Visual Assessment

- borderline excellent/good, hard to infer a scale from the photo, but vegetation looks thick, could be later in the growing season so the yellowing of the leaves

- This bed is on the low end of the Excellent spectrum (maybe high end of Good?) simply because the plants/canopy seem dense. It's difficult to truly assess without seeing more.

- high cover, moderate epiphytes, wondering about water clarity though

- Great density, plants don't look as healthy as some of the others

- Thick cover and minor macro algae 


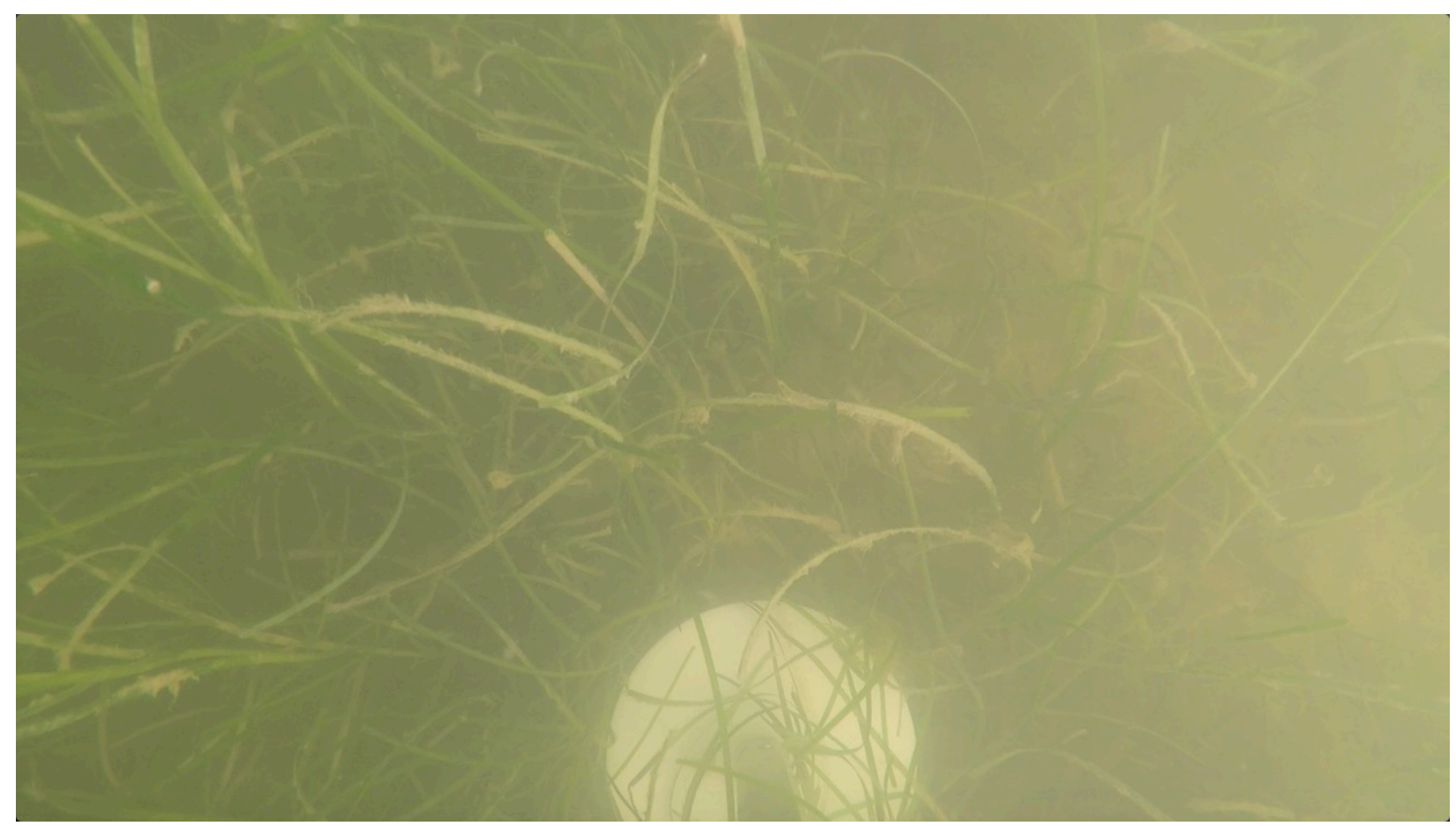

Q24.1 - How would you rate the health of the eelgrass in this frame?

EHI: 47.8

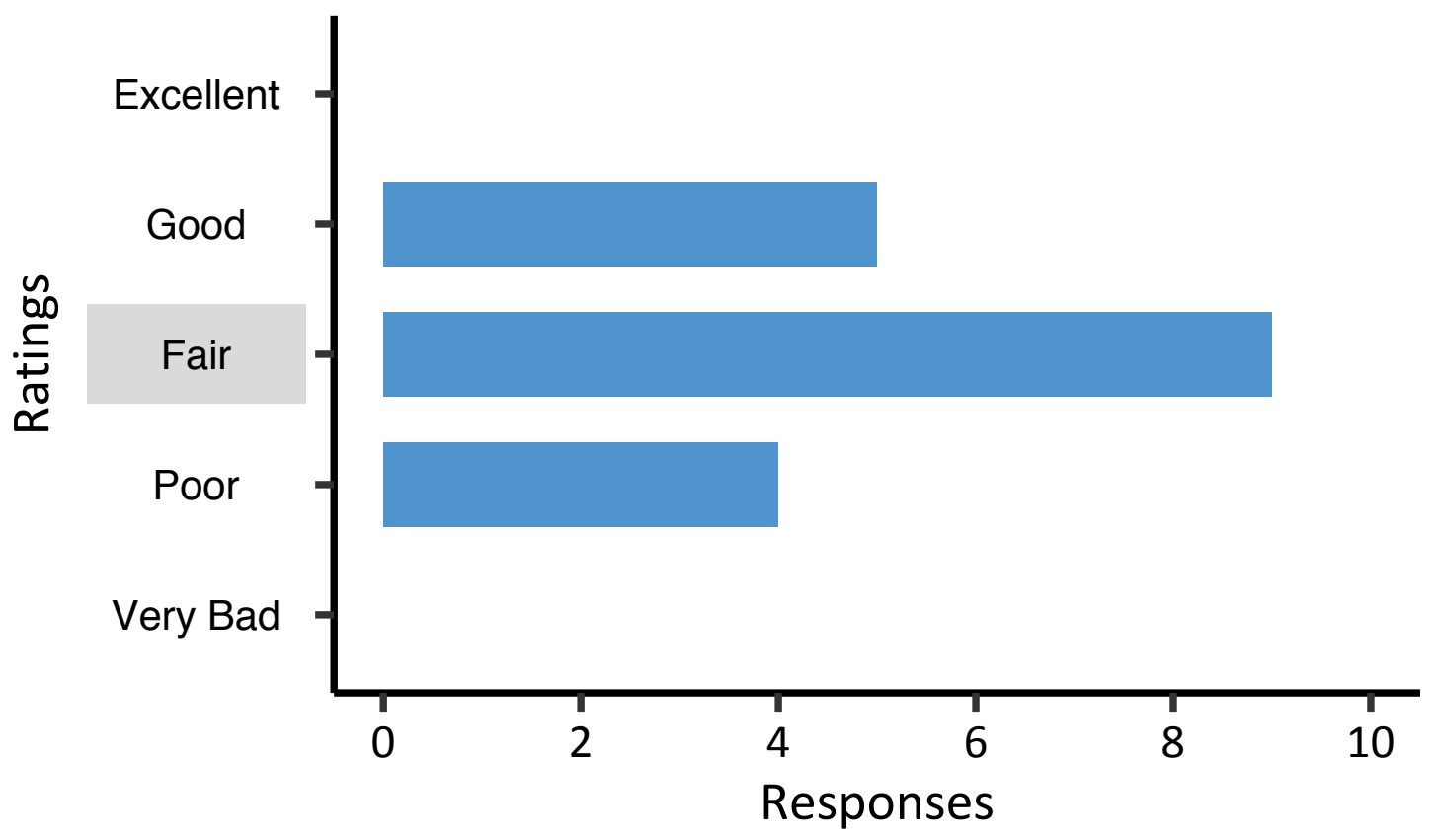


Q24.2 - Why did you select this rating? If you would like to use a specific value (1 - 100) to rate the eelgrass please include that here. (optional)

- Good density, maybe some kind of epiphyte?

- smaller plants, some epiphytization, lower water clarity/ light limitation

- Good plant cover but epiphytes and poor WQ

- borderline fair to good, shoot density is good, some evidence of epiphytes and water clarity is a bit cloudy, could be late season photo

- green leaves, dense, some algae

- Qualitative Visual Assessment

- High epiphytes

- More epiphytes are visible and water seems less clear, so rating it worse than the previous photo.

- Moderate density but fouled (hydroids, tunicates?), with lower water clarity than prior image

- Plants look ok but water quality not great 


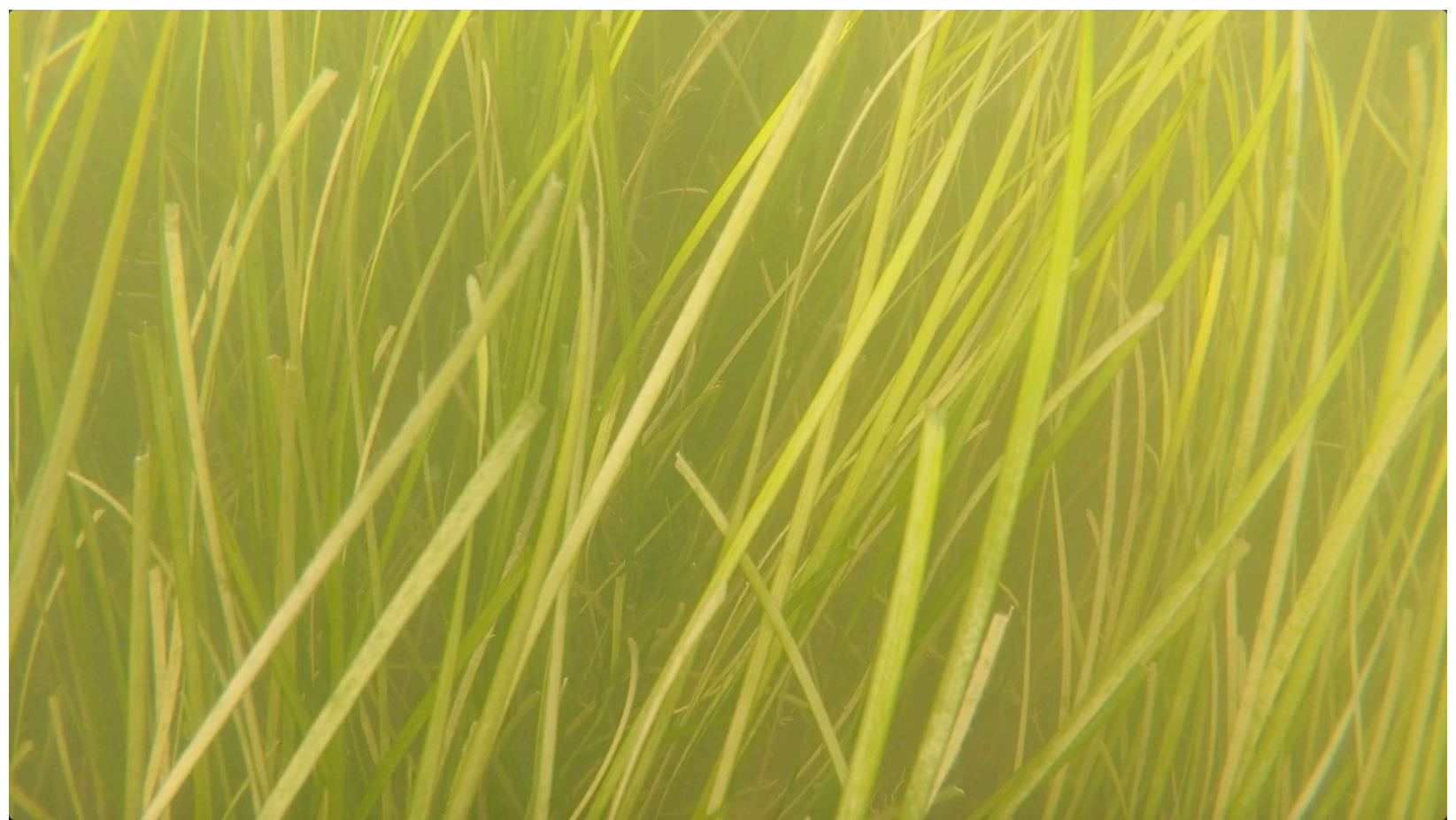

Q25.1 - How would you rate the health of the eelgrass in this frame?

\section{EHI: 76.0}

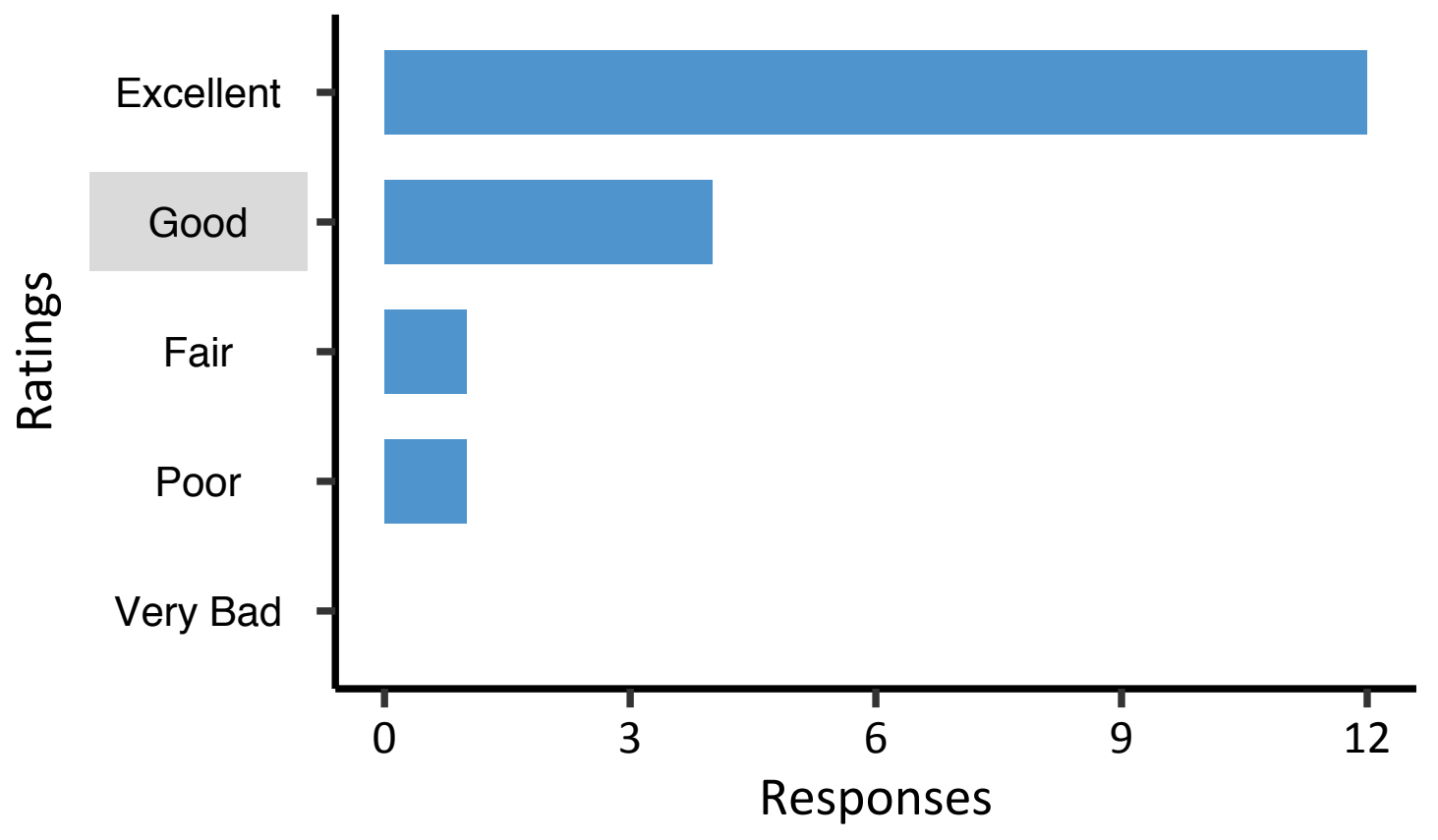


Q25.2 - Why did you select this rating? If you would like to use a specific value (1 - 100) to rate the eelgrass please include that here. (optional)

- Hard to know if yellowing of tissue is an artifact of the photo, but generally, high density and cover with minimal fouling demonstrates a healthier bed

- Great density

- upper end of good

- seems very dense but some of the grass seems as though it's been grazed on

- dense, clean plants

- Qualitative Visual Assessment

- high shoot density and shoot color is good, no epiphytes or disease

- dense, no algal or growth on blades 


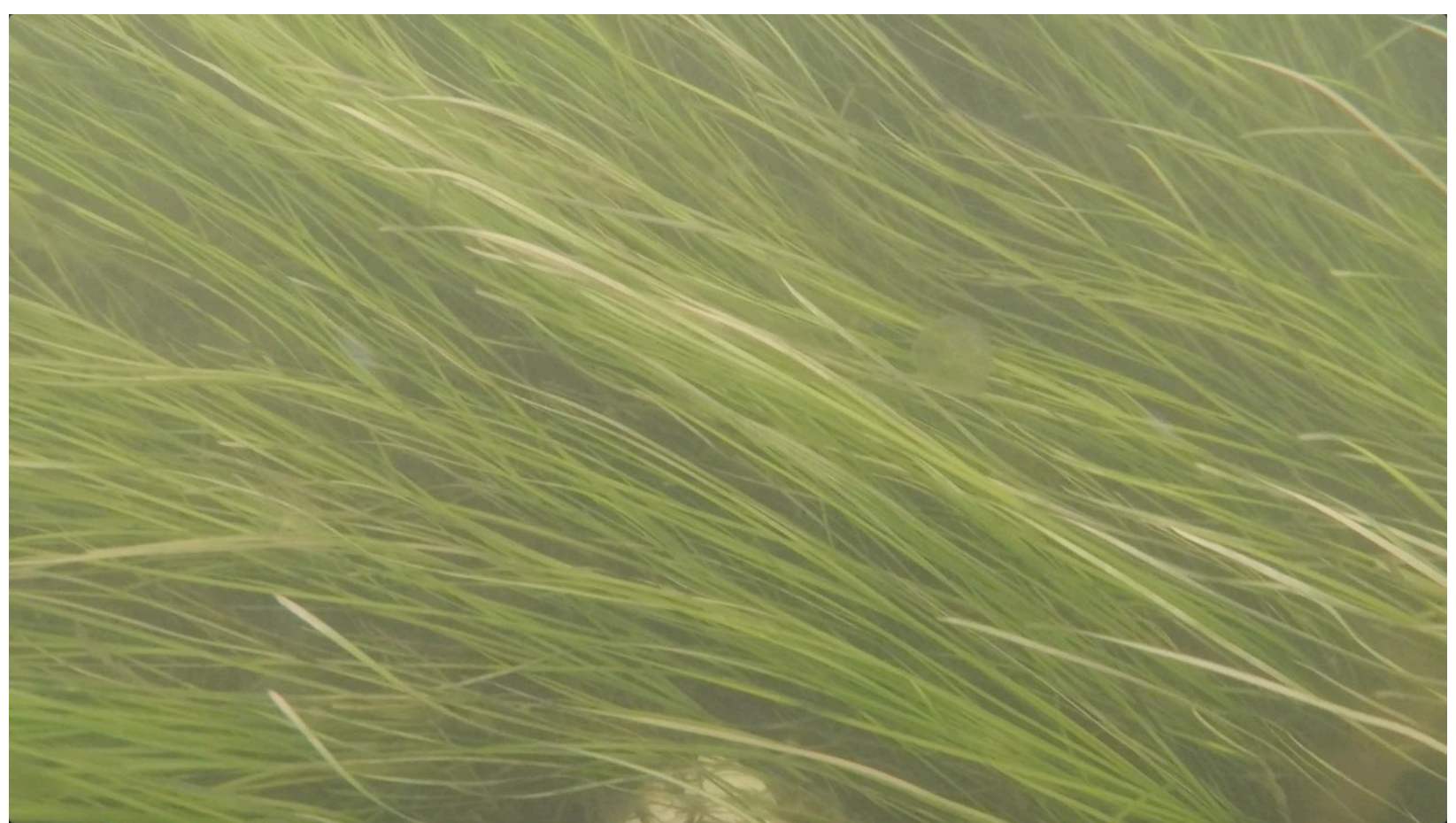

Q26.1 - How would you rate the health of the eelgrass in this frame?

\section{EHI: 63.9}

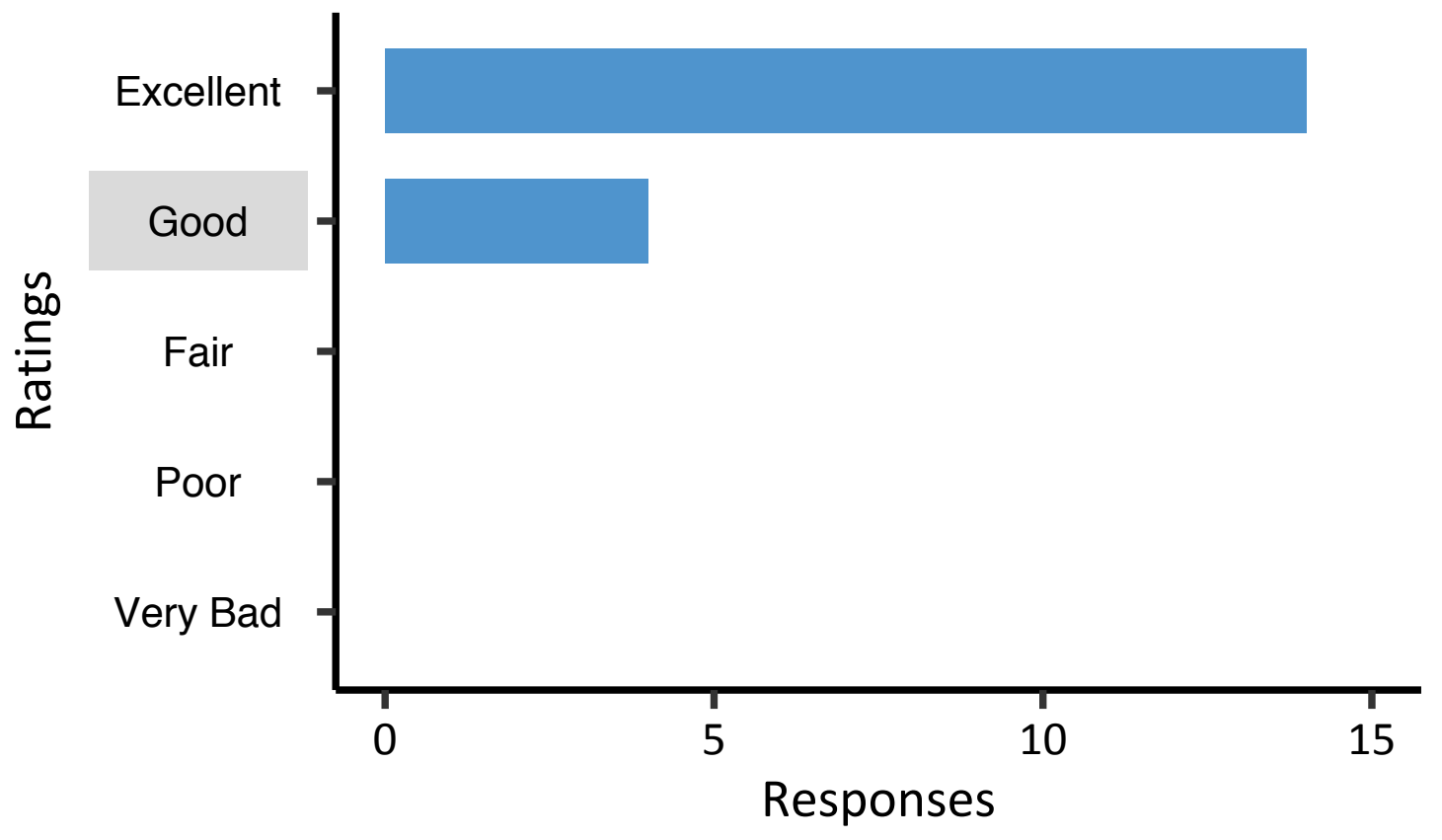


Q26.2 - Why did you select this rating? If you would like to use a specific value (1 - 100) to rate the eelgrass please include that here. (optional)

- dense, long healthy looking leaves

- lush meadow with great water clarity

- bright green, very dense, no algae, high water clarity

- luxuriant, but watch out for jellyfish!

- Great density, healthy looking plants

- high cover; hard to discern but maybe calcareous epiphytes

- Same comments as for prior photo

- Qualitative Visual Assessment

- Long thick, dense vegetation 


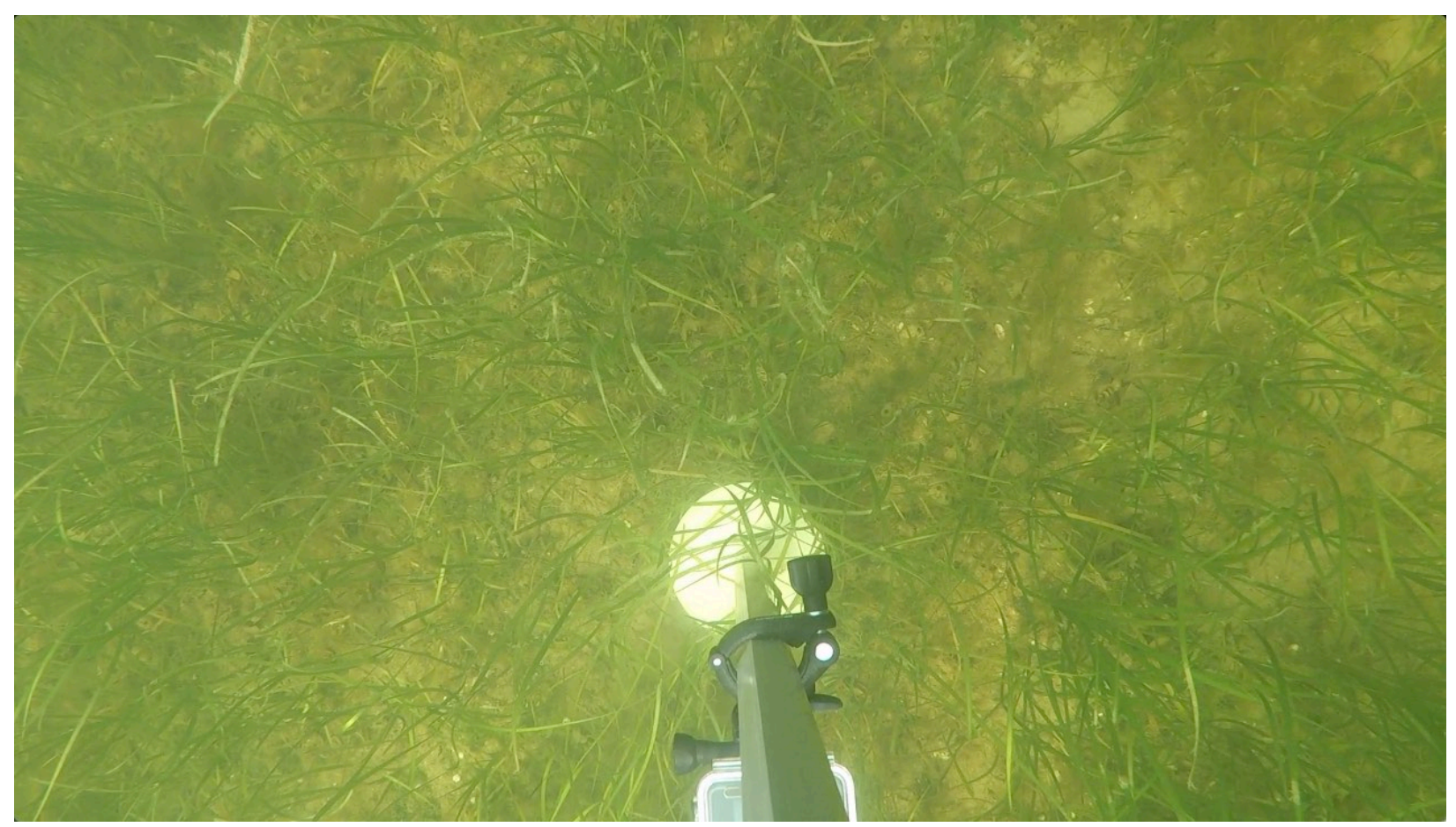

Q27.1 - How would you rate the health of the eelgrass in this frame?

\section{EHI: 42.8}

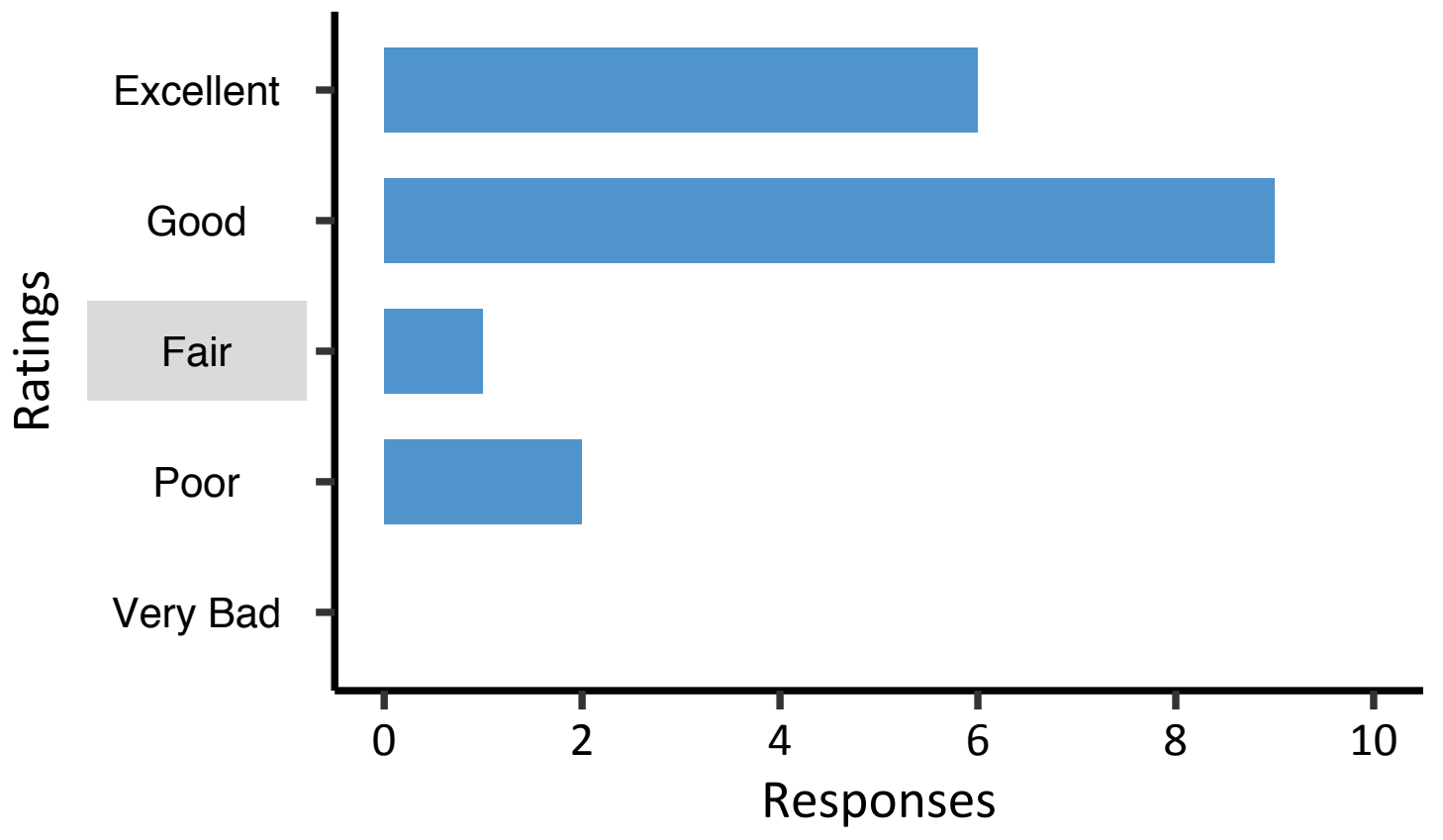


Q27.2 - Why did you select this rating? If you would like to use a specific value (1 - 100) to rate the eelgrass please include that here. (optional)

- Good clarity shoots look short and lower density but ok

- Thin

- borderline excellent to good, shoot density is good, while shoot/leave color and water clarity are excellent

- Short grasses $60 \%$ cover with some macroalgae but good WQ

- Good density and coverage, lack of macroalgae

- Qualitative Visual Assessment

- similar to first photo, good percent cover and clean plants, though density and canopy height could be higher

- green leaves, dense, little algae 


\section{Q28.1 - How would you rate the health of the eelgrass in this frame?}

\section{EHI: 25.4}

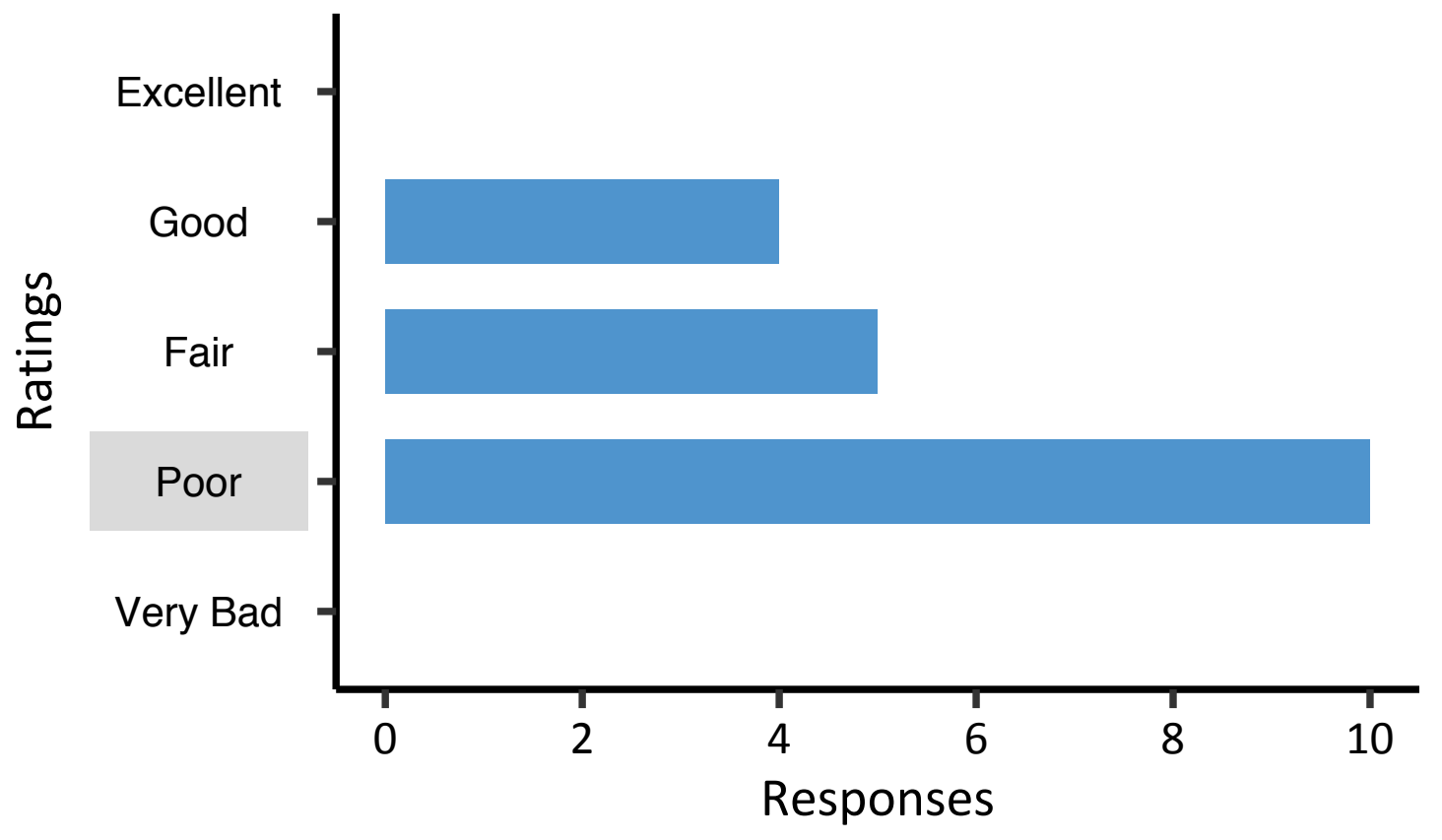


Q28.2 - Why did you select this rating? If you would like to use a specific value (1 - 100) to rate the eelgrass please include that here. (optional)

- densely vegetated with reduced water clarity

- water clarity is fair and shoot density is fair, hard to see the actual health of the individual shoots

- About $25 \%$ cover but poor WQ and either dead Zm or live red algae on bottom

- moderate density and height

- A "low fair" - Ok density, looks like macroalgae

- Bed falls in the upper end of Poor (maybe low end Fair?). Plant density is low and blades look small and muddy.

- no sign of wasting disease, moderate density and blade length

- Low clarity density low to moderate

- Qualitative Visual Assessment 
Q29.1 - How would you rate the health of the eelgrass in this frame?

\section{EHI: 7.77}

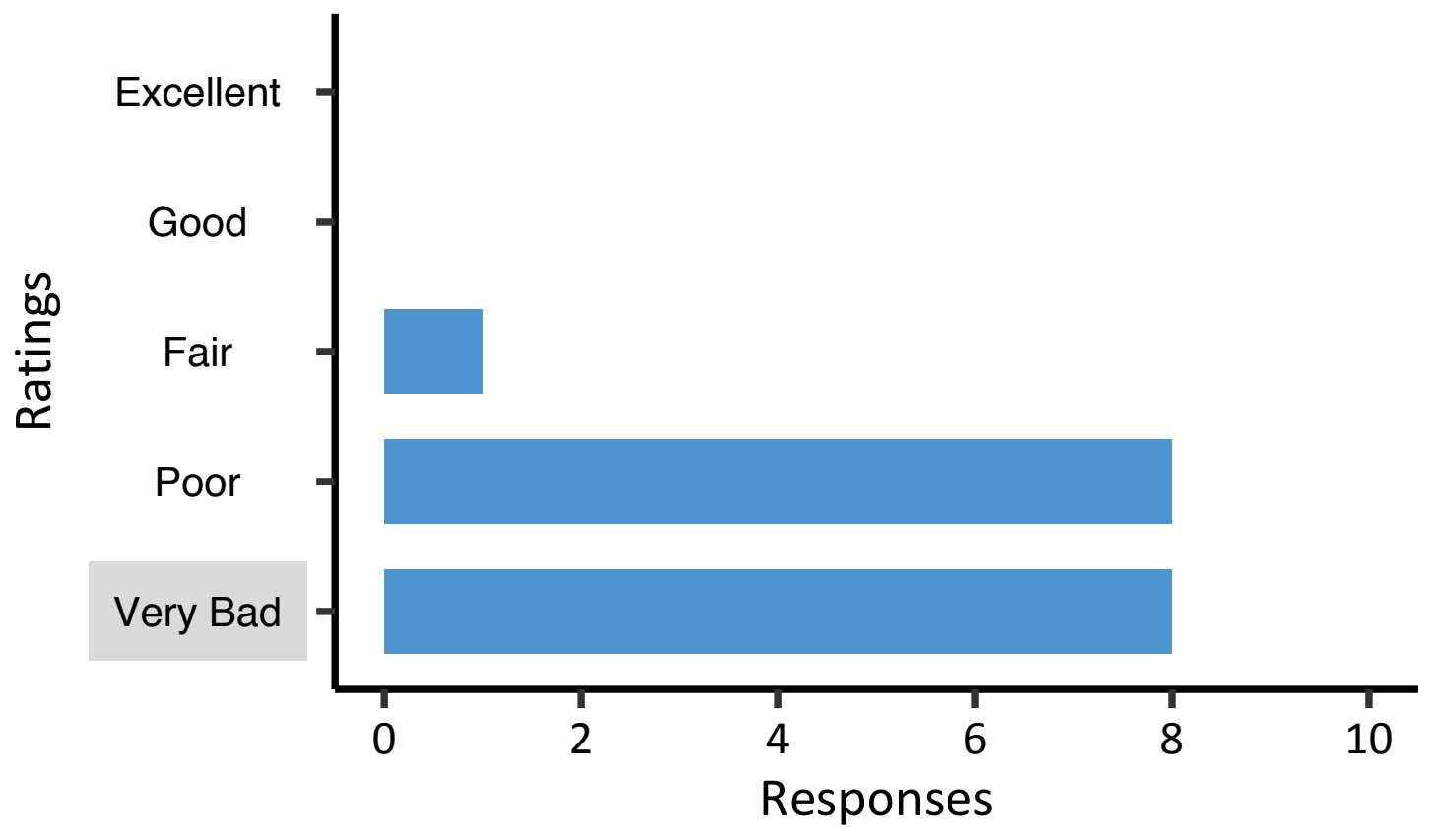


Q29.2 - Why did you select this rating? If you would like to use a specific value (1 - 100) to rate the eelgrass please include that here. (optional)

- Low density and clarity

- few blades, poor water clarity

- hard to judge, but water clarity is poor and shoot density seems low, but what I can see of the eelgrass looks free of epiphytes and disease

- about $10 \%$ plant cover with poor WQ

- can't tell, poor image

- Little too turbid to tell, but looks like a decent plant there... probably poor coverage/density

- Qualitative Visual Assessment - Hard too see

- hard to say. Water is very cloudy. Not a lot of grass visible.

- sparsely vegetated

- low cover, very poor water clarity 


\section{Q30.1 - How would you rate the health of the eelgrass in this frame?}

\section{EHI: 33.0}

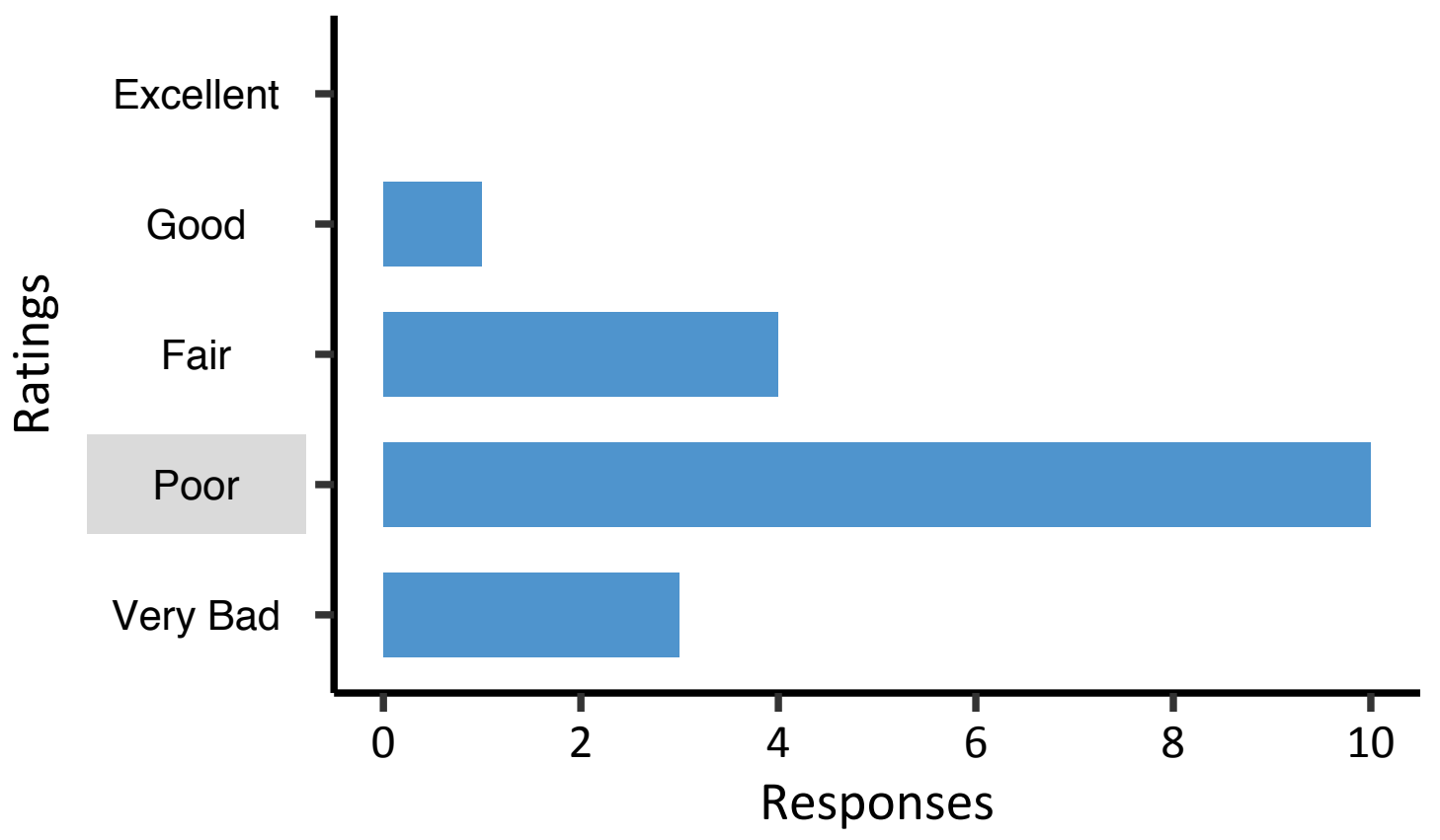


Q30.2 - Why did you select this rating? If you would like to use a specific value (1 - 100) to rate the eelgrass please include that here. (optional)

- I am not sure, given I do not know the size of the frame. I rated it fair as it seems the shoot density is not terribly high, also I believe I can see epiphytes

- Poor density

- About $25 \%$ cover by plants but poor WQ and some epiphytes and drift algae

- moderately dense

- Qualitative Visual Assessment

- limited water clarity and low shoot density 


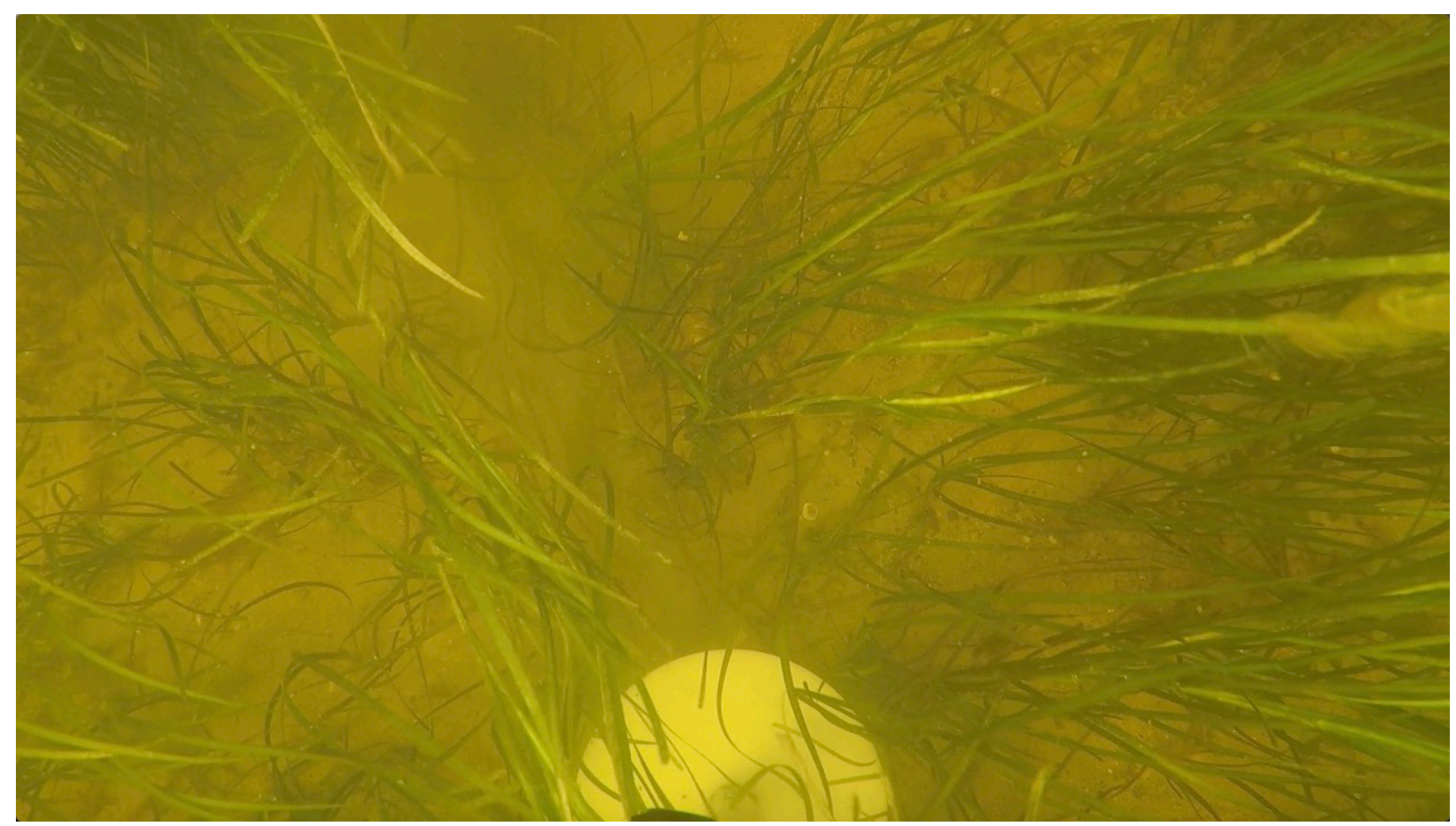

Q31.1 - How would you rate the health of the eelgrass in this frame?

\section{EHI: 49.6}

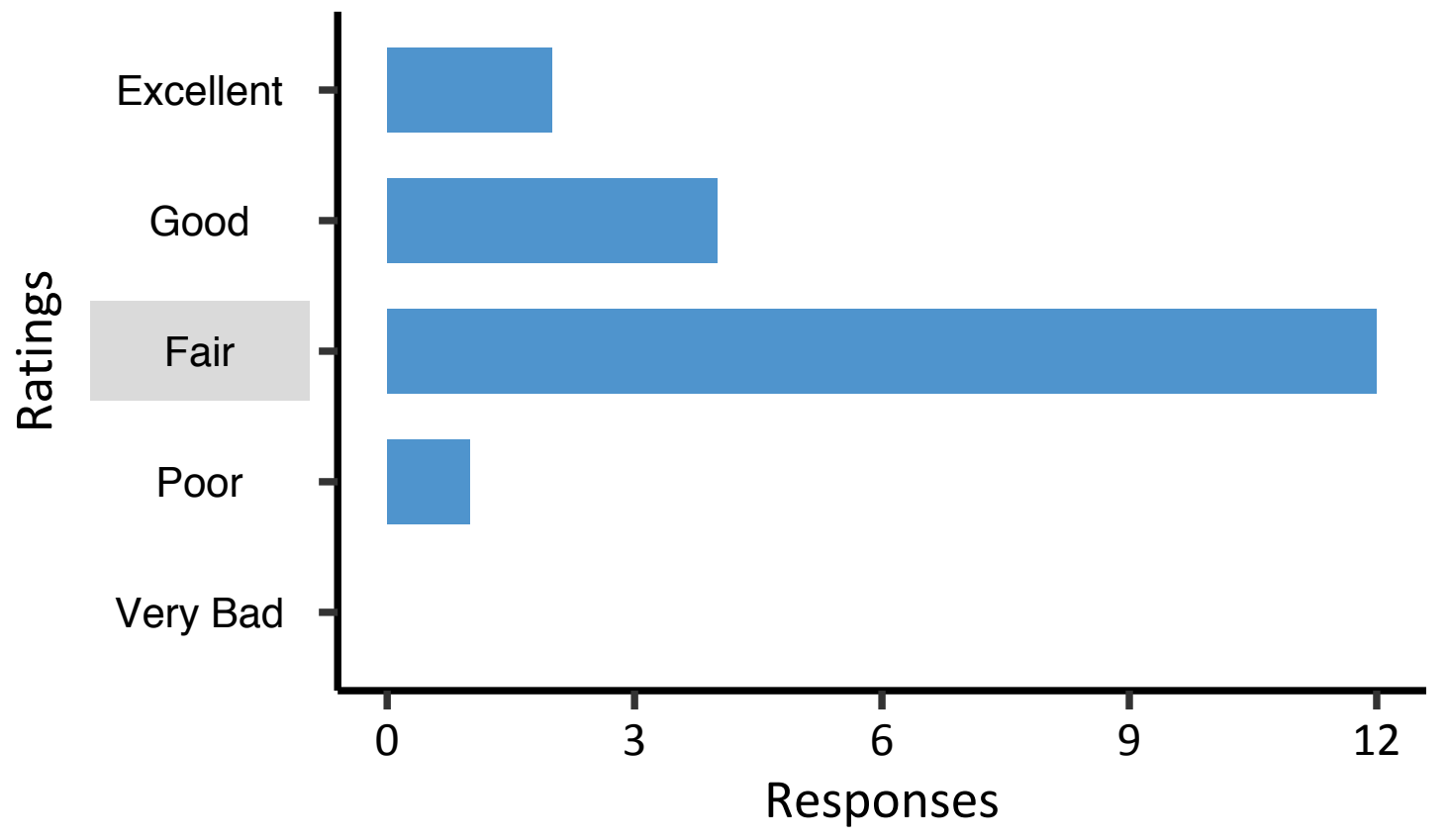


Q31.2 - Why did you select this rating? If you would like to use a specific value (1 - 100) to rate the eelgrass please include that here. (optional)

- $60 \%$ cover with clear water and some algae

- This bed is on the low end of the Excellent (or high end Good) spectrum. Density is pretty good and blades look green and healthy

- Qualitative Visual Assessment

- Eelgrass density is moderate but water is slightly yellow

- High percent cover, but could be more dense. Also, blades are clean without a lot of epiphytes.

- This is borderline fair to good, shoot density is low, but hard to tell the scale without quadrat. Some evidence of epiphytes, but plants look healthy green.

Inferring this is Julyish due to presence of reproductive shoots

- green leaves, dense, little algae

- Looks quite sparse but not smothered by seaweed 


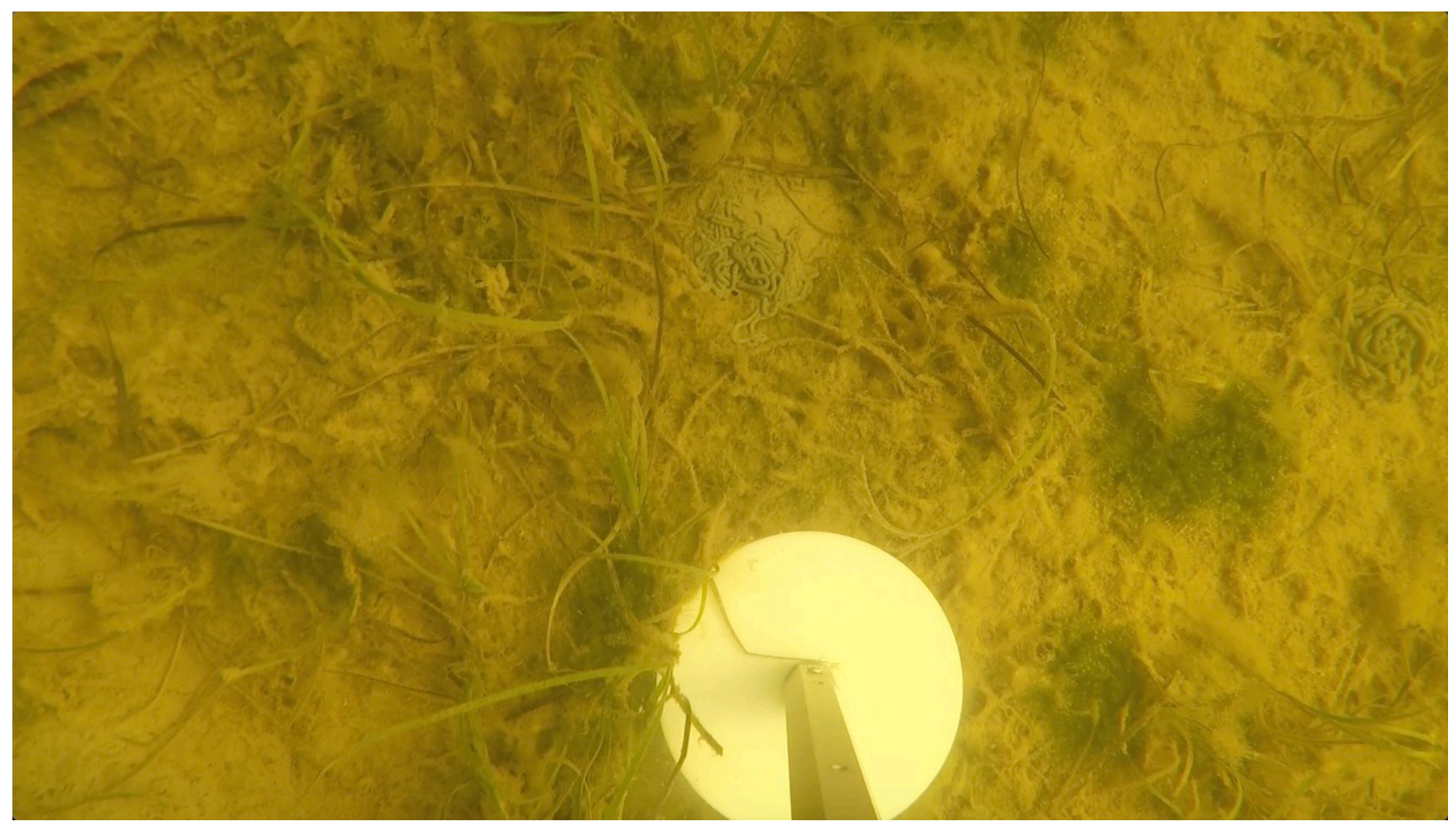

Q32.1 - How would you rate the health of the eelgrass in this frame?

\section{EHI: 9.89}

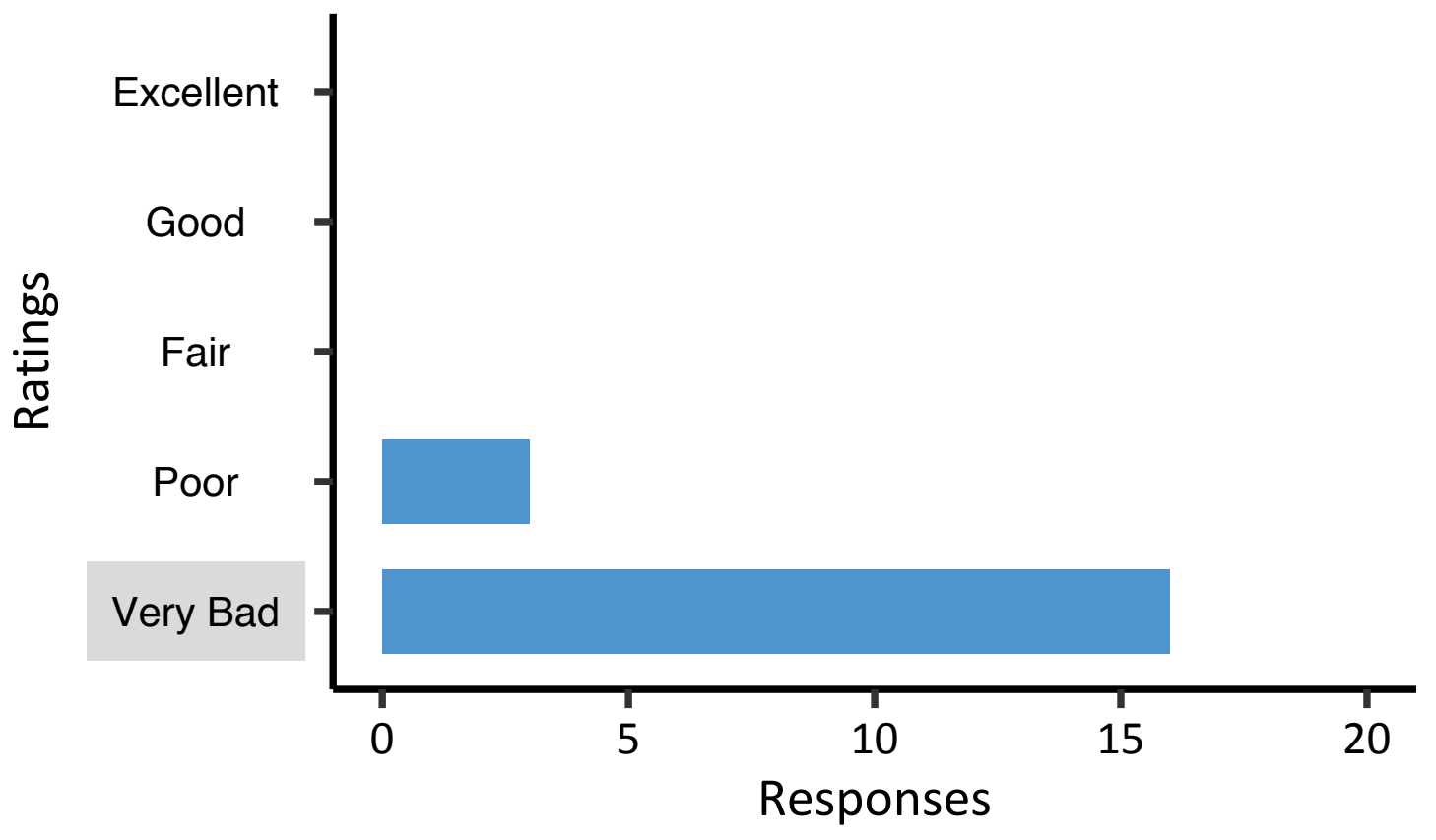


Q32.2 - Why did you select this rating? If you would like to use a specific value (1 - 100) to rate the eelgrass please include that here. (optional)

- Low density with shoots lacking buoyancy. Benthic surface appears enriched.

- epiphytes and algae dominated

- About $20 \%$ cover but smothered by algae and chlorobium patches indicating reduced sulfur is being released and metabolized at sediment surface

- low shoot density and the presence of algae and epiphytes

- Dead and silted

- Just a couple of struggling shoots among the macroalgae

- There's not much eelgrass and what is there is covered in mud, algae, and epiphytes.

- Qualitative Visual Assessment

- Everything is dead 


\section{Q33.1 - How would you rate the health of the eelgrass in this frame?}

\section{EHI: 28.0}

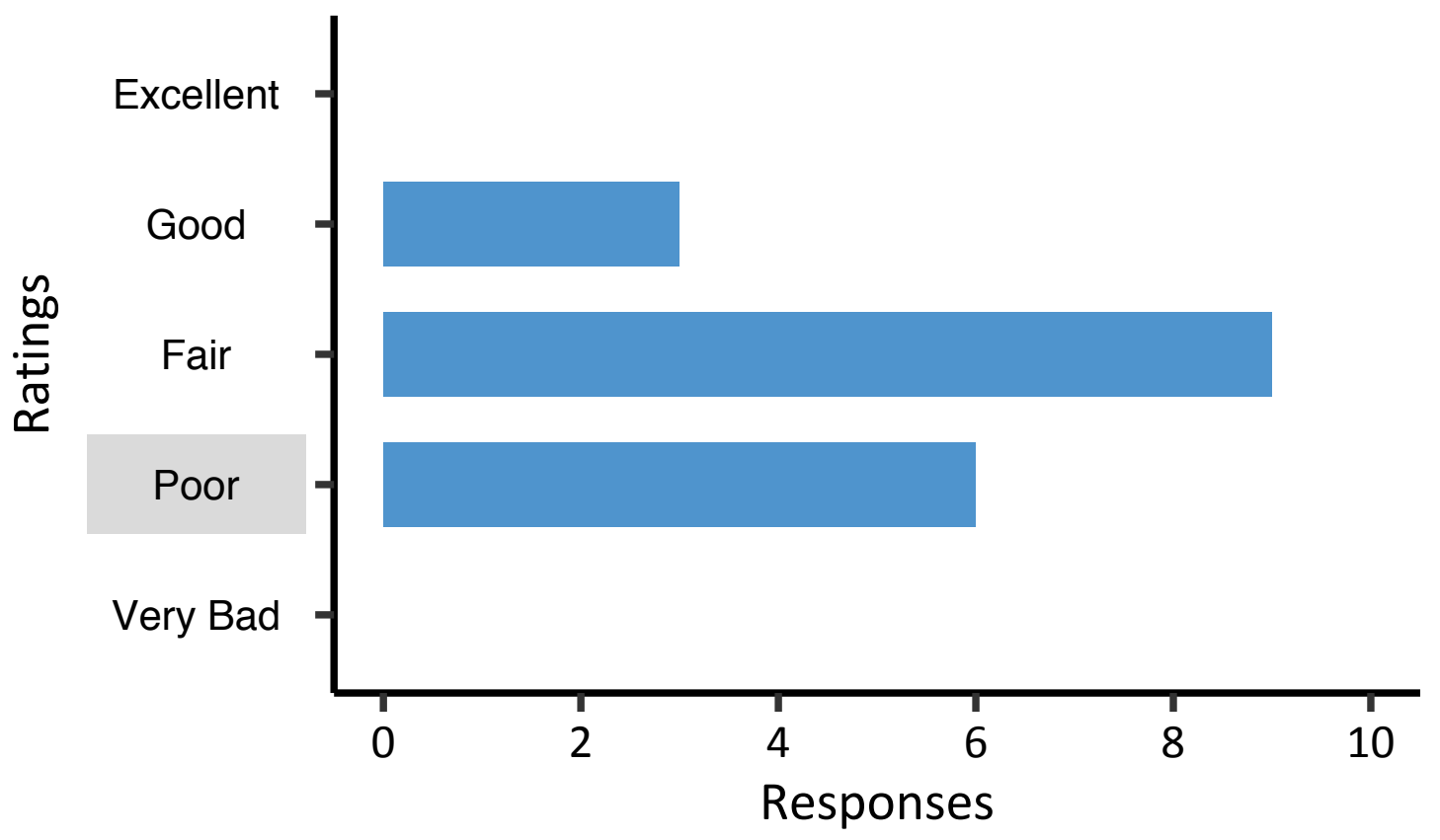


Q33.2 - Why did you select this rating? If you would like to use a specific value (1 - 100) to rate the eelgrass please include that here. (optional)

- fair to good, shoot density is a bit sparse to be good, but shoot color and water clarity seem good

- decent density, plants look ok

- Qualitative Visual Assessment

- low density, physical damage

- About $50 \%$ cover of vegetative plants some algae present 


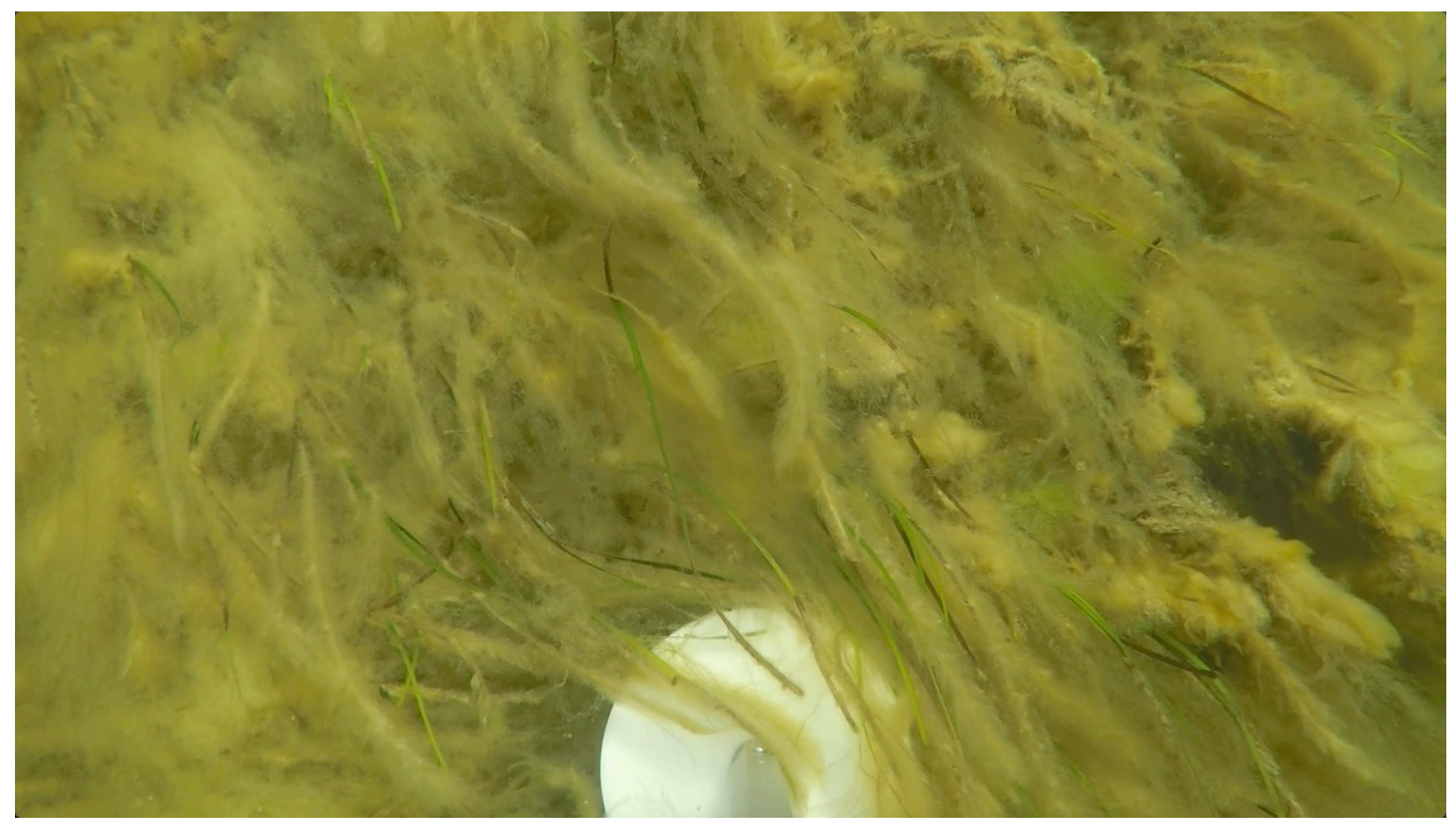

Q34.1 - How would you rate the health of the eelgrass in this frame?

\section{EHI: 12.9}

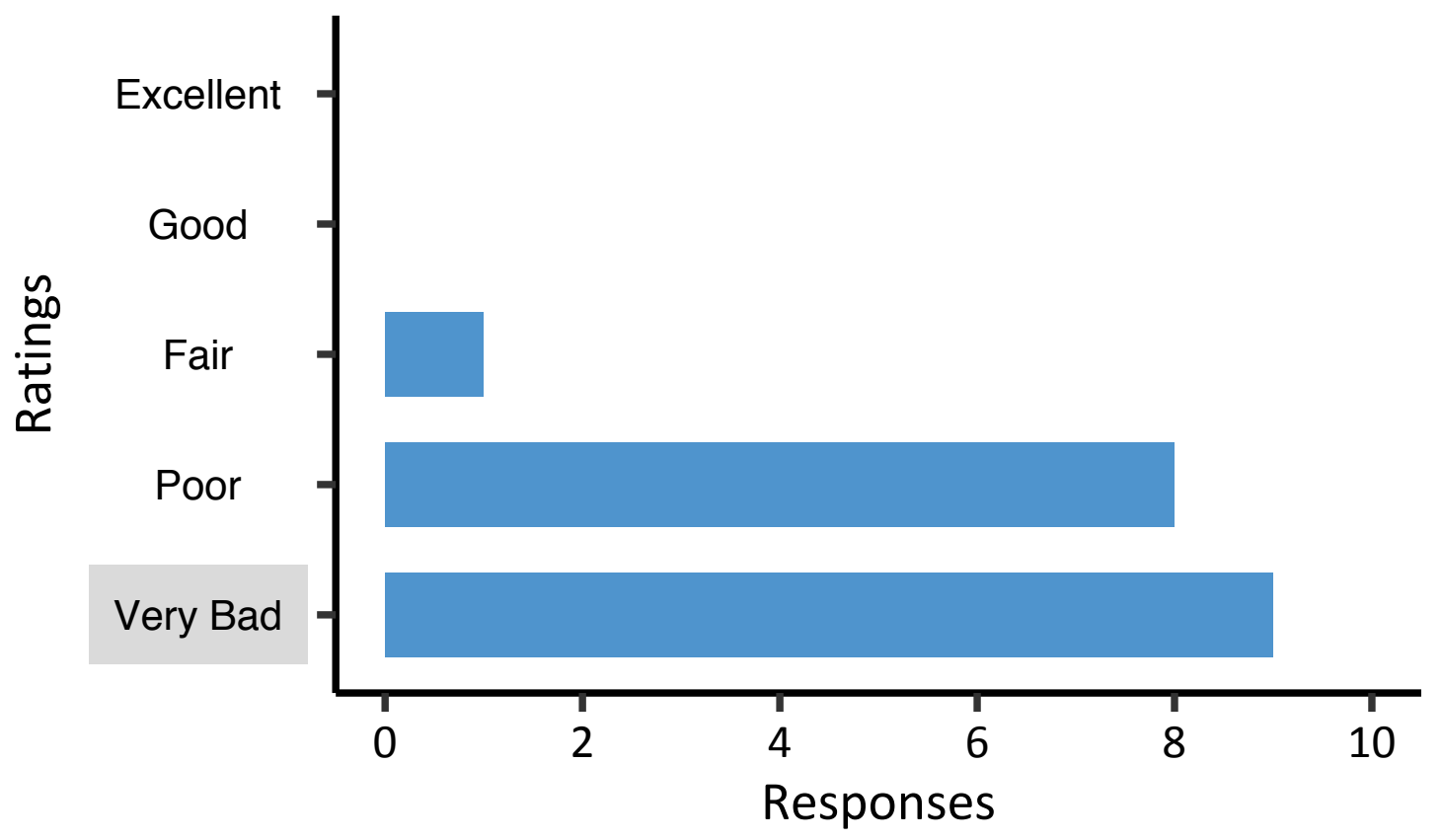


Q34.2 - Why did you select this rating? If you would like to use a specific value (1 - 100) to rate the eelgrass please include that here. (optional)

- Lots of algae smothering plants

- Highly epiphytized

- extensive epiphytic growth and evidence of wasting disease

- looks like $10 \%$ cover and covered by nasty algae

- dense epiphytes

- Whew... macroalgae

- Clearly enriched environment.

- algal/epiphyte growth

- Qualitative Visual Assessment

- eelgrass present, though covered in algae 


\section{Q35.1 - How would you rate the health of the eelgrass in this frame?}

\section{EHI: 31.9}

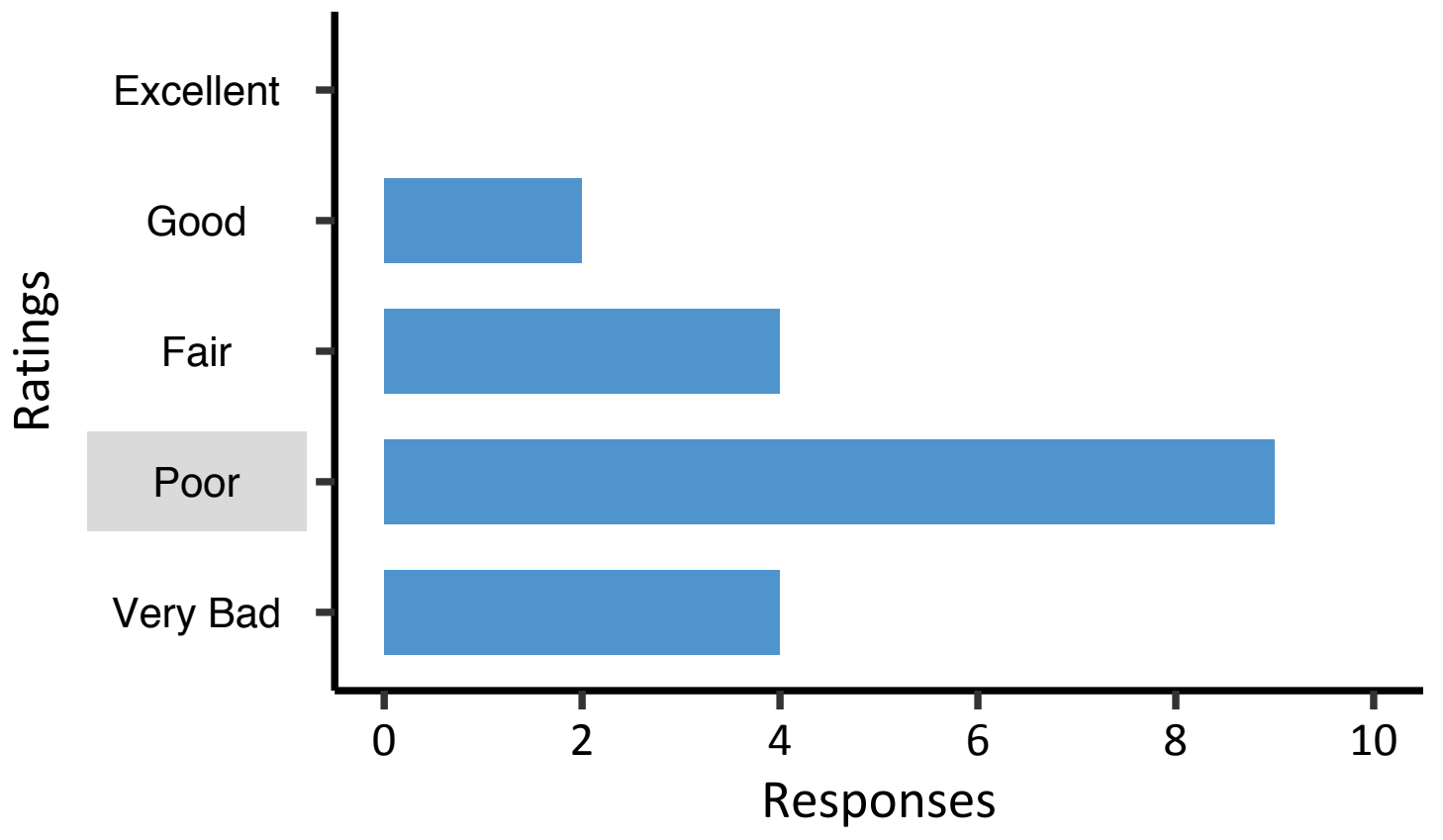


Q35.2 - Why did you select this rating? If you would like to use a specific value (1 - 100) to rate the eelgrass please include that here. (optional)

- $25 \%$ cover and clean plants but poor WQ

- Low density and poor water quality

- low cover, poor water clarity

- Qualitative Visual Assessment

- low shoot density and more limited water clarity

- A bit too turbid, but looks like low density bed

- Hard to tell from image quality, but greater density and cover than in prior photo, though fouling of shoots (sediment, bryozoans?) still evident

- This bed is on the low end of the Poor spectrum. The turbidity makes the grass hard to see but there are definitely a number of plants there which is good. Blades look covered in mud and epiphytes though.

- not a lot of coverage, the plants in frame look healthy, poor water clarity 
Q36.1 - How would you rate the health of the eelgrass in this frame?

EHI: 16.9

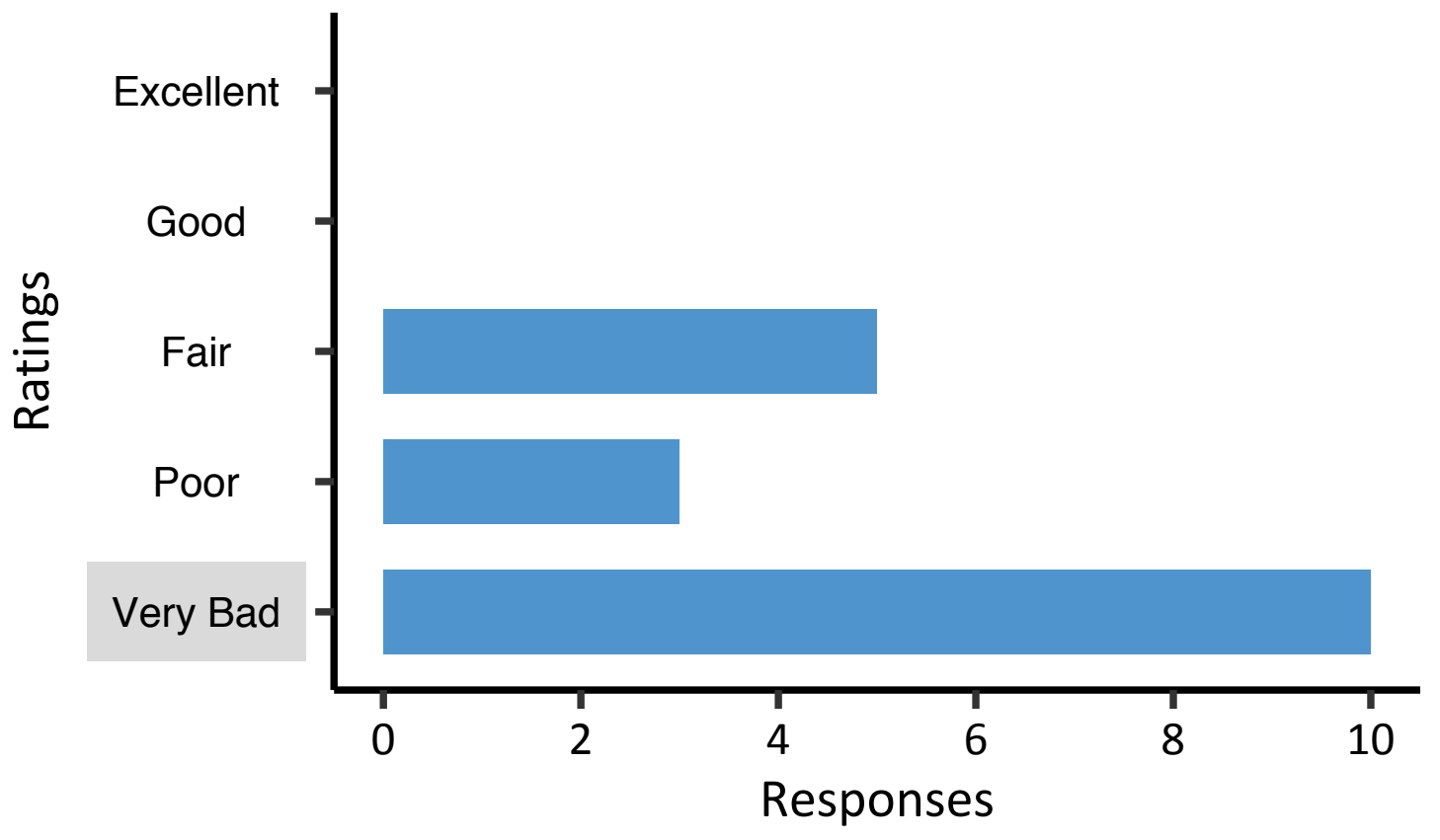


Q36.2 - Why did you select this rating? If you would like to use a specific value (1 - 100) to rate the eelgrass please include that here. (optional)

- Qualitative Visual Assessment

- About $15 \%$ cover and enshrouded by macroalgae

- low shoot density, colored water and some epiphytes

- sparsely vegetated and reduced water clarity.

- Very sparse

- Bad density \& coverage, hard to tell - but looks like poor biomass

- Same as last reponse

- very low density 